\title{
Effect of manufacturing process conditions on the durability of pultruded vinyl ester/glass composites
}

\author{
Chrystal Ann Garland \\ West Virginia University
}

Follow this and additional works at: https://researchrepository.wvu.edu/etd

\section{Recommended Citation}

Garland, Chrystal Ann, "Effect of manufacturing process conditions on the durability of pultruded vinyl ester/glass composites" (2000). Graduate Theses, Dissertations, and Problem Reports. 1141.

https://researchrepository.wvu.edu/etd/1141

This Thesis is protected by copyright and/or related rights. It has been brought to you by the The Research Repository @ WVU with permission from the rights-holder(s). You are free to use this Thesis in any way that is permitted by the copyright and related rights legislation that applies to your use. For other uses you must obtain permission from the rights-holder(s) directly, unless additional rights are indicated by a Creative Commons license in the record and/ or on the work itself. This Thesis has been accepted for inclusion in WVU Graduate Theses, Dissertations, and Problem Reports collection by an authorized administrator of The Research Repository @ WVU. For more information, please contact researchrepository@mail.wvu.edu. 


\title{
EFFECT OF MANUFACTURING PROCESS CONDITIONS ON THE DURABILITY OF PULTRUDED VINYL ESTER / GLASS COMPOSITES
}

\author{
Chrystal A. Garland
}

\author{
Thesis submitted to the \\ at West Virginia University \\ for the degree of

\section{Master of Science \\ in Engineering} College of Engineering and Mineral Resources in partial fulfillment of the requirements

\author{
Rakesh K. Gupta, Ph.D., Chair \\ Hota V.S. GangaRao, Ph.D \\ John W. Zondlo, Ph.D. \\ Department of Chemical Engineering \\ Morgantown, West Virginia
}

2000

Keywords: Composite, Pultrusion, Aging, Vinyl Ester, E-glass, FRP, Bending, Durability Copyright 2000 Chrystal A. Garland 


\section{ABSTRACT \\ Effect of Manufacturing Process Conditions on the Durability \\ of Pultruded Vinyl Ester / Glass Composites}

\section{Chrystal A. Garland}

Fiber reinforced polymer composites, FRPs, have an increased role in structural applications. Environmental durability is important for the design of structural components. Processes such as pultrusion are cost-effective methods of producing FRPs. This research focused on the durability of pultruded FRP with different processing conditions. Pultruded samples made at different line speeds (4, 8, and $12 \mathrm{ipm}$ ) were immersed in water at 25,50 , and $85^{\circ} \mathrm{C}$ for varying lengths of time and the mechanical properties evaluated via 3-point bending tests. A reduction in strength was observed for the samples immersed in 50 and $85^{\circ} \mathrm{C}$ water, with the largest reduction occurring at $85^{\circ} \mathrm{C}$. No difference was observed between those samples that had been subjected to mechanical stress and those that had not been stressed while immersed at $85^{\circ} \mathrm{C}$. Freezethaw cycling had no effect on the strength. DMTA analysis showed that an increase in glass transition temperature, $\mathrm{Tg}$, occurred with increased aging temperature, indicating additional cross-linking had occurred. However, results showed that line speed in the range examined did not affect mechanical properties or the degradation of those properties. 


\section{DEDICATION}

This thesis is dedicated to

my husband, Seth, and my parents. 


\section{ACKNOWLEDGEMENTS}

I would like to express my gratitude to my advisor Dr. Rakesh Gupta for his guidance and advice throughout my research. I am grateful to the members of my academic examining committee, Dr. Hota GangaRao and Dr. John Zondlo, for their invaluable comments and suggestions on my research. The time and encouragement they extended to me throughout this work is greatly appreciated.

I would like to express my sincere appreciation to Jay Toddie of Creative Pultrusions for all his help in manufacturing the pultruded samples for this work. My appreciation is extended to Jim Hall and David Turner for their assistance with the design and machining of equipment. A special thanks to Linda Rogers and Sharon Santos for their help in processing the necessary paperwork. I would like to acknowledge Jim Poston of the National Energy Technology Laboratory (NETL) and Adam Freed for their assistance with obtaining the micrographs for this research. I would also like to acknowledge Vilama Shekar for the assistance she provided with the theoretical calculations.

My heartfelt appreciation is extended to Shannon Stover for the countless hours devoted to assisting me through this process. I am truly grateful to my parents, Jim and Judy, for the constant encouragement and unconditional love they provided. To my loving husband, Seth, I am forever indebted for the patience, motivation, and assistance provided throughout the course of this work. It is through the support of my family and friends that I have accomplished so much in my life.

The United States Army Research Office through the Constructed Facilities Center at West Virginia University provided funding for this research. I would also like

to acknowledge the Department of Chemical Engineering for providing financial support during this research. 


\section{CONTENTS}

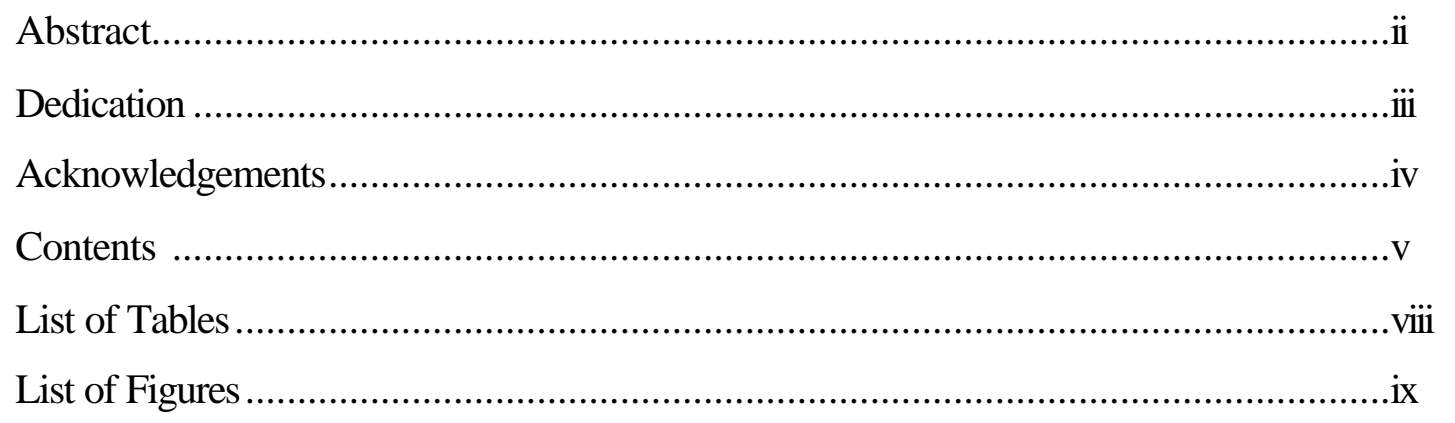

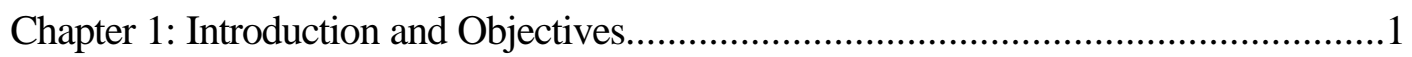

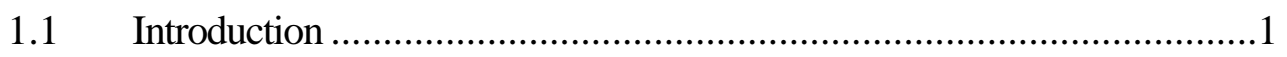

$1.2 \quad$ Research Objectives ......................................................................

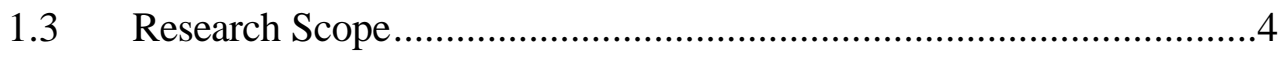

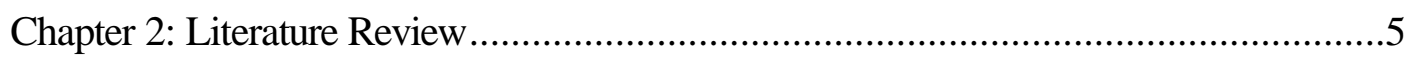

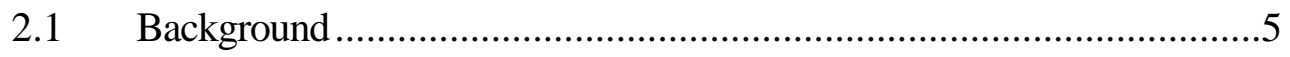

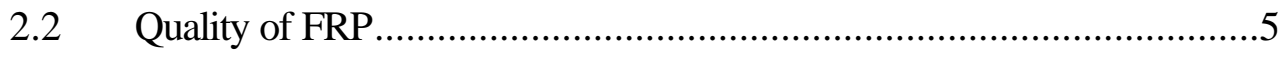

$2.3 \quad$ Strength and Stiffness .....................................................................

2.3.1 Effect of Moisture on Neat Resins ...........................................6

2.3.2 Effect of Moisture on Composites...............................................

2.3.3 Effect of Moisture on Glass Fibers.............................................

2.3.4 Effect of Temperature on FRP................................................

2.4 Long Term Behavior ..........................................................................

2.4.1 Principles of Accelerated Aging ………………….................10

2.4.2 Environmental Aging...............................................................11

Chapter 3: Materials Selection and Processes ............................................................14

3.1 Materials Overview.......................................................................14

3.1.1 Glass Fibers .......................................................................14

3.1.2 Vinyl Ester Resin....................................................................16

3.2 Pultrusion Process................................................................................17

3.3 Composition of Pultruded Coupons ………………………….............21

$3.4 \quad$ Environmental Conditioning Process .....................................................23 
Chapter 4: Experimental Procedure ……………………….....................................24

4.1 Sample Preparation .....................................................................24

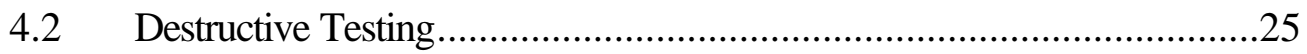

$4.3 \quad$ Non-Destructive Testing...................................................................28

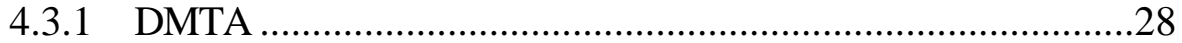

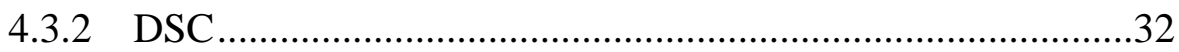

4.3.3 SEM and Optical Microscopy ……………………….............32

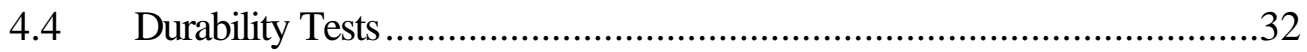

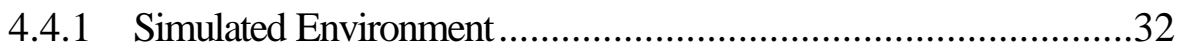

4.4.2 Sustained Stress........................................................................

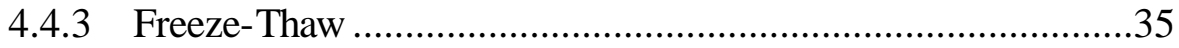

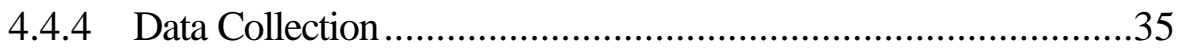

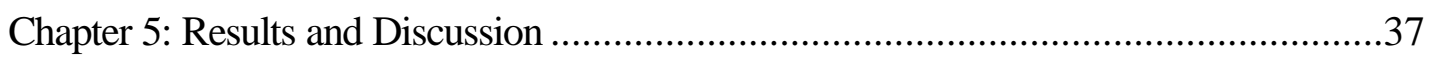

$5.1 \quad$ DSC Characterization ....................................................................

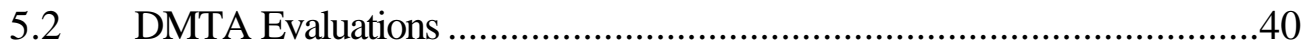

5.2.1 Effect of Aging Conditions on Tg ..............................................40

5.2.2 Effect of Aging Conditions on Storage Modulus ..........................43

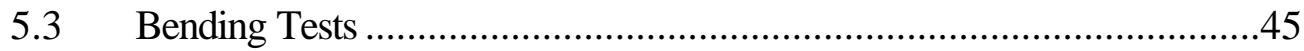

5.3.1 Strength of Neat Resin Samples...............................................49

5.3.2 Strength of Pultruded Samples.....................................................51

5.3.3 Stiffness of Pultruded Samples......................................................63

5.3.4 Correlation of Predicted and Experimental

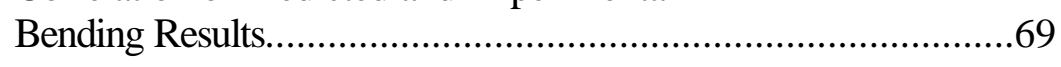

5.3.5 Other Results from Bending Tests.............................................70

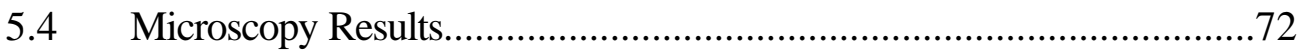

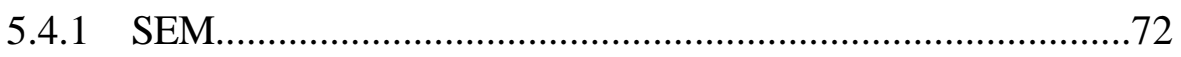

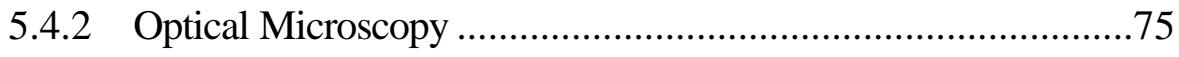

5.5 Water Sorption of Pultruded Samples..................................................78

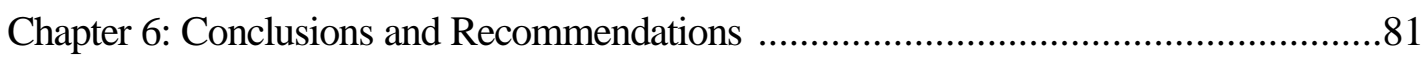

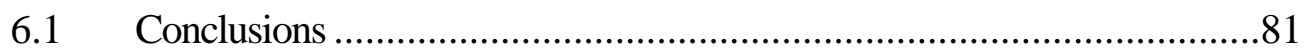

6.1.1 Effect of Aging on $\mathrm{Tg}$ and Storage Modulus..............................81 
6.1.2 Effect of Aging on Strength and Stiffness..............................81

6.1.3 Effect of Line Speed on Void Fraction..................................82

6.1.4 Effect of Line Speed on Water Sorption ...............................82

6.2 Recommendations for Future Work ............................................82

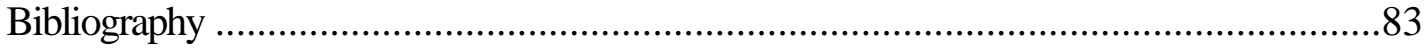

Appendix A: Basic Definitions and Properties of Fibers and Resins..........................87

Appendix B: $\quad$ Stress Fixtures and Teflon ${ }^{\circledR}$ Resin Mold Fabrication............................92

Appendix C: Derivation of Equations Used in Destructive Tests .............................95

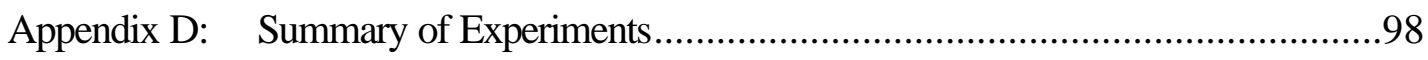

Appendix E: $\quad$ Prediction of Composite Properties ...................................................113 


\section{LIST OF TABLES}

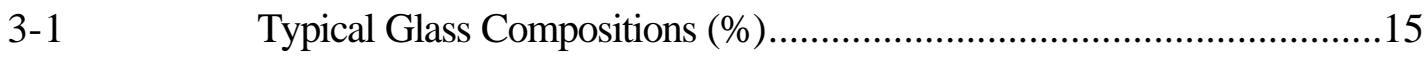

3-2 Composition of Vinyl Ester Resin..............................................21

5-1 Comparison of Tg for DMTA for Vinyl Ester Composites Aged in Different Temperature Water for 1000 Hours

5-2 Percent Change in Flexural Strength for Pultruded Samples (Average for All Line Speeds).....

5-3 Correlation of Experimental and Predicted Results for Pultruded Vinyl Ester Composites 


\section{LIST OF FIGURES}

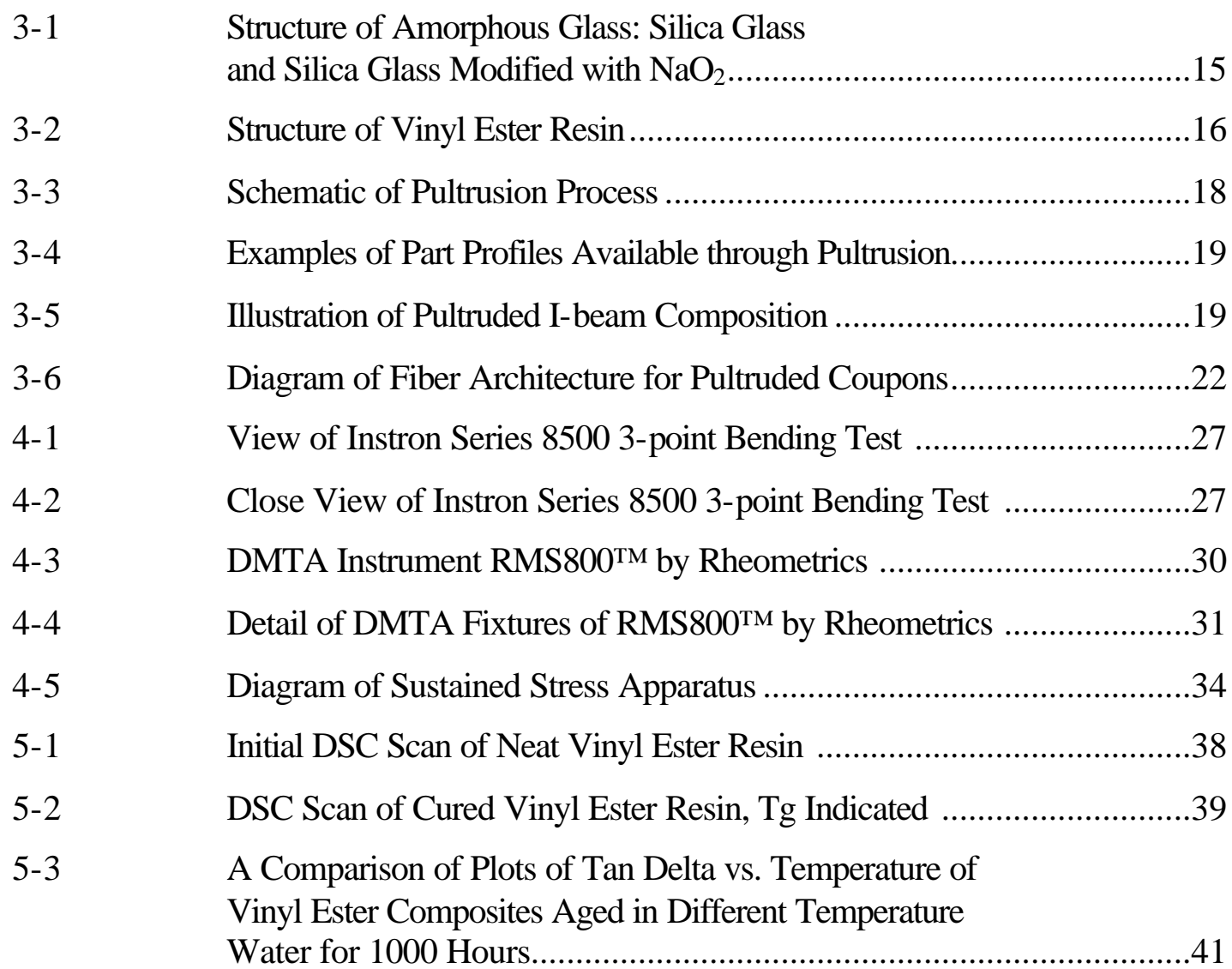

5-4 A Comparison of Storage Modulus Master Curves of Vinyl Ester Composites Aged in Different Temperature Water for 1000 Hours . . .44

5-5 Bending Test of Pultruded Sample Aged in $25^{\circ} \mathrm{C}$ Water for 3000 Hours (Sample W1-17).

5-6 Bending Test of Pultruded Sample Aged in $25^{\circ} \mathrm{C}$ Water for 3000 Hours (Sample W1-18) .

5-7 Determination of Initial Slope of Bending Tests for Modulus Calculation (Samples Aged in $25^{\circ} \mathrm{C}$ Water for 3000 Hours, $\mathrm{W} 1-16,17,18)$....... .48

5-8 Bending Strength of Aged Neat Resin...............................................50

5-9 Bending Strength of Pultruded Bars Aged in Water at $25^{\circ} \mathrm{C}$....................52

5-10 Bending Strength of Pultruded Bars Aged in Water at $50^{\circ} \mathrm{C}$...................53

5-11 Bending Strength of Pultruded Bars Aged in Water at $85^{\circ} \mathrm{C}$....................54

5-12 Bending Strength of Pultruded Bars Stressed in Water at $85^{\circ} \mathrm{C}$..............55 
5-13 Bending Strength of Pultruded Bars Aged by

Freeze-Thaw Cycling.

5-14 Temperature Profile within the Die during Manufacturing by Pultrusion ( $4 \mathrm{ipm}, \mathrm{T}_{1}=275^{\circ} \mathrm{F}, \mathrm{T}_{2}=325^{\circ} \mathrm{F}$ ).

5-15 Temperature Profile within the Die during Manufacturing by Pultrusion $\left(8 \mathrm{ipm}, \mathrm{T}_{1}=275^{\circ} \mathrm{F}, \mathrm{T}_{2}=325^{\circ} \mathrm{F}\right)$.

5-16 Temperature Profile within the Die during Manufacturing by Pultrusion $\left(12 \mathrm{ipm}, \mathrm{T}_{1}=275^{\circ} \mathrm{F}, \mathrm{T}_{2}=325^{\circ} \mathrm{F}\right)$.

5-17 Temperature Profile within the Die during Manufacturing by Pultrusion $\left(8 \mathrm{ipm}, \mathrm{T}_{1}=325^{\circ} \mathrm{F}, \mathrm{T}_{2}=275^{\circ} \mathrm{F}\right)$. .62

Stiffness of Pultruded Bars Aged in Water at $25^{\circ} \mathrm{C}$

Stiffness of Pultruded Bars Aged in Water at $50^{\circ} \mathrm{C}$ .65

Stiffness of Pultruded Bars Aged in Water at $85^{\circ} \mathrm{C}$

Stiffness of Pultruded Bars Stressed in Water at $85^{\circ} \mathrm{C}$ .67

SEM of Pultruded Sample at 500X in which

No Voids are Evident. .74

View of Pultruded Sample from Optical Microscope.. . .76

View of Voids in Pultruded Sample in Optical Microscope .76

View of Cracks in Pultruded Sample in Optical Microscope...

5-31 Percent Water Absorbed Compared for Different Line Speeds (Water Temperature of $25^{\circ} \mathrm{C}$ ). .79

5-32 Percent Water Absorbed Compared for Different Temperatures (Line Speed of $12 \mathrm{ipm}$ ) .80 


\section{CHAPTER 1 \\ INTRODUCTION AND OBJECTIVES}

\subsection{Introduction}

The repair of deteriorating structures in an economical manner with minimal user inconvenience is a challenge facing engineers in the new century. Many highway bridges are structurally deficient or functionally obsolete because of increased highway traffic, deterioration due to environmental attack or simply because of the age of the structure. The Federal Highway Administration has reported that nearly 32 percent of the nation's 581,942 bridges need to be repaired or replaced due to loss of critical structural and mechanical properties [1]. Repair and rehabilitation of civil structures can be performed in a competitive manner using new materials and technologies to increase their performance and life span.

Fiber-reinforced polymer composite materials, FRPs, have been utilized in small quantities in the construction industry for decades [2]. Due to the need to repair and retrofit deteriorating infrastructure in recent years, the potential market for using FRP for repair is beginning to be realized to a much greater extent. Bridges, piers, building panels, walkways, and pipelines have been successfully constructed using FRP materials.

FRP materials have a number of advantages when compared to traditional materials such as steel and concrete. Compared to conventional materials, FRPs offer excellent corrosion resistance to environmental agents as well as the advantages of high stiffness-to-weight and strength-to-weight ratios. Other advantages of FRPs include low thermal expansion, good damage tolerance and fatigue performance, ease of transportation and handling and low energy consumption during fabrication [3]. The biggest advantage is tailorability; reinforcement can be arranged to provide optimum performance.

The current demand for FRP in the construction industry continues to increase at a rate of 2.5 percent per year [4]. The most significant obstacle preventing the extensive use of FRP materials is the limited amount of long-term durability and performance data. Until recently, most of the FRP applications and research were aimed at the aerospace or automotive industries. The expected service life of a structure is much longer in 
infrastructure applications. Bridge structures, unlike aerospace structures, are designed for a 70-80 year service life. Furthermore, the construction industry has focused predominantly on lower-cost glass reinforcement rather than more expensive carbon or aramid fiber reinforcement, which is used in aerospace applications. Most of the past research on glass fiber reinforcement is for short fibers and has not been tested at loadings associated with structural applications. The construction industry must be concerned with long-term behavior as well as different materials and service environments as compared to the aerospace industry. New data pertaining to infrastructure applications are in great demand, especially for composites produced by low-cost, large-volume processing methods like pultrusion.

The objective of this research was to determine the extent of environmental degradation of composite samples made through pultrusion; results would be relevant to bridge decks made by the same process. A composite bridge deck is expected to have a longer service life compared to conventional bridges and to have a better capability to withstand environmental extremes. The nature of the mechanical response and the longterm degradation of the composites have to be investigated to establish durability of the bridge decks. High humidity and temperature conditions inflict unavoidable environmental stresses on structures that affect material properties in various ways including weakening glass fibers, changing intermolecular bond strength or adhesive strength at the interface, altering chemical composition, etc. These changes lead to strength and stiffness variations in constituent materials (matrix, adhesives, etc.) resulting in a decrease in performance. In order to build safe structures, behavior of FRP materials in these environments must be well established. Information on the amount of strength loss due to environmental factors is essential to predicting the service life of these structures.

Strength loss should not be influenced by the manufacturing process employed to produce the structural parts. However, variations in a specific manufacturing process, such as processing temperature and rate of production may affect the internal chemical structure, and this can affect the properties of the FRP material and the structural part. These internal chemical structural changes may result in premature aging and strength loss. To understand such aging of composite materials, research on the effect of 
environmental exposure of FRPs was performed in this study and material degradation rates evaluated. Conditions that are commonly encountered in service, including high humidity, high temperatures, freeze-thaw and sustained stress were simulated.

\subsection{Research Objectives}

The present study focused on the mechanical property characterization and accelerated aging response of neat resin, glass fiber reinforcement and resin combination, as well as specimens manufactured by the pultrusion process. A detailed description of the pultrusion process is provided in Chapter 2. The degradation rates of pultruded samples with varying process conditions were compared to determine any degradation effect due to changes in process parameters.

The void fraction, degree of fiber wet-out, and extent of cure may vary when process conditions are changed even without changing the manufacturing method; this is likely to influence the performance of the composite. The research conducted herein determined if these variables are factors in the material response degradation by direct comparison testing of mass-produced pultruded samples (obtained from Creative Pultrusions) with those carefully handmade in the laboratory. In order to determine the effect of line speed in the pultrusion process, samples at various line speeds were tested.

Both the neat resin and fiber composites were tested to determine the effect of aging on each component. The materials used in the handmade samples were the same as those used in the pultruded samples. The resin and the fibers were exactly the same, thereby providing the same fiber-matrix interface, where most chemical attack and degradation is thought to occur. Differences in the aging process may also occur with change in the die temperature for the pultrusion process. To determine the effect, if any, two samples were obtained at the same line speed, but at different die temperature profiles. 


\subsection{Research Scope}

The scope of this research is divided into the following tasks:

- Laboratory manufacturing of both neat resin and composite coupons.

- Acquisition of pultruded samples at varying manufacturing process conditions, i.e. line speed and die temperature.

- Use of microscopy to verify the presence of voids, defects, or dry spots in pultruded coupons.

- Observation of the stiffness/strength degradation, dimensional stability, moisture content, and decay of coupons.

- Study of the factors that influence the bonding between the fibers and matrix such as moisture, temperature, and stress.

- Suggestion of methods to preserve performance of composites under the influence of harsh conditions.

- Establishment of degradation rates and calibration of life expectancy based on degradation rates. 


\section{CHAPTER 2}

\section{LITERATURE REVIEW}

\subsection{Background}

An extensive review of the literature dealing with the accelerated testing of FRP materials has been carried out to understand the existing analytical and experimental methods that predict changes in material properties during exposure to various environments. The strength and stiffness of polymer composites as well as the long-term changes in material are addressed. Furthermore, effects of manufacturing conditions on the retention of properties upon aging are addressed.

The level of degradation in the composite structure depends on numerous parameters including: the material constituents, the fiber volume fraction, manufacturing technique, time of exposure, moisture concentration, temperature, and interfacial bond strength. The interfacial bond strength is a measure of the adhesion between the fibers and the matrix and is affected by sizing on the fibers and additives to the resin. The effect of moisture and temperature will be discussed in greater detail for both neat resin and composite specimens in Section 2.3. Few degradation studies using alkaline, acidic, and salt solutions have been performed on both the neat resin and composite systems. Rather, investigators have focused on one system only; the results from those studies will be presented. Furthermore, little information is available on the effect of process conditions on structural properties upon exposure to aging environments. The research conducted herein greatly adds to the volume of information on the subject of process conditions and the effect on degradation of composite structures.

\subsection{Quality of FRP}

Standard tests and process control are vital to the quality assurance of polymer composite production. Raw materials, both fibers and resins, must meet standards prior to use in FRP parts. New measures for quality control are being implemented for the finished part because numerous defects can occur during the production of composite components [5]. These include:

- Excessive void content or porosity 
- Contamination or foreign particle inclusions

- Variation in the degree of resin cure

- Inconsistent fiber volume fraction, giving fiber- or resin-rich areas

- Translaminar cracks

- Dimensional inaccuracies like thickness variation

- Incorrect fiber alignment

- Poor fiber/matrix bonding

- Broken, damaged, or incorrectly joined fibers.

A composite structure may also be damaged in service due to physical damage such as static overload, impact or fatigue creep. The influence of the environment on a component due to moisture ingress, exposure to hot and wet conditions, and contamination from oils and fluids may also cause damage to the structure. This damage includes surface abrasion and dents, delamination, matrix or fiber cracking, fiber/matrix bond failures, chemical attack, and aging of the resin. These defects can be detrimental to the mechanical integrity, and consequently to the structural performance of a component. The extent to which a defect will affect the performance depends on the location and orientation of the defect, the amount of stress applied, and the working environment.

\subsection{Strength and Stiffness of FRP}

As previously stated, moisture and temperature adversely affect the performance of composite materials. The mechanical properties that may be altered include: tensile and compressive strengths, shear strength, elastic and shear moduli, fatigue behavior, creep, stress rupture, response to dynamic impact, electrical resistance, and swelling [6]. In the following sections, the effect of moisture and temperature on both the neat resin and the composite systems is presented.

\subsubsection{Effect of Moisture on Neat Resins}

Many degradation studies have examined the decrease in strength due to water exposure either by total immersion or high relative humidity. Moisture absorption and elevated temperatures may lead to matrix swelling and non-uniform thermal expansions 
of polymer based composite materials, which cause stresses within the material. Aqueous, alkaline and salt solutions are some of the environments in which resins were tested. Resinous matrices have a tendency to absorb water and as a result exhibit a decrease in stiffness and strength [7]. However, this process can be reversible to a degree if no chemical changes have occurred. Many resin systems tend to recover their properties upon drying. Therefore, permanent degradation of resins from moisture is not a major concern. Resins, especially vinyl esters and epoxies, are highly resistant to chemical attack. The regions of attack are generally the fiber-matrix interface region and the fibers themselves. These areas will be discussed further in Section 2.3.2.

\subsubsection{Effect of Moisture on Composites}

The major impact of environmental loads on composite materials is the degradation of the strength and stiffness of the material at the coupon and component level. The apparent causes of degradation in composite materials include [8]:

- Loss of adhesion and interfacial bond strength due to degradation of the interface between fibers and matrix.

- Permeability and aging of the matrix due to corrosive agents, such as water, which accelerate the above-mentioned items. The aging of the resin may change the crosslink density and weaken interlaminar bond strength.

- Strength loss in fibers due to a stress-corrosion mechanism. Corrosion can be caused by leaching at the atomic level by chemicals in the surrounding environment.

- Viscoelastic dependence of the matrix modulus, adhesion, and strength with respect to temperature.

The swelling of the matrix and resulting non-uniform expansion might cause changes in fiber volume fraction in the composite laminate, and consequently in material properties. Many degradation studies have examined the decrease in interfacial strength due to water exposure either by total immersion or relative humidity. In epoxy composites exposed to alkaline and salt solutions, the interlaminar shear strength decreased the greatest amount (over 80 percent) in the first 200 hours of exposure [9]. Alkaline solutions were most damaging for the composite systems, in contrast to the neat 
resin samples. It has been speculated that extra stresses at the interface region cause the strength reduction in the composites.

It has also been shown that leaching of alkaline components from the fibers and the consequent increase in $\mathrm{pH}$ surrounding the fibers cause enhanced degradation of the fiber/matrix interface, which involved both accelerated fiber dissolution and loss of acidic components of the matrix [10]. The deterioration and opening up of the interface allowed further water penetration, which promoted hydrolytic depolymerization of the matrix. Eventually the degradation, concentrated around the interface, led to the formation of microscopic cracks and voids that further facilitated aqueous attack.

Experiments for determining whether changes in strength and modulus are permanent were performed after drying polyester and vinyl ester specimens at $66^{\circ} \mathrm{C}$ for three weeks [11]. By drying the composite material, some, but not all losses in strength and modulus are recovered. It appears, therefore, that changes in the composite material properties are permanent. Drying of the composite material does not restore either the strength or the modulus to their original values.

It has been shown that moisture exposure lowers the glass transition temperature of polymeric resins [12]. This change is due to moisture altering the effective free volume in the resin. For vinyl ester resins, total immersion in water at $60^{\circ} \mathrm{C}$ for 4000 hours resulted in significant hydrolysis, which was detected through FTIR evaluation. For glass reinforced composites in the same environment, plasticization mainly occurs during times less than 2500 hours.

\subsubsection{Effect of Moisture on Glass Fibers}

A study conducted on glass-epoxy specimens conditioned in water concluded that both components of the material, i.e., fibers and matrix, are subjected to degradation [13]. As previously mentioned, resinous matrices have a tendency to absorb water and decrease in stiffness and strength; this process can be reversible to a degree since many resin systems tend to recover their properties upon drying. Glass fibers do not present such a tendency and may show corrosion effects that lead to a loss of effective cross-

section. Glass-fiber reinforced composites can lose up to 10 percent of their flexural strength due to moisture. It has been shown that the dissolution of glass fibers in basic 
environments increases the amount of hydrolytic attack on the polymer, which further accelerates the degradation process [10].

In the case of glass fibers, which reinforce vinyl ester and polyester resins, it has been shown that exposure to a moist environment affects both the strength and modulus of the material [11]. The changes in strength and modulus depend on the material, the temperature, and the environment. The temperature and the environment seem to be more significant factors. Exposure to saturated salt water has the most pronounced effect on the mechanical properties. Though weight changes were also large under these conditions, clear correlations could not be established between weight change and the change in mechanical properties [14]. It is well known that bulk glass is susceptible to stress corrosion in the presence of water or water vapor. The strength of E-glass is therefore expected to be time dependent in the presence of quite small amounts of moisture. The polyester component of glass reinforced plastic is also subject to water attack; when the resin is free from inorganic impurities, water merely acts as a swelling agent and plasticizes the resin. The resulting osmotic pressure within the resin leads to cracking. Thus, when E-glass fibers, which may give rise to alkaline hydrolysis products, are embedded in a polyester resin (usually producing acid hydrolysis products) the interface will tend to become more hydrophilic and three distinct but interrelated effects may be predicted:

- The individual fibers will be weakened as a result of crack growth promoted by water that has penetrated the resin.

- Resin swelling will produce a radial stress at the interface that will be reinforced by the pressure of water and lead to fiber debonding, increase in transfer length, and consequent weakening of the composite.

- Plasticization of the resin by water will result in an increase in the viscoelasticity and hence a further increase in transfer length.

\subsubsection{Effect of Temperature on FRP}

Temperature affects not only the rate of moisture absorption in a composite material, but the mechanical properties of the material as well. It has been shown that mechanical properties of fiber reinforced plastics decrease when the material is exposed 
to elevated temperatures $\left(37^{\circ} \mathrm{C}\right.$ to $190^{\circ} \mathrm{C}$ ) and after some exposure time (only after softening point) strengths and moduli may become so low that the material cannot sustain applied loads or maintain allowable deflections [6]. It is well known that high temperature causes time-dependent effects such as creep and stress relaxation [14]. The available information for temperature effects on mechanical properties of FRPs can be separated into experimental data from tests performed on several glass-fiber reinforced polymers by various researchers and analytical formulae that have been proposed to predict the change in strength and stiffness due to temperature variations.

Boiling water is frequently used in industries or research centers to accelerate the aging process of a material; however there is little thought given to the accuracy of such a method since the accelerated conditions may not exactly simulate conditions the material will be subjected to during its real service life. No damage was observed in fiber glassepoxy resin samples at $22^{\circ} \mathrm{C}$ after several years of exposure whereas immersion in boiling water produced cracking and leaching of matrix after 10 hours [15]. Hence, it is important to decouple the effects of heating to a certain temperature from those due to water environment. As temperature affects moisture absorption, this decoupling may seem more of a necessity over a certain temperature range.

Vinyl ester composites aged at high temperatures in an aqueous environment showed an overall decrease in strength with an increase in the duration of conditioning at a given condition, particularly at higher temperatures [12]. However, there was a fair amount of scatter in the results, often encountered in the characterization of mechanical properties of composites. Variations in the material that may have occurred in the manufacturing process were enhanced by the environmental conditions and the application of load during conditioning. Samples subjected to sustained load showed a more rapid decrease in strength for lower temperature conditions. The drop in strength was comparable for unloaded and loaded samples at the higher temperature condition.

\subsection{Long Term Behavior}

\subsubsection{Principles of Accelerated Aging}

The mechanical, thermal and chemical properties of fiber reinforced polymer composites change during environmental exposure. These changes in properties must be 
evaluated by tests, which may last months or years. Unfortunately, under most circumstances such lengthy tests are impractical, and testing time must be reduced. Therefore, this investigation utilized accelerated testing and techniques to reduce the time required to perform environmental tests. The accelerated procedure introduces moisture into the material faster than just soaking the specimens in a solution, with the mechanical properties being the equivalent of regular and accelerated environmental conditioning. The problem at hand is to select change-over time, which should satisfy the following conditions [16]: at the end of a given exposure time and at every point inside the material, the moisture concentration agrees with the desired uniform moisture concentration and also the desired uniform moisture concentration is reached in the shortest possible time.

\subsubsection{Environmental Aging}

During the service life of a composite structure, the structure will encounter a number of different environmental conditions that it must withstand. Environmental aging tests must be conducted to assure proper durability of the composite structure, preventing premature failure with potentially catastrophic results.

A number of investigations have been conducted to understand the effects of water on the aging of composite samples [17-20]. Water is the main cause of degradation in the interfacial bond between the fiber and matrix. This degradation causes a decrease in the load transfer, and thus a decrease in the composite strength. Macro-mechanical tests have shown a decrease in composite strength upon exposure to moisture. Also, there have not been many investigations that have examined composite strength over long periods of time, a year or longer.

The strength degradation of composite laminate samples exposed to water, salt water, and an alkali solution was analyzed [19]. The total exposure time for all the samples in solution was 700 hours. The laminates were made from glass/epoxy, glass/vinyl ester, and glass/isophthalic polyester. Three-point bending tests according to ASTM D2344 were conducted to evaluate the strength of the samples. The investigation was able to demonstrate that the largest decrease in the interlaminar shear strength occurred from alkali exposure. The vinyl ester composite was the least affected by the 
aging conditions. Additionally, the majority of the strength decrease in the epoxy and polyester occurred in the first $100 \mathrm{hrs}$ of exposure.

The interfacial shear strength of E-glass embedded in epoxy and vinyl ester was investigated; the tensile strength of composite samples was also measured [17,18]. Specimens were aged by means of water exposure in combination with elevated temperature. Both the fragmentation specimens and the composite samples gave similar degradation trends in strength. A simple volume rule of mixture was used to predict the composite strength from the fragmentation measurements. This rule consistently overpredicted the amount of strength loss in the composite due to degradation. It was also noted that there was stress corrosion, due to matrix swelling, of the fiber/matrix interface.

The environmental degradation of two neat resins: vinyl ester, and isopolyester was anaylzed [20]. Thin films of the resins were made to determine the glass transition temperature of the resin by means of DMTA. Dogbone samples of the resins were used to determine the tensile strength in the resins. The samples were exposed to 1300 hours of environmental conditioning under water, salt water, and alkali solutions. From their investigation they found no significant change in the glass transition temperature, $\mathrm{T}_{\mathrm{g}}$, or tensile strength of samples after 1300 hours of environmental exposure.

The accelerated aging of epoxy in several environments, namely, deionized water, sodium chloride solution, hydrogen chloride solution ( $\mathrm{pH}$ 2), and sodium hydroxide solution ( $\mathrm{pH}$ 12) was studied [21]. Samples were also examined under sustained stress (15-60 percent Ult.) while immersed in the above solutions in addition to freeze-thaw cycling. The ultimate strength was measured and correlated with non-destructive test results. After four months of applied stress in water, little or no property changes were noticed for 15 percent stress applied. Tests with higher stress applied are currently being conducted. No degradation was found for the freeze-thaw cycles. Water was found to be more damaging than the alkaline or acid solutions, especially on the composite samples. The composite samples were cut from large sheets, which rendered the edges porous. This may have lead to enhanced capillary diffusion to the interface.

The aging of pultruded vinyl ester specimens was examined [22]. The samples were cut from plates to the dimensions of $5 \times 1 / 2 \times 1 / 4$ in and evaluated by a 4point bend test. Specimens were preconditioned by immersion in three media at room-temperature: 
deionized water (5 months), 5 percent salt solution (6 months) and 10 percent salt solution (6 months). These solutions were chosen to simulate rain and salt spray encountered in the field. Mass change and sorption rates were recorded regularly. The preconditioned specimens showed a fractional decrease of 5-15 percent in flexural strength. Samples loaded cyclically at or above 45 percent of the average flexural strength showed no fatigue life, with or without preconditioning.

The durability of pultruded vinyl ester composites was investigated by means of freeze-thaw tests [23]. Samples were subjected to 3 levels of exposure: 100, 300, and 500 cycles. A cycle consisted of a ramp from $4.4^{\circ} \mathrm{C}$ to $-17.8^{\circ} \mathrm{C}$, followed by a hold at $-17.8^{\circ} \mathrm{C}$ and a ramp to $4.4^{\circ} \mathrm{C}$. The aging time was split with 75 percent devoted for freezing and 25 percent devoted to thawing. The strength and strain-to-failure was approximately 50 percent lower after saturation for all three samples. Stiffness values remained unchanged.

It has been shown that the residual strength of GFRP (Glass/isophthalic resin, and glass/filled, flame retardant resin) never varied by more than 5 percent of initial value after 64 weeks exposure to natural weathering under stress [24]. Also, when stressed at 25 percent Uts, only about a 5 percent decline in tensile strength was observed after 32 weeks.

Upon longer-term exposure and in more severe environment, substantial degradation is seen. Composite panels were subjected to outdoor weathering (hot-wet, hot-dry, and temperate) for up to 8 years [25]. It was found that the greatest degradation of properties took place at the hot-wet site. Substantial drops in flexural strength, flexural modulus, tensile strength, and tensile modulus were observed. It was also found that freeze-thaw cycling from $4.4^{\circ} \mathrm{C}$ to $-7.8^{\circ} \mathrm{C}$ for about 900 hours in 2 percent (by mass) solution of sodium chloride showed a significant decrease in flexural strength, flexural modulus, and toughness in a study on E-glass/vinyl ester and E-glass/isophthalic polyester [26]. 


\section{CHAPTER 3}

\section{MATERIALS SELECTION AND PROCESSES}

\subsection{Materials Overview}

A composite material consists of two or more distinct phases, one of which, the fibrous, is embedded in a continuous matrix phase. The fibers are the primary load bearing elements within the composite. The matrix binds the fibers together and transfers the load between them, while also providing protection from environmental attack and damage due to handling. The fibers have a strong influence on the mechanical properties of the composite, such as strength, elastic modulus and deformation properties.

Glass, carbon and polyaramid fibers are commonly used in fiber reinforced polymer composites. More information on the types of fibers and their properties can be found in Appendix A. Polyesters, epoxies, polyurethanes, phenolics, and vinyl esters are

commonly used resins for FRPs. A brief discussion and comparison of various types of resins is also presented in Appendix A. Vinyl ester was used for the research conducted herein due to its good chemical resistance, high strength and impact damage resistance.

\subsubsection{Glass Fibers}

Glass fibers are the most common of all reinforcing fibers for polymer composites. The use of glass fibers in modern composites dates back to the 1940s [7]. Glass fibers are available in a variety of forms for use in composites, e.g. continuous rovings, woven rovings, cloths, and random chopped mats. Glass fiber reinforcement is supplied in a variety of forms: A, C, E, and S. Alkali glass (A) was once the most common reinforcement, but has been superseded by electrical grade glass (E), a very low alkali content borosilicate glass providing good electrical, mechanical and chemical resistant properties [27]. 'C' glass is a special chemical resistant glass used for surface tissue manufacture, whereas ' $\mathrm{S}$ ' glass is a high strength glass mostly used in aerospace applications. Typical compositions for the types of glass above are given in Table 3.1. The internal structure of glass fibers is a three dimensional network of silicon, oxygen and other atoms like boron and aluminum arranged in a random fashion. Thus, glass 
fibers are amorphous and isotropic in nature. A two-dimensional representation of the structure of glass is given in Figure 3-1.

Table 3-1. Typical Glass Compositions (\%) [27]

\begin{tabular}{||c|c|c|c|c||}
\hline Component & $\mathbf{E}$ & $\mathbf{C}$ & $\mathbf{S}$ & $\mathbf{A}$ \\
\hline \hline $\mathbf{S i O}_{2}$ & 52.4 & 63.6 & 64 & 72.5 \\
\hline $\begin{array}{c}\mathbf{A l}_{2} \mathbf{O}_{3} \\
\mathbf{F e}_{2} \mathbf{O}_{3}\end{array}$ & 14.4 & 4.0 & 26 & 1.5 \\
\hline $\begin{array}{c}\mathbf{C a O} \\
\mathbf{M g O}\end{array}$ & 21.8 & 16.6 & 10 & 12.5 \\
\hline $\begin{array}{c}\mathbf{B}_{2} \mathbf{O}_{3} \\
\mathbf{N a}_{2} \mathbf{O}\end{array}$ & 10.6 & 6.7 & - & - \\
\hline $\mathbf{K}_{2} \mathbf{O}$ & 0.8 & 9.1 & - & 13.5 \\
\hline \hline
\end{tabular}
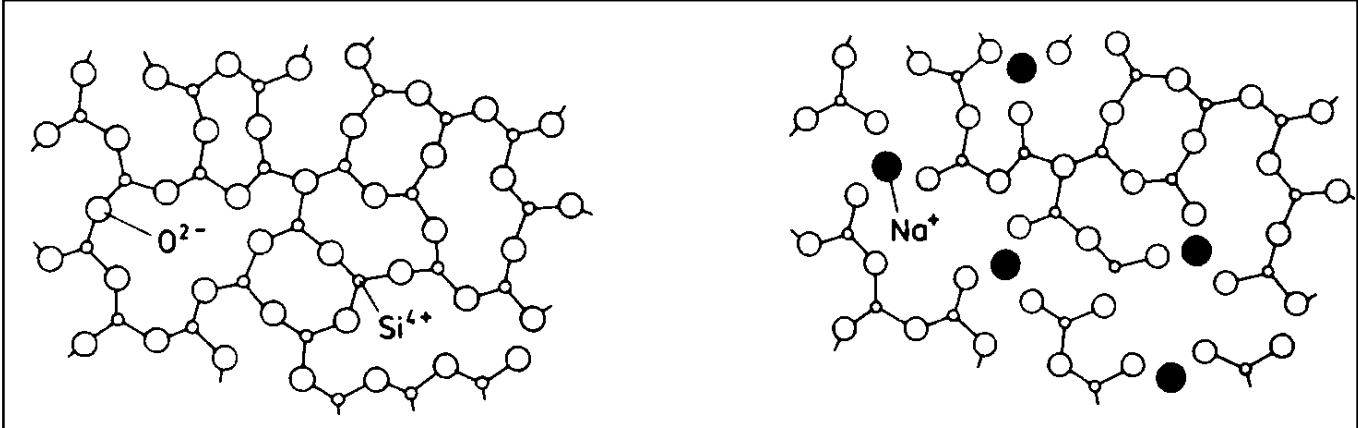

Figure 3-1. Structure of Amorphous Glass:

Silica Glass and Silica Glass Modified with $\mathrm{NaO}_{2}$ [7]

Sizing is applied to glass filaments shortly after the drawing process. Sizing performs a number of functions including the application of a linking agent to the glass and protection of the glass from interfilament abrasion. Typical forming sizes are applied as emulsions and consist of [27]: 
- A coupling agent, which is generally an organo-silicon compound or chromium complex.

- A film former, which may be an emulsified polyester resin that protects the filaments during manufacture and handling.

- A lubricant such as silicone or acid amides that aids in the passage of the filaments through and over guide points.

- Anti-static agents to reduce the build-up of static.

\subsubsection{Vinyl Ester Resin}

Vinyl ester resin is similar to polyester resins in that it is composed of an unsaturated oligomer dissolved in styrene and cured via a free radical reaction [7, 27]. A typical chemical structure of vinyl ester resin is shown in Figure 3-2. The main backbone is the bisphenol ' $A$ ' epoxy structure, which does not have a weak chemical link susceptible to chemical attack or corrosion. Also unsaturation is found only at the ends of the molecule, not as part of the repeat unit, which gives the resin a higher failure strain and impact damage resistance.

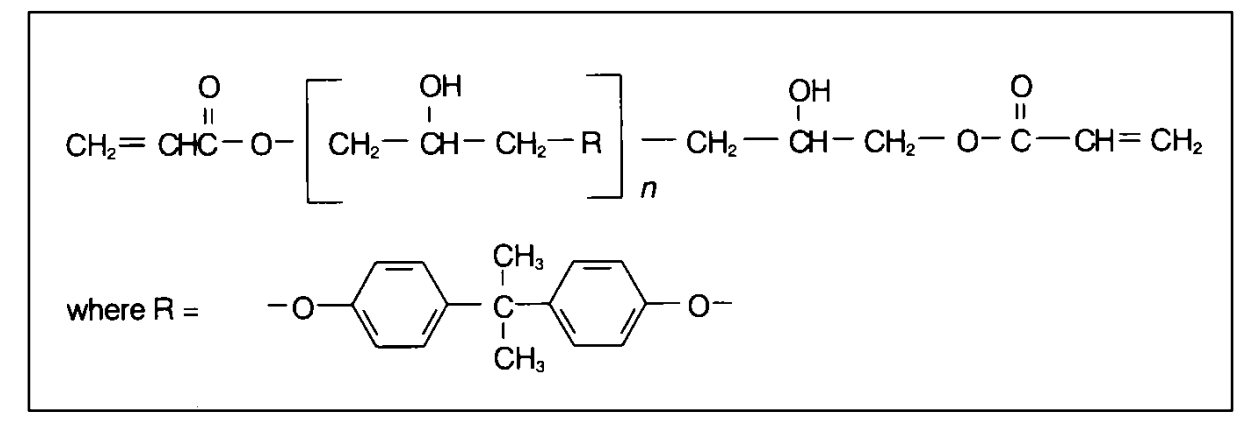

Figure 3-2. Structure of Vinyl Ester Resin [27]

Vinyl esters are cured at room temperature with initiator/promoter systems. However, these resins are not fully cured under ambient conditions. The degree of cure increases with time, but if maximum properties are required, then a postcuring step could be necessary. The most common initiator is methyl ethyl ketone peroxide (MEKP). MEKP is not a true catalyst because it is consumed in the reaction. A promotor such as 
cobalt naphthenate (CoNaph) is required for room temperature cure of vinyl esters because MEKP decomposes into free radicals too slowly. A copromotor such as dimethylaniline (DMTA) is often used to reduce the occurrence of gel time drift. An increase in gel time occurs with the age of a prepromoted resin.

Numerous types of fillers are added to resins for both performance improvement and cost reduction. Clays are frequently added as inexpensive filler and may provide a high glossy finish. Ballotini, solid glass microspheres, coated with a silicone coupling agent improve adhesion, increase modulus, chemical and abrasion resistance, while also providing a reduction in water absorption. Pigments are added to provide a wide range of colors for finished parts. In addition, halogenated compounds are added for fire retardation and other compounds are added to improve resistance to UV exposure.

\subsection{Pultrusion Process}

To a large extent, fiber reinforced polymer composites have been far more expensive to produce and install than traditional materials. However, advancements in the production of fiber reinforced polymer composites, such as large-volume processing methods like pultrusion, have lowered costs and greatly changed the market potential of FRP materials.

Conventional pultrusion is a continuous process involving the production of composite materials with constant cross-sectional area. Once initiated, pultrusion is a relatively automated process requiring little labor. A schematic of the pultrusion process is shown in Figure 3-3. The manufacturing conditions used for pultrusion are diverse and vast in combination. For example, line speed can range from a few inches per minute to a few feet per minute, depending on the complexity of the part manufactured. Examples of some of the many profiles of manufactured parts are shown in Figure 3-4. Figure 3-5 illustrates the typical composition of an I-beam manufactured through pultrusion.

The pultrusion equipment consists of a fiber delivery system, a resin bath, preform fixtures, a heated die, synchronized pullers and a cut-off saw. The filaments or mats are passed from a creel and pulled through a resin bath where they are impregnated with the resin. The resin-embedded fibers are then pulled through the preform fixtures, which contour the fiber/resin combination to the desired shape and align the fibers. 


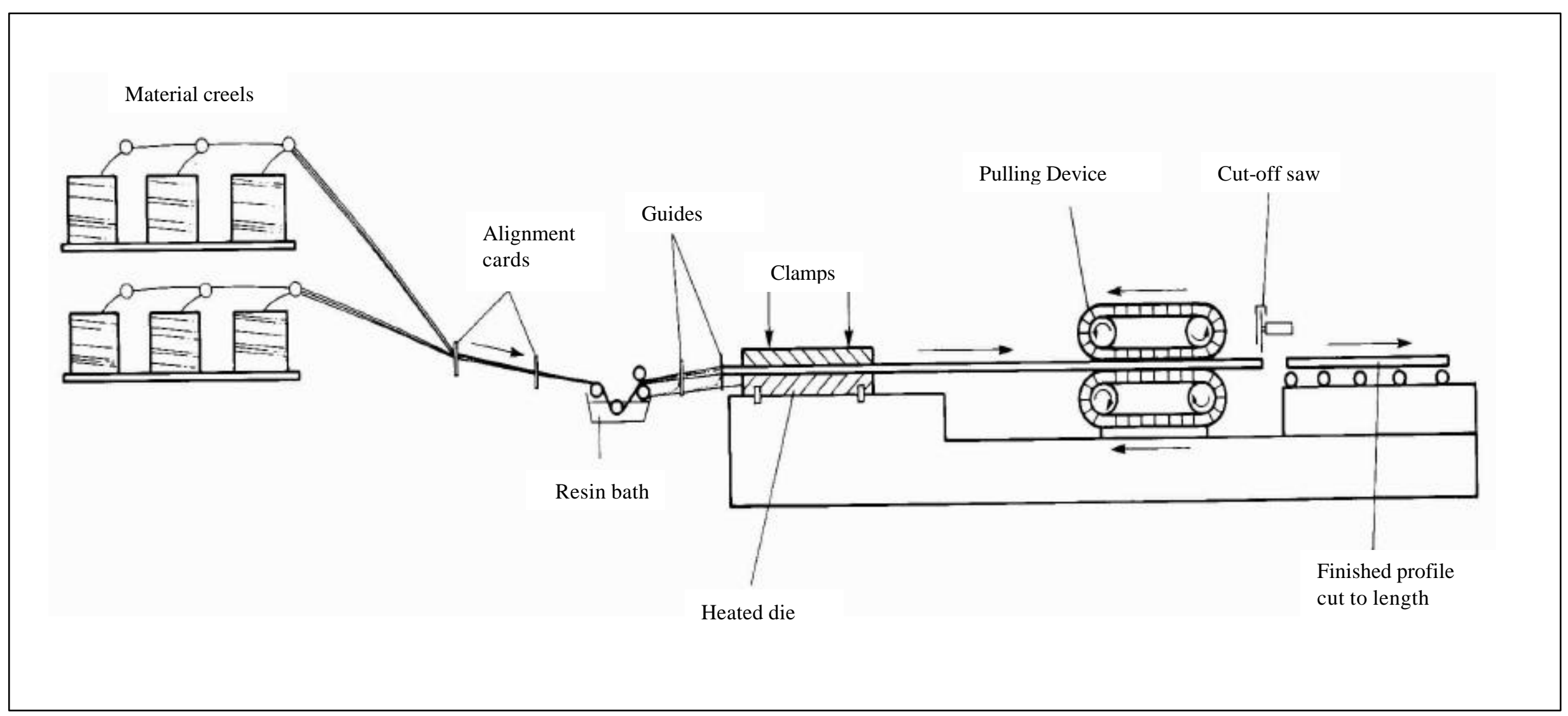

Figure 3-3. Schematic of Pultrusion Process [27] 


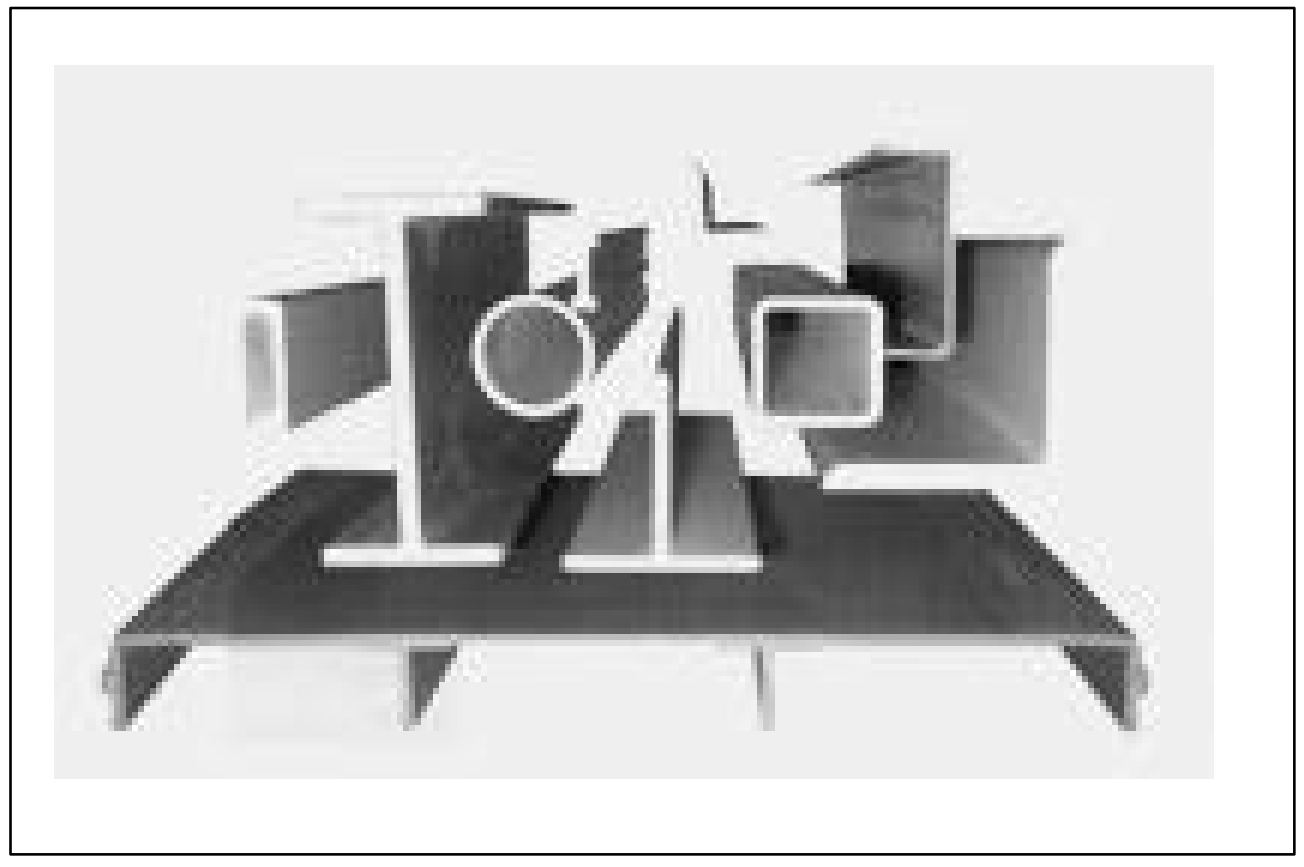

Figure 3-4. Examples of Part Profiles Available through Pultrusion [28]

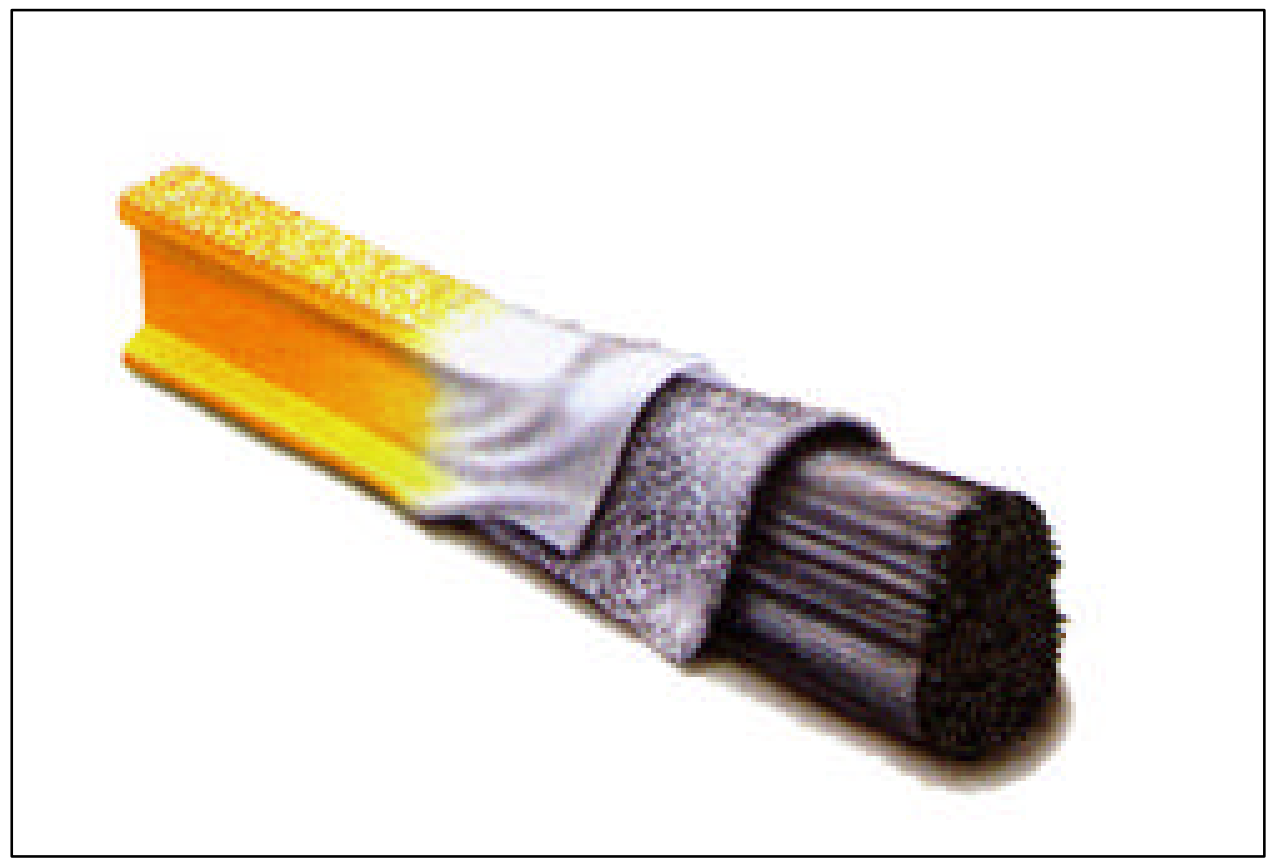

Figure 3-5. Illustration of Pultruded I-beam Composition [28] 
After passing through the preforms, the fibers and uncured resin then pass through a heated chrome-plated tool steel die. The entrance area of the die is sometimes water cooled to prevent premature resin coagulation at the die entrance. Multiple sets of heaters in direct contact with the die are used to heat the die to the desired temperature profile. The heater temperatures can be controlled to achieve a desired temperature profile along the length of the die. The heat from the die wall initiates an exothermic chemical reaction in the resin, thereby causing the matrix to gel. As the exothermic chemical reaction continues to release heat, the interior of the composite can attain a temperature that is greater than the die wall temperature. The finished product exiting the die is a highly cured product that requires minimal post-fabrication processing. The cured product is extracted from the die by a set of pullers and directed towards a saw to be cut into useable segments.

Many processing parameters can influence the integrity of a finished composite. Proper choice of pull speed, correct die wall temperatures, optimum fiber volume, selection and compatibility of fibers and matrix, good packing of fibers, kinetic properties of the resin and proper resin impregnation play instrumental roles in terms of product quality.

Glass fibers embedded in a vinyl ester resin were used in the current research due to their low cost, high strength, good chemical resistance and insulating properties. Even with lower cost E-glass fibers, the installed cost of glass-fiber-reinforced plastics is greater than that of equivalent steel and concrete structures. The total costs include both material costs and processing costs. The material costs are fixed, but the processing costs can be varied. One way of lowering processing costs is to increase the line speed of the pultrusion process to produce more material in a shorter time. However, there is a tradeoff between lowering process cost by increasing processing speed and product quality. Voids may occur due to lack of fiber wet-out, incomplete cure due to short residence time in the die, etc. This tradeoff was examined in the work presented herein. 


\subsection{Composition of Pultruded Coupons}

Both the pultruded coupons and the laboratory made coupons were prepared using the same resin. The resin, Atlac 580-A, is produced by Reichhold Chemicals. The pultruded samples, obtained from Creative Pultrusions, contain small amounts of fillers and UV inhibitors that were not duplicated in the samples made in the laboratory at WVU. The composition of the resin is given in Table 3-2.

Table 3-2. Composition of Vinyl Ester Resin

\begin{tabular}{||l|c|c||}
\hline \multicolumn{1}{|c|}{ Compound } & Creative & WVU \\
\hline \hline Vinyl ester & $100 \mathrm{lb}$ & $100 \mathrm{lb}$ \\
\hline Styrene & $3 \mathrm{lb}$ & $3 \mathrm{lb}$ \\
\hline MEK peroxide & $1.2 \mathrm{lb}$ & $1.2 \mathrm{lb}$ \\
\hline Cobalt naphthenate & $0.4 \mathrm{lb}$ & $0.4 \mathrm{lb}$ \\
\hline Clay & $20 \mathrm{lb}$ & - \\
\hline Bromine powder & $15 \mathrm{lb}$ & - \\
\hline Glass beads & $1 \mathrm{lb}$ & - \\
\hline UV inhibitor & $0.5 \mathrm{lb}$ & - \\
\hline
\end{tabular}

The samples obtained from Creative Pultrusions had a cross-section that was in the form of a right angle and these samples were $3 / 8$ " in thickness. The samples obtained were pultruded at line speeds of 4,8 , and 12 inch per minute (ipm). A cross-section of the fiber architecture for the pultruded samples is shown in Figure 3-6. The fiber volume fraction for the pultruded samples was confirmed by a burn test to be 35 percent. 


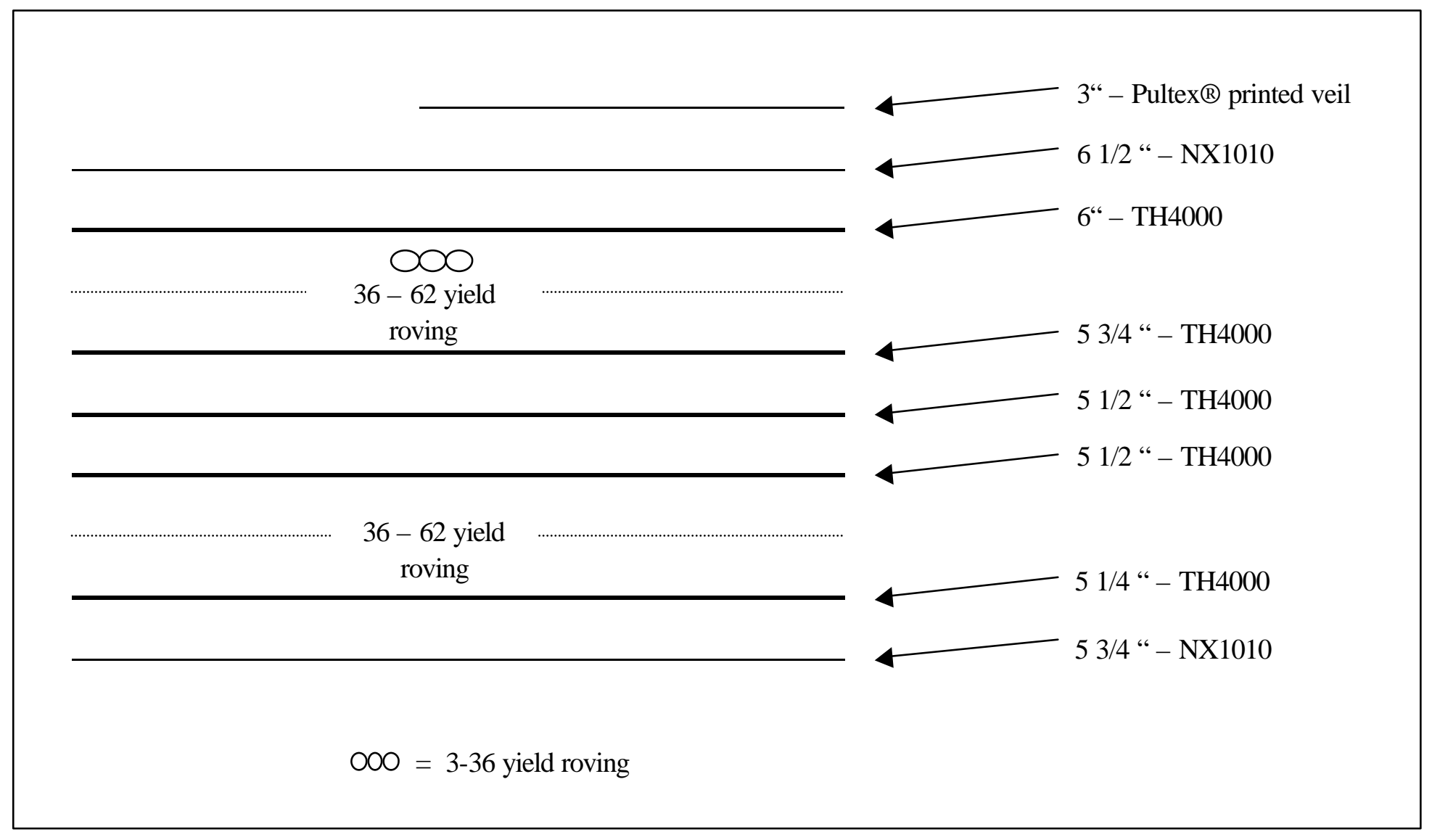

Figure 3-6. Diagram of Fiber Architecture for Pultruded Coupons 


\subsection{Environmental Conditioning Process}

Various aging conditions were used to determine the effect on degradation of the composites. Three samples were tested for a given condition for statistical purposes. The samples were subjected to the following aging conditions:

- 100 percent humidity at 25,50 , and $85^{\circ} \mathrm{C}$; the highest temperature is below the $\mathrm{Tg}$ of the resin, approximately $100^{\circ} \mathrm{C}$, but within range of potential application exposure.

- Freeze-thaw cycling in $4 \mathrm{M} \mathrm{NaCl}$ solution for 20 cycles to simulate harsh winter conditions.

- Stressed at 40 percent of ultimate flexural strength of the composite while being immersed in water at $85^{\circ} \mathrm{C}$.

Since aging tests on a variety of thermosetting polymers in the past have found that immersion in water was as degrading as immersion in salt or basic environments, the tests were conducted using only water immersion. Also because degradation has been observed in as few as $200-1000$ hours [19], the conditioning was conducted for 3000 hours, which is a substantial time length to observe degradation. In addition to testing virgin samples, samples were evaluated after 1000, 2000, and 3000 hours of exposure to monitor changes in the material properties with time.

The samples were tested using both destructive and nondestructive methods. Nondestructive tests were performed using Dynamic Mechanical Thermal Analysis (DMTA). DMTA is a small strain test and measures changes in the modulus due to aging. Destructive tests were performed using an Instron $^{\mathrm{TM}}$ machine with 3-point bending apparatus to measure changes in the flexural properties due to aging. Both handmade and pultruded samples were subjected to 3-point bending tests following the guidelines of ASTM D790-92. Further tests were conducted using Differential Scanning Calorimetery (DSC). DSC was used to determine the glass transition temperature, $\mathrm{T}_{\mathrm{g}}$, of the resin. These methods will be discussed in further detail in Chapter 4.

The results reveal the importance of the manufacturing technique in giving good initial mechanical properties and in determining how well these properties are retained during the process of chemical aging. 


\section{CHAPTER 4}

\section{EXPERIMENTAL PROCEDURE}

The effectiveness of a composite bridge deck is determined by its performance in the field. When installed in the field, the composite may be affected by several factors such as mechanical stress, temperature, and the presence of chemicals and moisture. Moisture can degrade the bond between the fibers and resin. It can also produce variations in dimensions and strength and can weaken the structure. Elevated temperatures can further cure the matrix, and can also accelerate any degradation process.

Testing of unaged coupons is required to ensure that the materials and manufacturing processes used for the composite structure possess the requisite strength. Accelerated aging tests are performed to predict durability of the composite in the field. Tests directly comparing handmade samples and pultruded samples for degradation are not found in the literature, especially for pultruded samples produced at varying line speeds.

Test procedures are in three categories: destructive tests, non-destructive tests, and durability tests. The testing procedures will be discussed in detail in Sections 4.2, 4.3, and 4.4.

\subsection{Sample Preparation}

Two types of samples were prepared by hand in the laboratory. (1) Neat resin samples were cast in the cavities of Teflon ${ }^{\circledR}$ molds. A detailed description of the mold design is given in Appendix B. (2) Glass fiber-resin composites were prepared by compressing resin-impregnated glass fabric between two metal plates, covered with Teflon ${ }^{\circledR}$ sheets. The sheet of composite was cured and cut to the appropriate size bar for testing. Both sample types, which used the pre-promoted resin, were cured at room temperature for 24 hours prior to handling. If necessary, the ends of the composite samples were sanded, allowing them to fit into the fixtures of the RMS 800 dynamic mechanical analyzer. A third sample type was obtained in sheet form from the pultrusion company, Creative Pultrusion, in the form of an even leg angle with dimensions of 3 " $\mathrm{x}$ 3" $x$ 3/8". These samples were cut to the appropriate size as determined by the ASTM 
for testing. A diamond-bit saw was used to cut all samples. The die used for the pultruded samples was 36" in length and was heated in two zones. Zone one was set at $275^{\circ} \mathrm{F}$ with the heat source 6 " from the die entrance while zone two was set at $325^{\circ} \mathrm{F}$ with the heat source 18" from the die entrance.

The materials recommended by the sponsor and used in this research are as follows:

- Vinyl ester resin 580-05 from Reichhold Chemical for pultruded samples. The composition of the resin is given in Table 3-2.

- Vinyl ester resin 580-05A from Reichhold Chemical for handmade samples. The composition of this pre-promoted resin is given in Table 3-2.

- E-glass fabric and rovings. The architecture for pultruded samples is given in Figure 3-4.

- Single-layer E-glass fabric, specifically TH4000, for laboratory composite samples.

- Pultruded vinyl ester samples at various line speeds (4, 8, 12 ipm) from Creative Pultrusions in the shape of even leg angles with dimension 3" x 3" x 3/8", which were cut to ASTM size for testing.

- Pultruded vinyl ester samples at identical line speed (8 ipm), but with different die temperature profile from Creative Pultrusions. Original profile: $\mathrm{T}_{1}=275^{\circ} \mathrm{F}, \mathrm{T}_{2}=325^{\circ} \mathrm{F}$. New Profile: $\mathrm{T}_{1}=325^{\circ} \mathrm{F}, \mathrm{T}_{2}=275^{\circ} \mathrm{F}$.

\subsection{Destructive Testing}

Destructive testing applies load on an entire area and evaluates the strength as a whole. However, it destroys the coupon and the specimen cannot be used further. It is used to reveal changes in strength and modulus. The direction of load placed on a test specimen until failure characterizes the destructive testing procedure.

In the research conducted herein, samples were evaluated by 3-point bending tests that determined the flexural properties of unreinforced and reinforced plastics in the form of rectangular bars. Bending tests were used because of the simplicity of the sample preparation and testing. Gripping, buckling and end-tabbing are not concerns for this

test. Other testing procedures, like tensile testing, must address these issues. The bending tests were carried out following ASTM D 790-92 specifications. Following Test 
Method I, a 3-point bend test was conducted utilizing center loading on a simply supported beam [29]. Procedure A, which is designed for materials that break with small deflections, was used. A span to depth ratio of 16:1 was used, which determined the sample size and rate of crosshead motion. Neat resin bars, composite bars cut from sheets, as well as pultruded bars obtained from Creative Pultrusions were tested. An Instron Series 8500 Two-Column Load Frame (30,000lbs capacity) was used for this purpose. The Instron Series 8500 is shown in Figures 4-1 and 4-2.

The sample size and crosshead rate were determined by the ASTM guideline. For the handmade samples, the ASTM guidelines gave a length of 2", width of 1" for a specimen depth of 1/16". For the pultruded samples, ASTM guidelines gave a length of $71 / 2$, width of $1 / 2$ for a depth of $3 / 8$ ". The crosshead motion was $0.03 \mathrm{in} / \mathrm{min}$ for the small samples and $0.16 \mathrm{in} / \mathrm{min}$ for the larger pultruded samples.

The specimen was placed in the 3-point bending apparatus and loaded in a continuous manner by the movable head of the instrument at a constant rate until failure. The flexural strength and tangent modulus of elasticity were calculated. These properties were calculated by using Equations 4-1 and 4-2 from ASTM D-790 [29]. These equations are derived in Appendix C.

$$
\begin{array}{ll}
S=3 P L / 2 b d^{2} & \text { Equation 4-1 } \\
E_{B}=L^{3} m / 4 b d^{3} & \text { Equation 4-2 }
\end{array}
$$

Where,

$S=$ stress in outer fibers at midspan, psi

$P=$ load at given point, $\mathrm{lb}_{\mathrm{f}}$

$L=$ support span, in

$b=$ width of beam tested, in

$d=$ depth of beam tested, in

$E_{B}=$ modulus of elasticity in bending, psi

$m=$ slope of tangent to initial straight-line portion of load-deflection curve, $\mathrm{lb}_{\mathrm{f}} /$ in 

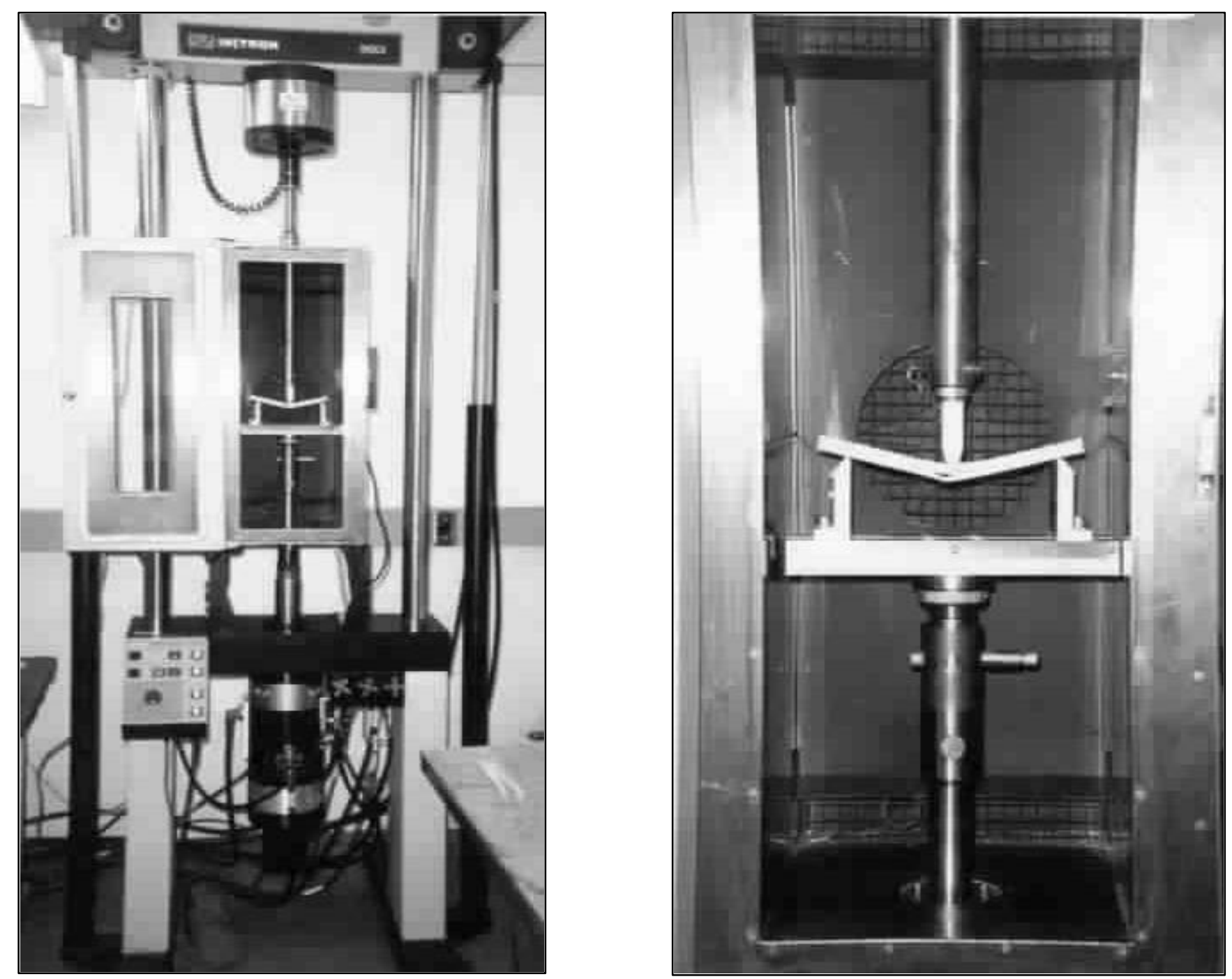

Figure 4-1. View of Instron Series 8500 3-point Bending Test

Figure 4-2. Close View of Instron Series 8500 3-point Bending Test 
The effect of the line speed on the strength of pultruded samples was determined from these bending tests. Furthermore, the data were correlated with the nondestructive dynamic mechanical results to determine better the degree and nature of degradation that occurred in the samples.

\subsection{Non-destructive Testing}

Non-destructive testing is carried out on specimens so that they can continue to be used after testing. This type of testing does not damage the sample because the sample is not loaded to failure. Non-destructive testing is conducted to understand better the causes of strength degradation and the factors involved. In the experimental work conducted herein, non-destructive testing of resins was performed using DSC and DMTA. Both of these methods can be used to evaluate and monitor changes in the glass transition temperature as influenced by the imposed environmental conditions.

\subsubsection{DMTA}

Dynamic Mechanical Thermal Analysis (DMTA) is used to measure changes in the modulus and glass transition temperature, $\mathrm{T}_{\mathrm{g}}$, of polymeric and composite materials. A torsional cyclic strain is applied while the samples are analyzed through temperature and frequency sweeps on the $\mathrm{RMS} 800^{\mathrm{TM}}$ by Rheometrics. The resulting stress is measured and the storage modulus is determined. The storage modulus, G, is similar to Young's modulus and indicates the inherent stiffness of a material under dynamic loading. The loss modulus, G, represents the amount of energy dissipated as heat during the test. Dividing the loss modulus by the storage modulus gives the tan delta or the internal friction. The glass transition temperature can be accurately determined from the plot of tan delta versus temperature.

The temperature at which a polymer changes from a hard glassy state to a rubbery state is defined as the glass transition temperature $\left(T_{g}\right)$ and is characteristic of a polymer [30]. At temperatures below $\mathrm{T}_{\mathrm{g}}$, the motion of polymeric chains is frozen. Strain occurs by stretching of bonds and the modulus decreases slowly. At temperatures above $\mathrm{T}_{\mathrm{g}}$,

polymer chain segments move past one another, so modulus decreases drastically. The glass transition temperature is an important parameter since physical and mechanical 
properties vary greatly upon passing through this temperature. In general, the strength of polymer materials above $\mathrm{Tg}$ is lower than that below $\mathrm{Tg}$. Therefore, structural applications require the polymer $\mathrm{T}_{\mathrm{g}}$ to be greater than ambient temperature. The $\mathrm{Tg}$ also provides insight to the degree of cure within the polymer. Physical and chemical aging can produce changes in modulus and $\mathrm{T}_{\mathrm{g}}$ of the polymer and the composite specimen. The $\mathrm{Tg}$ generally increases with increasing degree of cross-linking and provides an index of the degree of cure or extent of reaction. In general, the $\mathrm{Tg}$ is dependent upon chain flexibility and the free volume associated with the chemical structure.

The sample size for this test was $50 \mathrm{~mm} \times 10 \mathrm{~mm} \times 1.5 \mathrm{~mm}$. Note the sample size is smaller than that of the bending test. The maximum width for the RMS 800 samples is $10 \mathrm{~mm}$ for the current fixtures. Only a limited number of samples were tested using DMTA because of the special sample preparation and long experimental testing time. Pultruded coupons cannot be evaluated by this method because their size exceeds the limits of the instrument. Figure 4-3 shows the instrument used for testing. More details of the fixture and sample set up are shown in Figure 4-4. 


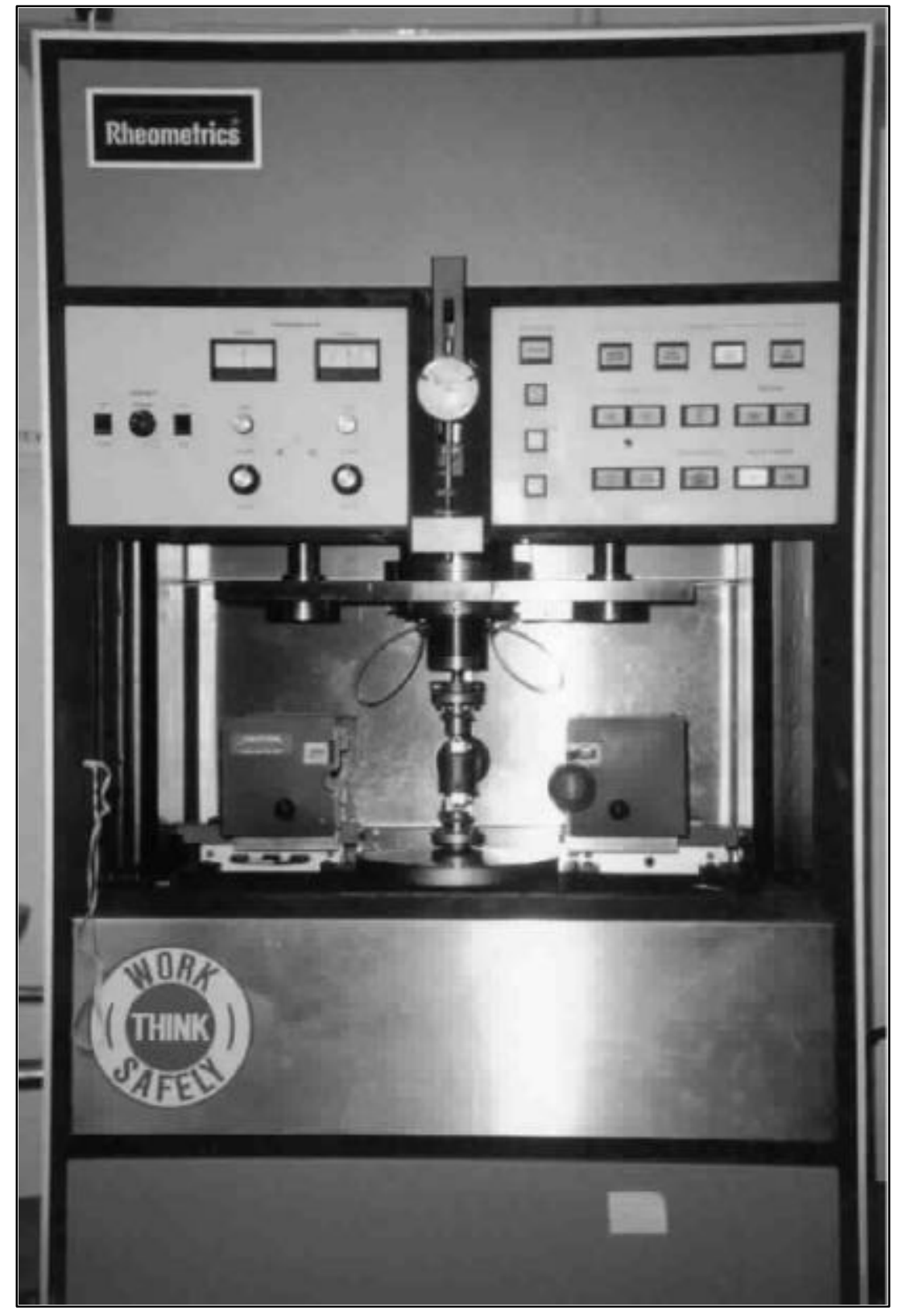

Figure 4-3. DMTA Instrument RMS800 ${ }^{\mathrm{TM}}$ by Rheometrics 


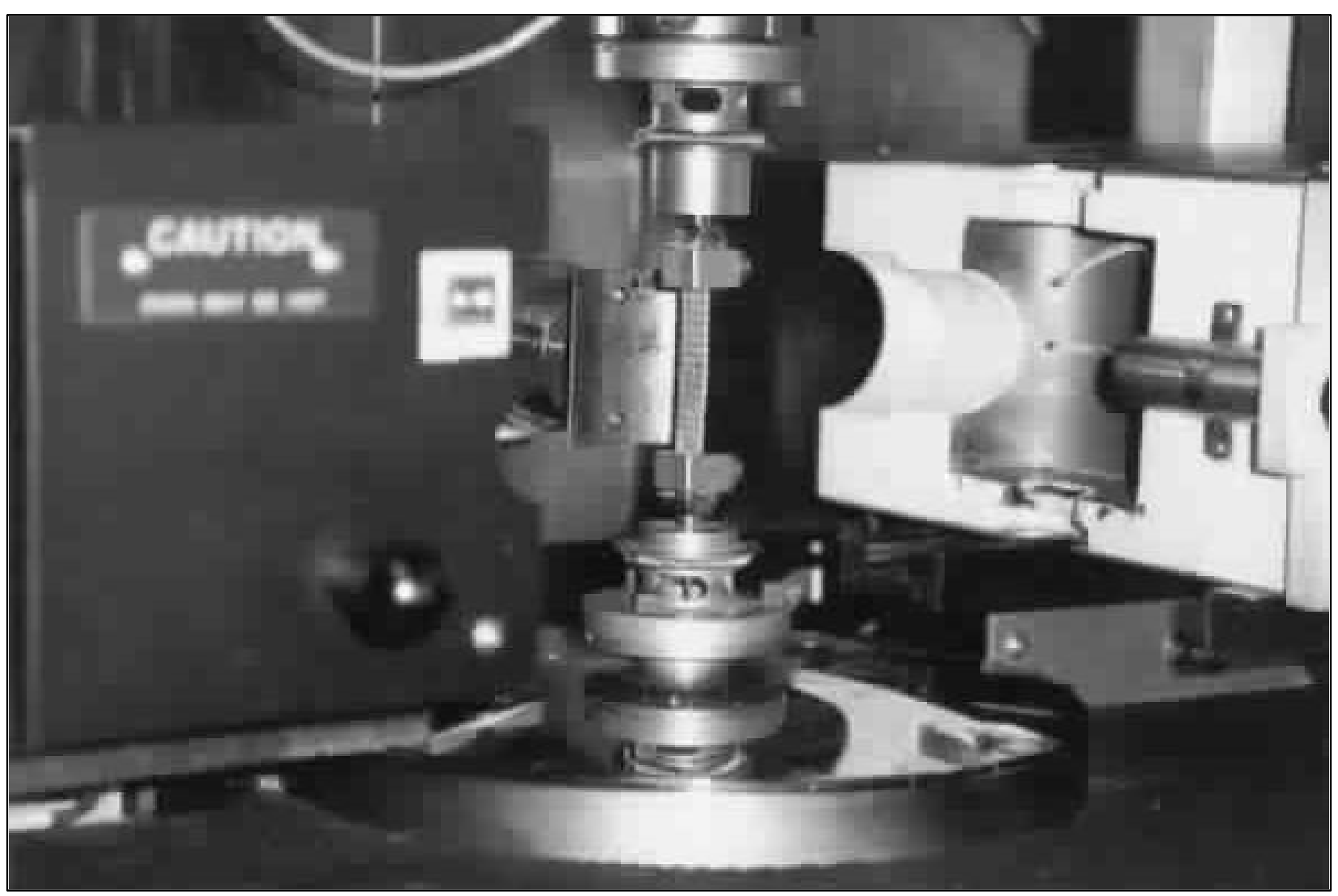

Figure 4-4. Detail of DMTA Fixtures of RMS800 ${ }^{\mathrm{TM}}$ by Rheometrics 


\subsubsection{DSC}

Differential Scanning Calorimetry (DSC) is a thermal analysis technique that is used to characterize the properties of polymeric and composite materials. It is a convenient method with which to monitor the course of chemical reactions, whether exothermic or endothermic. These reactions include those involved in the cure of vinyl ester resin and other thermosetting resins. DSC also provides measurements of thermal transitions such as the glass transition temperature, $\mathrm{Tg}$, which is associated with the degree of cross-linking or cure of a resin. The $T_{g}$ is identified by plotting the rate of differential heat flow into the polymer as a function of temperature.

\subsubsection{SEM and Optical Microscopy}

Scanning Electron Microscopy (SEM) and optical microscopy were used in an effort to detect a change in quality of samples from the pultrusion process due to process conditions, i.e. line speed. Samples of each line speed were examined for void content and irregularities that may contribute to strength loss upon aging. These results were correlated with those from both destructive and non-destructive tests.

\subsection{Durability Tests}

Several conditions were used to simulate the degradation of the composite and neat resin samples, which may take place during their service life. Samples were evaluated at regular intervals of exposure. Both the laboratory samples and the pultruded samples were subjected to the following conditions.

\subsubsection{Simulated Environment}

Samples were immersed in room-temperature water, which remained at $25^{\circ} \mathrm{C}$ for the duration of the experiment. In order to determine if the water immersion damage was reversible, the samples were tested after a drying period. The presence of water lowers the properties due to plasticization of the matrix. Samples were also immersed in water at two elevated temperatures, 50 and $85^{\circ} \mathrm{C}$, in order to determine the effect of water sorption at elevated temperatures. The samples were kept in a water bath in an oven, which maintained a constant temperature. The moisture absorption was measured and 
compared by sample type and condition to determine whether manufacturing variables such as fiber wet-out and void fraction affect sorption rate. In addition, the samples were weighed prior to aging and testing to assure water content was not a factor in the variation of the composite properties of the test specimens. The three water immersion samples $\left(25,50\right.$, and $\left.85^{\circ} \mathrm{C}\right)$ were tested after 1000,2000 , and 3000 hours of aging.

\subsubsection{Sustained Stress}

It has been shown that sustained stress coupled with environmental attack accelerates the degradation process [31]. Therefore, samples were subjected to a sustained stress of 40 percent ultimate flexural strength while submerged in water. Samples were aged in $85^{\circ} \mathrm{C}$ water to compare with the unstressed samples aged at $85^{\circ} \mathrm{C}$ to determine the effect of applied stress. As previously stated, moisture and elevated temperature degrade composite systems; therefore the highest simulated environment temperature, $85^{\circ} \mathrm{C}$, was chosen to stress the samples. The stressed samples were tested after 500, 1000, and 1500 hours of aging.

The application of the sustained load while immersed differed from the method used at WVU in the past [31]. Due to the high tensile strength of the pultruded specimens, a sustained tension of 40 percent ultimate tensile would require a special gripping system since wires alone would pull through any holes drilled in the specimen. The samples were stressed under a 3-point flexural load of $220 \mathrm{lbs}$, or 40 percent ultimate flexural strength of the unaged specimens. This load was applied with two Belleville washers to assure constant load application, if deformation of the specimen occurred. The fixtures were aluminum to assure no chemical changes in the environment due to rust, which would alter the $\mathrm{pH}$ of the environment. Details regarding the fabrication of the stress fixtures are provided in Appendix B. A diagram of the apparatus is shown in Figure 4-5. 


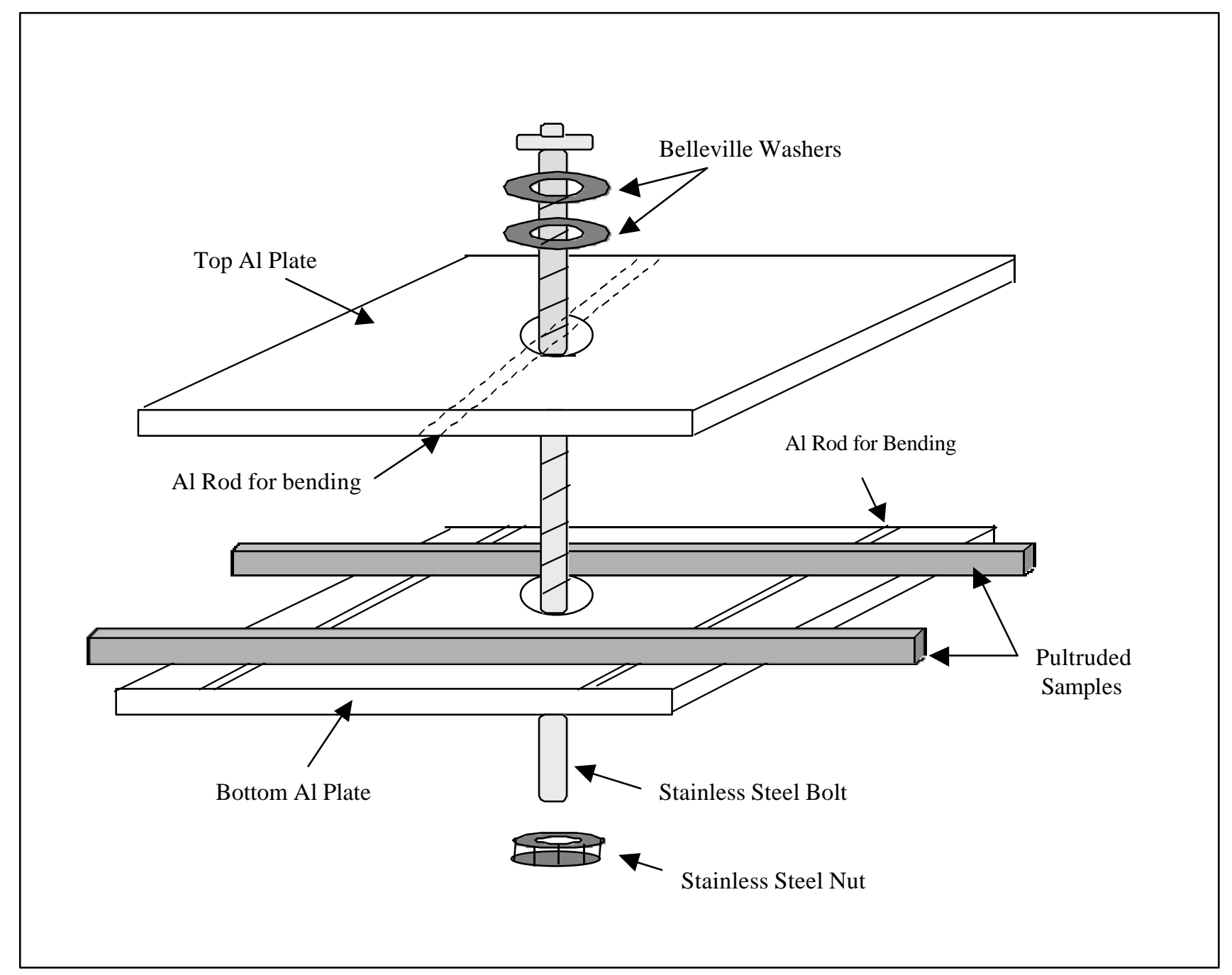

Figure 4-5. Diagram of Sustained Stress Apparatus 


\subsubsection{Freeze-Thaw}

The method consisted of soaking in a $4 \mathrm{M} \mathrm{NaCl}$ solution, followed by freeze-thaw cycling, and simulated long-term aging effects of harsh environmental conditions. Each cycle of the 20-cycle aging procedure consisted of the following steps:

- freezing for 20 hours at $-15^{\circ} \mathrm{C}$

- thawing for 4 hours at room-temperature

These harsh conditions further stressed the material by enhancing any cracks present through the process of expansion and contraction, which further accelerated the degradation process.

\subsubsection{Data Collection}

Both pultruded and laboratory samples were subjected to chemical and accelerated aging and tested using destructive tests and non-destructive tests as previously described. Any changes in the flexural strength, modulus, percent water absorbed, and $\mathrm{T}_{\mathrm{g}}$ due to aging were observed and reported. In addition, visual examinations were performed to identify the failure region.

In order to determine the amount of water absorbed during aging, the mass of each sample was recorded prior to environmental exposure and immediately after removal from the aging medium and surface drying. The percent water absorbed was determined by Equation 4-3.

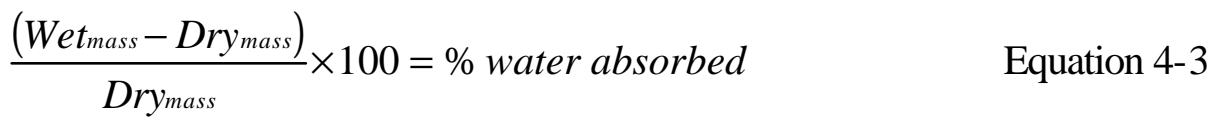

To assure minimal water content upon testing, the sample mass was recorded prior to testing and compared with the original dry weight. This was performed in order that the maximum properties were determined during testing rather than lower properties due to plasticization of the resin.

As noted earlier, three samples were tested for a given condition. One example is the sample set pulled at $4 \mathrm{ipm}$ and aged at $25^{\circ} \mathrm{C}$ for 1000 hours. The given sample numbers for each condition are provided in Appendix D. During the bending test, the 
ultimate load sustained was determined for each sample and averaged for the given condition. From this average, the standard deviation and standard error was determined from Equations 4-5 and 4-6 [32].

$$
\begin{aligned}
& s^{2}=\frac{\sum(y-\bar{y})^{2}}{n-1} \\
& s=\sqrt{s^{2}} \\
& S E=\frac{s}{\sqrt{n}}
\end{aligned}
$$

Where,

$$
\begin{aligned}
& y=\text { single sample value } \\
& \bar{y}=\text { sample set average } \\
& n=\text { number of samples in set } \\
& s^{2}=\text { sample set variance } \\
& s=\text { standard deviation } \\
& S E=\text { standard error }
\end{aligned}
$$

This load data was then transformed into strength data via Equation 4-1. The modulus of the sample was determined from the initial slope of the load-displacement data. The initial slope, in units of $\mathrm{lb}_{\mathrm{f}} /$ in was averaged for the three specimens in the sample set. The standard deviation and standard error were determined for the sample set by Equations 4-5 and 4-6. This slope data was transformed into the modulus data via Equation 4-2. 


\section{CHAPTER 5}

\section{RESULTS AND DISCUSSION}

An essential element in the development of pultruded FRP shapes for new structural applications is the experimental evaluation of the resulting physical properties. Exposure of the fiber reinforced polymer composites to aqueous solutions at different temperature levels or in combination with a sustained load has been shown to adversely affect the physical properties of the material [29]. Such changes were monitored and observed here with bending tests along with DSC and DMTA characterization. Further analysis was conducted via SEM and optical microscopy. The results of these measurements are presented in this chapter.

\subsection{DSC Characterization}

The vinyl ester resin was characterized by DSC and the glass transition temperature $(\mathrm{Tg})$ determined. The $\mathrm{Tg}$ of the resin was a determining factor for the conditions used to age and further evaluate the vinyl ester composites. DSC curves, as shown in Figure 5-1, show an exothermic peak, where the resin is undergoing cure and cross-linking. It was assumed that the curing reaction of the resin was complete after the first DSC run. A second DSC scan was performed to identify the Tg of the resin and is shown in Figure 5-2. The neat resin sample tested was not aged or stressed prior to testing. The $\mathrm{Tg}$ of neat vinyl ester resin, which is identified at the inflection point of the large drop in heat flow in the DSC curve, is approximately $108^{\circ} \mathrm{C}$. 


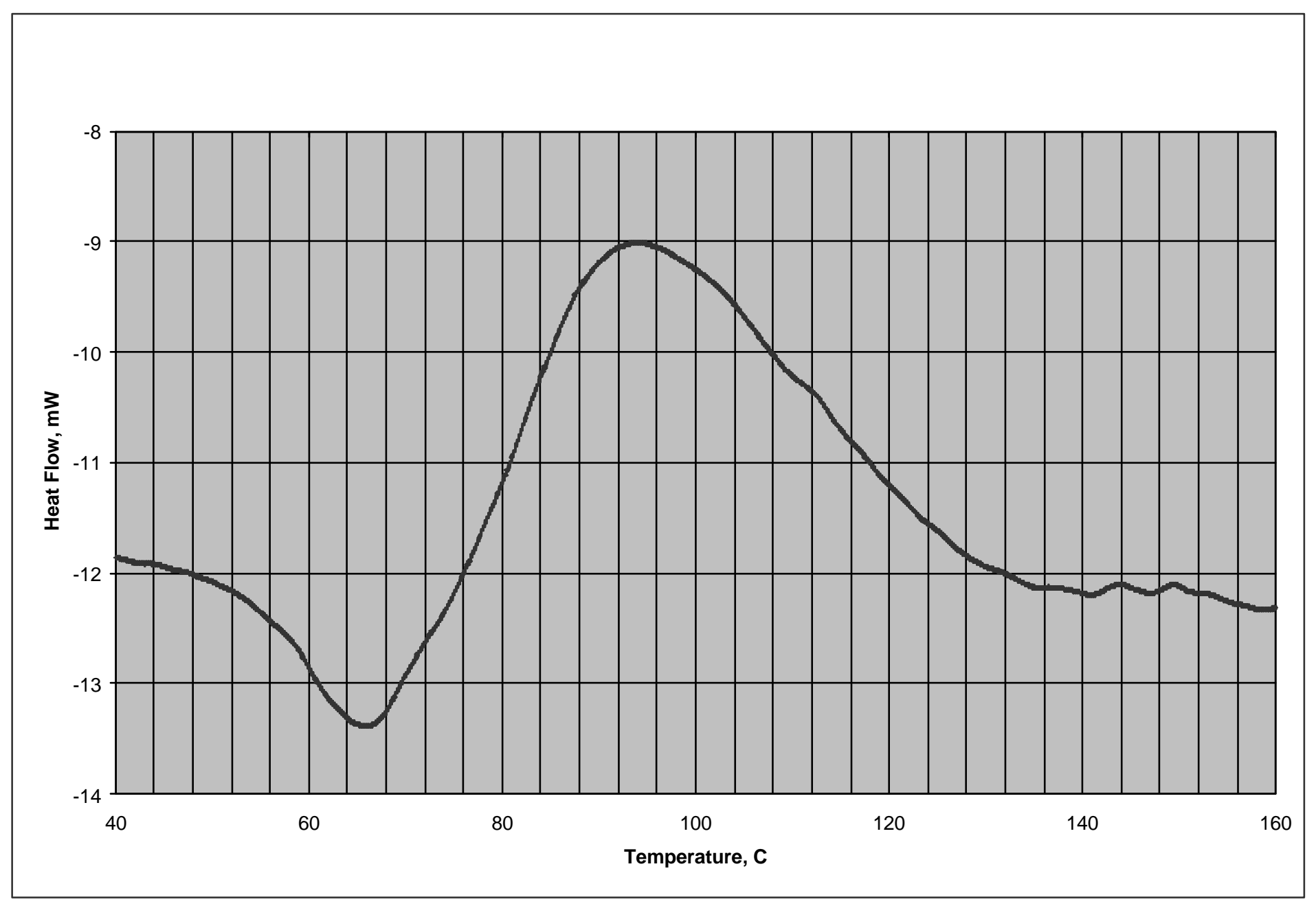

Figure 5-1. Initial DSC Scan of Neat Vinyl Ester Resin 


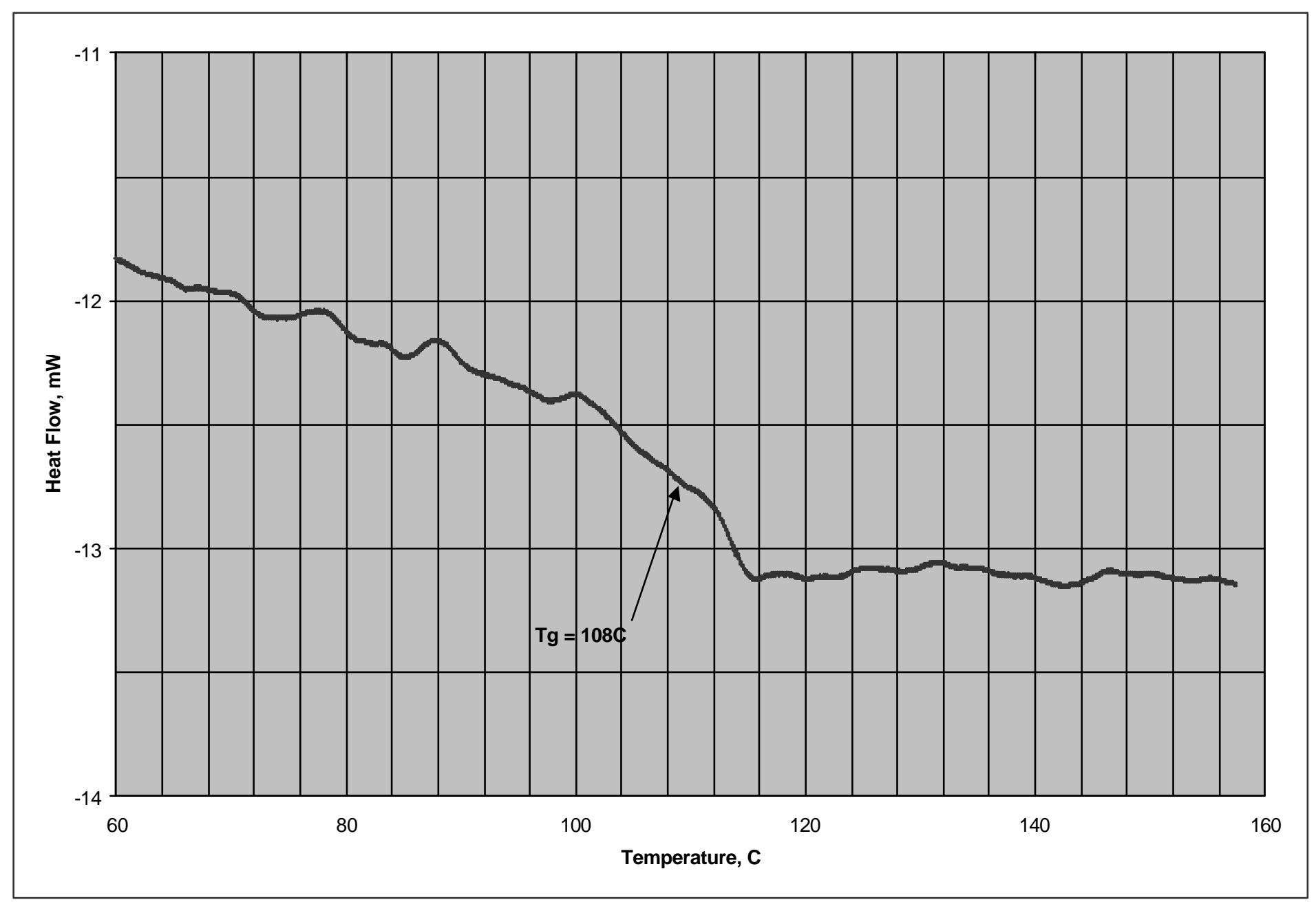

Figure 5-2. DSC Scan of Cured Vinyl Ester Resin, Tg Indicated 


\subsection{DMTA Evaluations}

Single-layer vinyl ester composites were analyzed via dynamic mechanical thermal analysis (DMTA). Temperature and frequency sweeps were conducted on virgin and aged samples to determine if environmental exposure resulted in a change in physical properties of the composite. Properties such as storage modulus and glass transition temperature (Tg) were investigated before and after aging for 1000 hours in 25, 50 , and $85^{\circ} \mathrm{C}$ water. The temperature of the aging media was monitored regularly to assure that the temperature remained constant throughout the experiment. In the study conducted, a temperature sweep was conducted to obtain the tan delta curve as a function of temperature. As described in Chapter 4, Tg is accurately determined from the peak of the tan delta - temperature curve. The tan delta curve is sensitive to structural changes that occur at the molecular level during aging. In addition, frequency sweep tests were conducted to obtain a storage modulus master curve for each aging condition.

\subsubsection{Effect of Aging Conditions on Tg}

The results of the temperature sweep tests on unaged and aged vinyl ester composites are shown in Figure 5-3. The temperature sweep was conducted at a frequency of $6.28 \mathrm{rads} / \mathrm{s}$, in a temperature range of $50-150^{\circ} \mathrm{C}$, and with an applied strain of 0.1 percent. The observed $\mathrm{Tg}$ of the unaged control sample is about $98^{\circ} \mathrm{C}$, which was determined as the temperature of the peak of the tan delta curve of the DMTA test. This $\mathrm{Tg}$ is about $10^{\circ} \mathrm{C}$ lower than that measured by DSC, but such a difference is not unusual. It is also important to note that the control sample was not tested immediately after the 24-hour initial cure. Several days had passed, which allowed the control sample to further cure prior to DMTA evaluation; this could possibly lead to an increase of the $\mathrm{Tg}$ from the initial value.

The $\mathrm{Tg}$ of a polymer changes with exposure to moisture and elevated temperature. Absorption of water during the aging process results in plasticization and a reduction in $\mathrm{Tg}$. This lowering in $\mathrm{Tg}$ allows further curing and additional cross-linking, which results in the $\mathrm{Tg}$ of the dry aged resin being higher than that of the control sample. This effect is observed to a greater extent with the samples aged in higher temperature environments. 


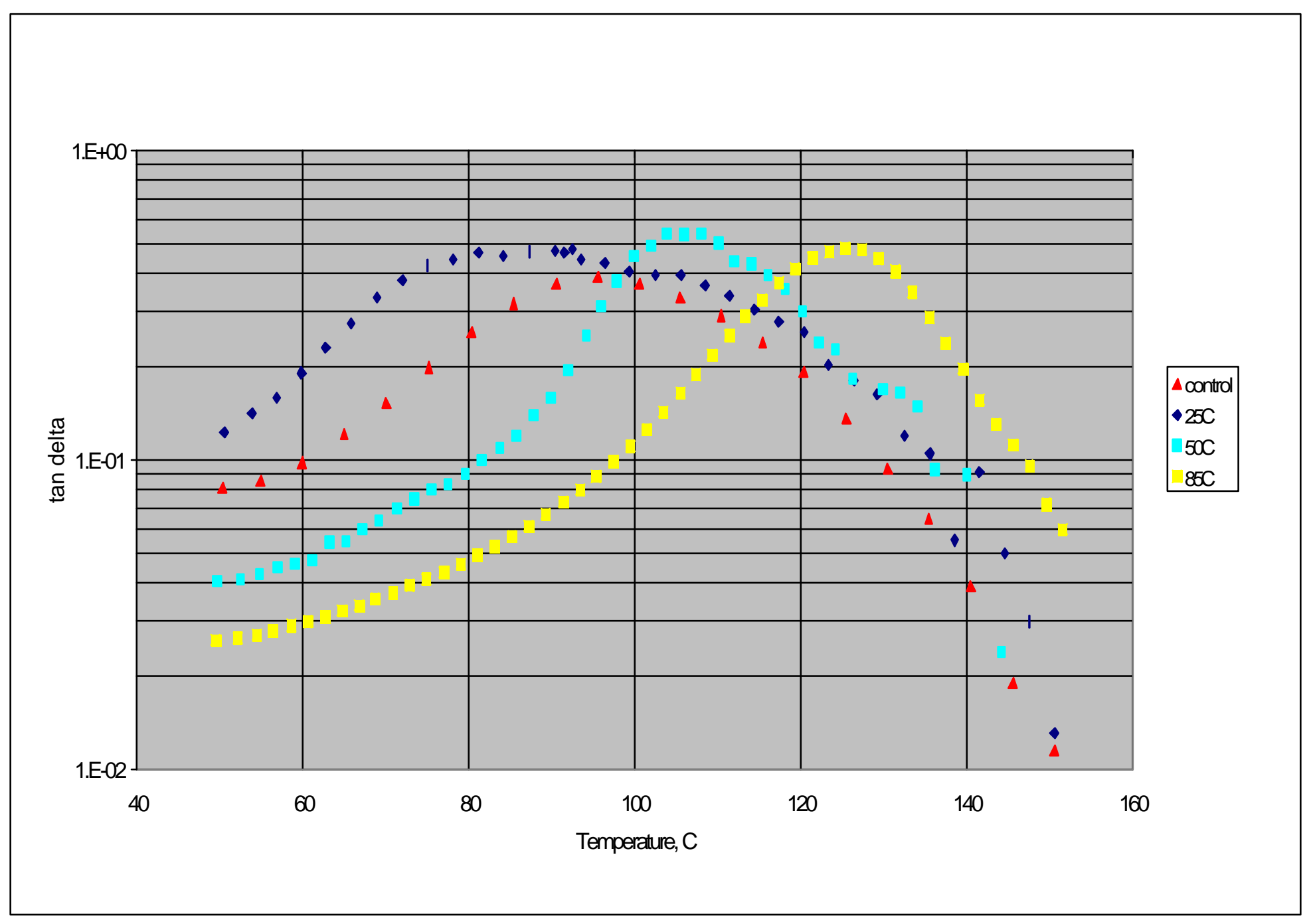

Figure 5-3. A Comparison of Plots of Tan Delta vs. Temperature of

Vinyl Ester Composites Aged in Different Temperature Water for 1000 Hours 
From Figure 5-3, it seems that the degree of cross-linking is greater in the sample aged in water at $85^{\circ} \mathrm{C}$, which results in a $\mathrm{Tg}$ of $125^{\circ} \mathrm{C}$ or an increase of $25^{\circ} \mathrm{C}$ from that of the control sample. For the same duration of aging, a smaller increase was observed for the sample aged in water at $50^{\circ} \mathrm{C}$. The $\mathrm{Tg}$ for this sample is $107^{\circ} \mathrm{C}$ or an increase of $10^{\circ} \mathrm{C}$ from that of the unaged control sample.

The tan delta peak of the sample aged in water at $25^{\circ} \mathrm{C}$ displayed different behavior than the other samples. A broad curve is observed, consisting of two overlapping curves. A split in the tan delta curve appears, indicating that a phase separation occurred in the resin. This phase separation is most likely due to plasticization of the resin by water during the aging process. The split in the tan delta should disappear upon fully drying the sample. The $\mathrm{Tg}$ of the sample aged at $25^{\circ} \mathrm{C}$ is difficult to determine from the broad bimodal peak, but is estimated to be in the range of $85-105^{\circ} \mathrm{C}$. The degree of additional cross-linking is greater in the samples aged at higher temperatures, which results in an increase in the $\mathrm{Tg}$ for the aged samples, as expected. Table 5-1 compares the $\mathrm{Tg}$ of the single-layer composite samples for different aging conditions.

A change in shape of the tan delta peak was also noticed with varying temperature in the plots of tan delta in Figure 5-3. The tan delta peak of the sample aged in $85^{\circ} \mathrm{C}$ water is considerably narrower than that of the control, unaged sample. This is due to further curing during the aging process, in which the cross-link density has increased and become uniform within the polymer. The uniform cross-link density translates to small molecular weight distribution within the polymer and to a narrow appearance in the tan delta peak and narrow range in the Tg. The tan delta peak for the sample aged in $50^{\circ} \mathrm{C}$ water also showed a narrower appearance when compared to the control sample. This sample also experienced a change in molecular weight distribution due to cross-linking, but not to the same extent as the sample aged at $85^{\circ} \mathrm{C}$. In contrast to the other two samples, the tan delta peak of the sample aged in $25^{\circ} \mathrm{C}$ water is much broader than the control sample. This is due to varying cross-link density within the sample due to plasticization and incomplete cure. The varying cross-link density along with the plasticization translate to different molecular weight distributions within the polymer and to a broader appearance in the tan delta peak and wider range in the $\mathrm{Tg}$. 


\section{Table 5-1. Comparison of Tg for DMTA for Vinyl Ester Composites}

Aged in Different Temperature Water for 1000 Hours

\begin{tabular}{||c|c||}
\hline Condition & Tg \\
\hline \hline Unaged & $98^{\circ} \mathrm{C}$ \\
\hline Aged at $25^{\circ} \mathrm{C}$ & $85-105^{\circ} \mathrm{C}$ \\
\hline Aged at $50^{\circ} \mathrm{C}$ & $107^{\circ} \mathrm{C}$ \\
\hline Aged at $85^{\circ} \mathrm{C}$ & $125^{\circ} \mathrm{C}$ \\
\hline
\end{tabular}

\subsubsection{Effect of Aging Conditions on Storage Modulus}

In addition to temperature tests, frequency tests were conducted on these samples to determine the change in modulus. These were conducted at $75^{\circ} \mathrm{C}$, at 0.5 percent strain in the range of 0.1 to $100 \mathrm{rads} / \mathrm{s}$. The results of these tests are shown in Figure 5-4. The storage modulus is similar to Young's modulus and indicates the inherent stiffness of the material. From Figure 5-4, it is apparent that the sample aged in $85^{\circ} \mathrm{C}$ water has the highest modulus of the samples tested. This correlates with the results of the temperature sweep in which the highest degree of cross-linking was observed in the sample aged at $85^{\circ} \mathrm{C}$. The storage modulus increased for the sample aged at 50 and $25^{\circ} \mathrm{C}$, but not to the extent of the sample aged at $85^{\circ} \mathrm{C}$. The same pattern that was observed with the $\mathrm{Tg}$ is observed in the storage modulus, which correlates with the degree of cross-linking for the samples.

A linear relationship between frequency and modulus is observed. This indicates that the material behaves as an elastic solid in the region of interest. Additionally, the information from the frequency sweep can be used to estimate the behavior of the material over a time span, which is inversely proportional to the frequency of the sweep. Here the vinyl ester resin behaves as an elastic solid over the short time scale of interest. 


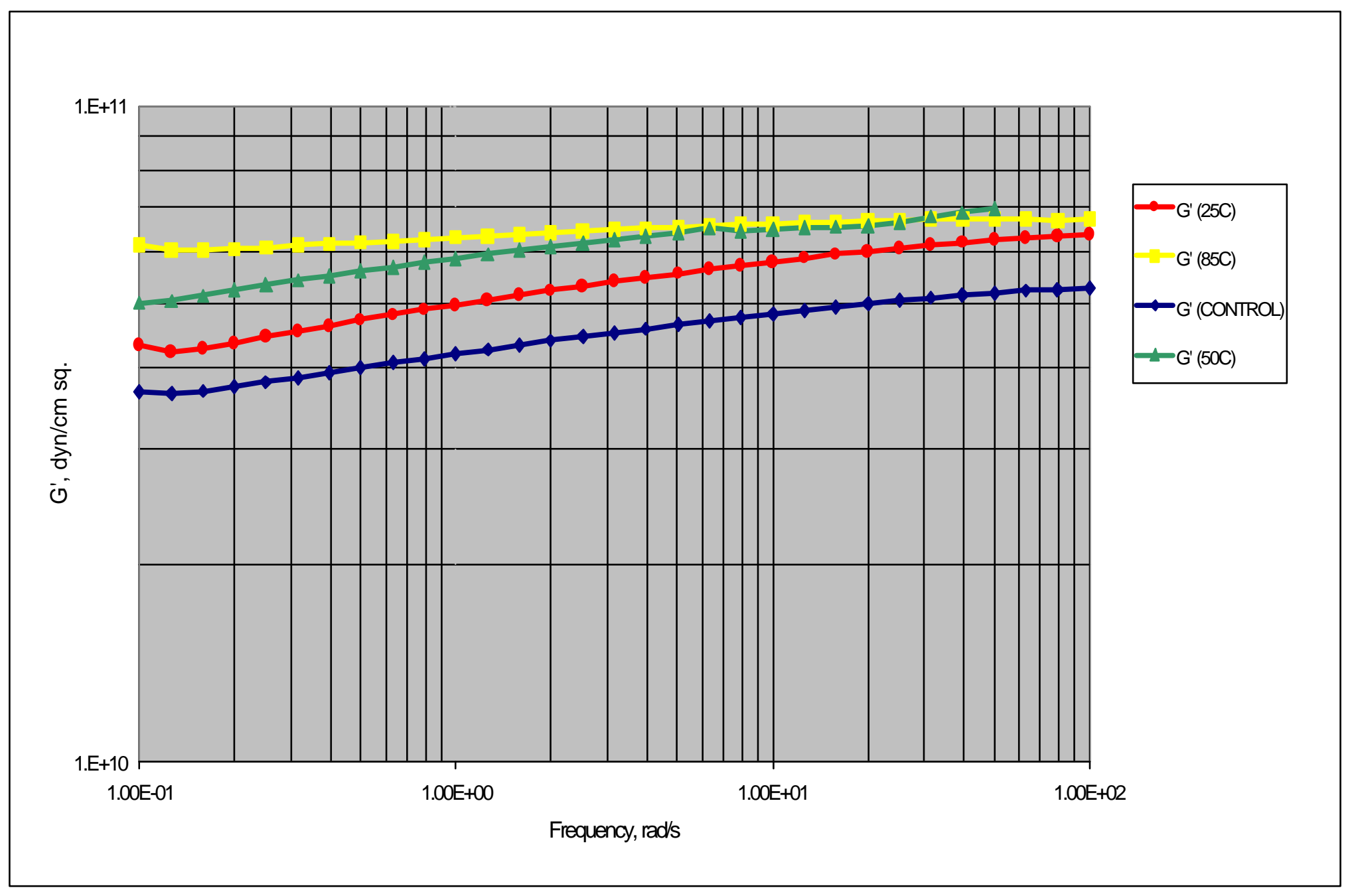

Figure 5-4. A Comparison of Storage Modulus Master Curves of Vinyl Ester Composites Aged in Different Temperature Water for 1000 Hours 


\subsection{Bending Tests}

Bend to failure tests were performed to monitor the strength and stiffness changes as a result of environmental exposure for neat resin, single-layer composite and pultruded FRP produced at varying line speeds and die temperature profiles. The samples were investigated before and after aging for 1000, 2000, and 3000 hours in 25,50 , and $85^{\circ} \mathrm{C}$ water. In addition, samples were subjected to sustained stress while being submerged in $85^{\circ} \mathrm{C}$ water. Tests were also conducted on samples subjected to freeze-thaw cycling. To determine the effect, if any, of sealing cut edges, several samples were sealed with neat resin prior to aging. The results from all these tests are presented below.

During the bending test, the ultimate load sustained was determined for each sample from the load-displacement diagram. As Figures 5-5 and 5-6 illustrate, the shape of the load-displacement data varied. Both figures involve samples that were pulled at 4 ipm after being aged in $25^{\circ} \mathrm{C}$ water for 3000 hours. In Figure 5-5, the failure of the sample is slow and spread over a large distance. For structural applications, this type of failure is desirable as it would provide adequate warning and prevent a catastrophic failure. Figure 5-6 shows a more catastrophic failure that occurs over a small distance. The ultimate load for each sample, along with the average for the sample set, is provided in Appendix D.

The modulus of the sample was determined from the initial slope of the loaddisplacement data, as shown in Figure 5-7. The bending curves, up to 0.1 in of displacement, were plotted, and linear regression was used to determine the initial slope of the three samples in the set for the given condition. The correlation coefficient, $\mathrm{R}^{2}$, for the linear regressions indicated a very good fit and gave confidence in the values used. The slope was statistically analyzed for the sample set. The values of slope and $\mathrm{R}^{2}$ for each sample, along with the average for the sample set, are provided in Appendix D. 


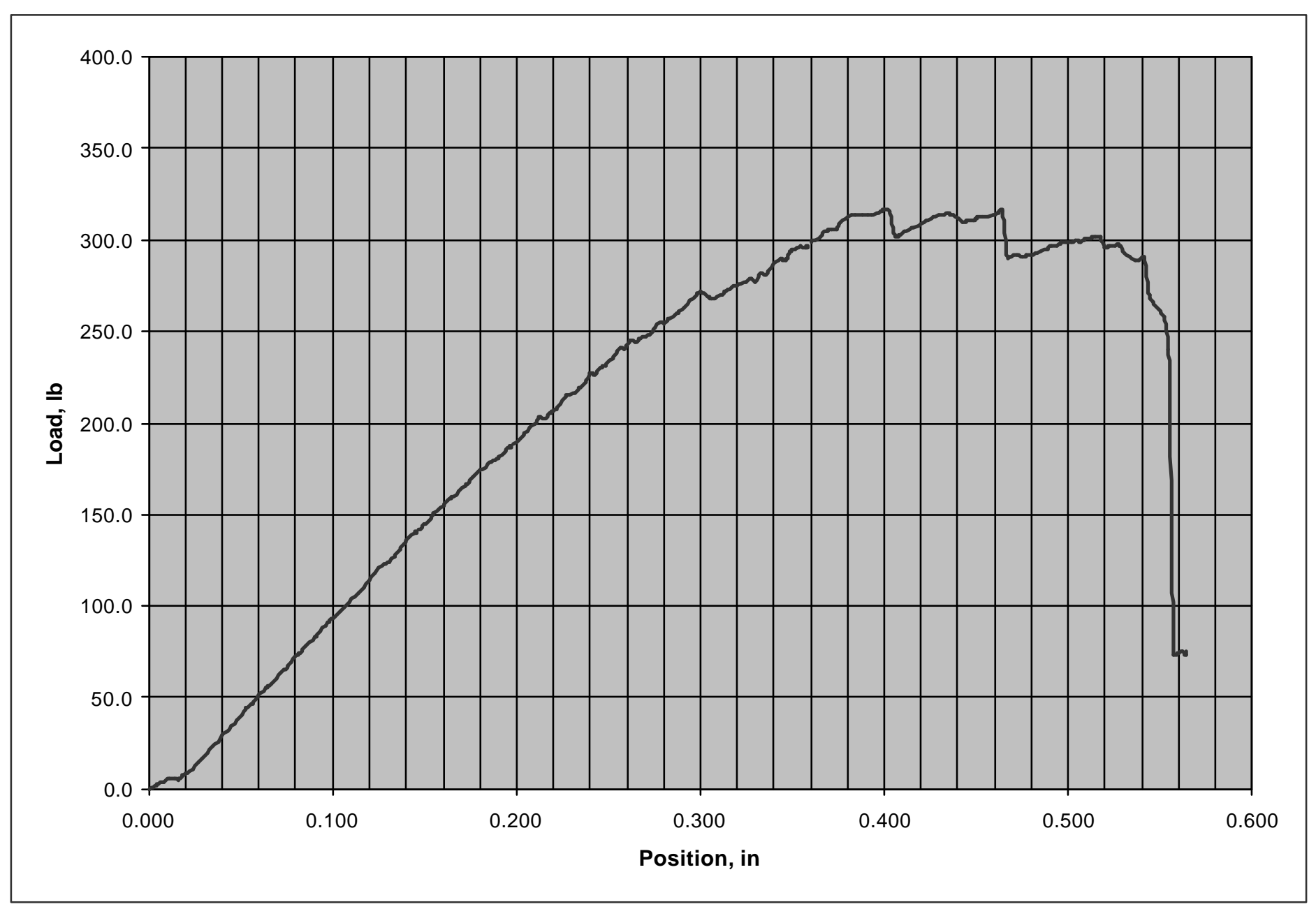

Figure 5-5. Bending Test of Pultruded Sample Aged in $25^{\circ} \mathrm{C}$ Water for 3000 Hours (Sample W1-17) 


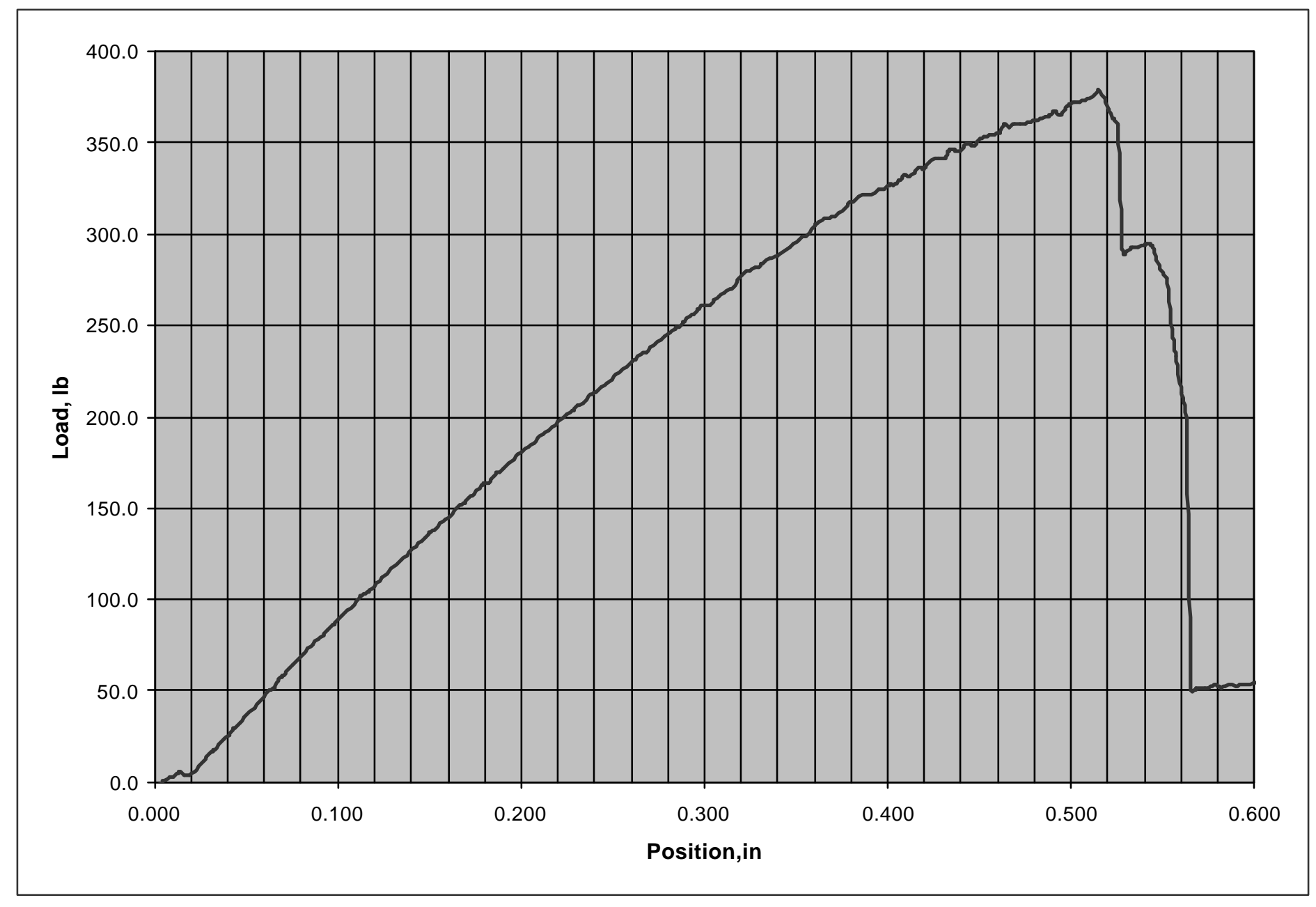

Figure 5-6. Bending Test of Pultruded Sample Aged in $25^{\circ} \mathrm{C}$ Water for 3000 Hours (Sample W1-18) 


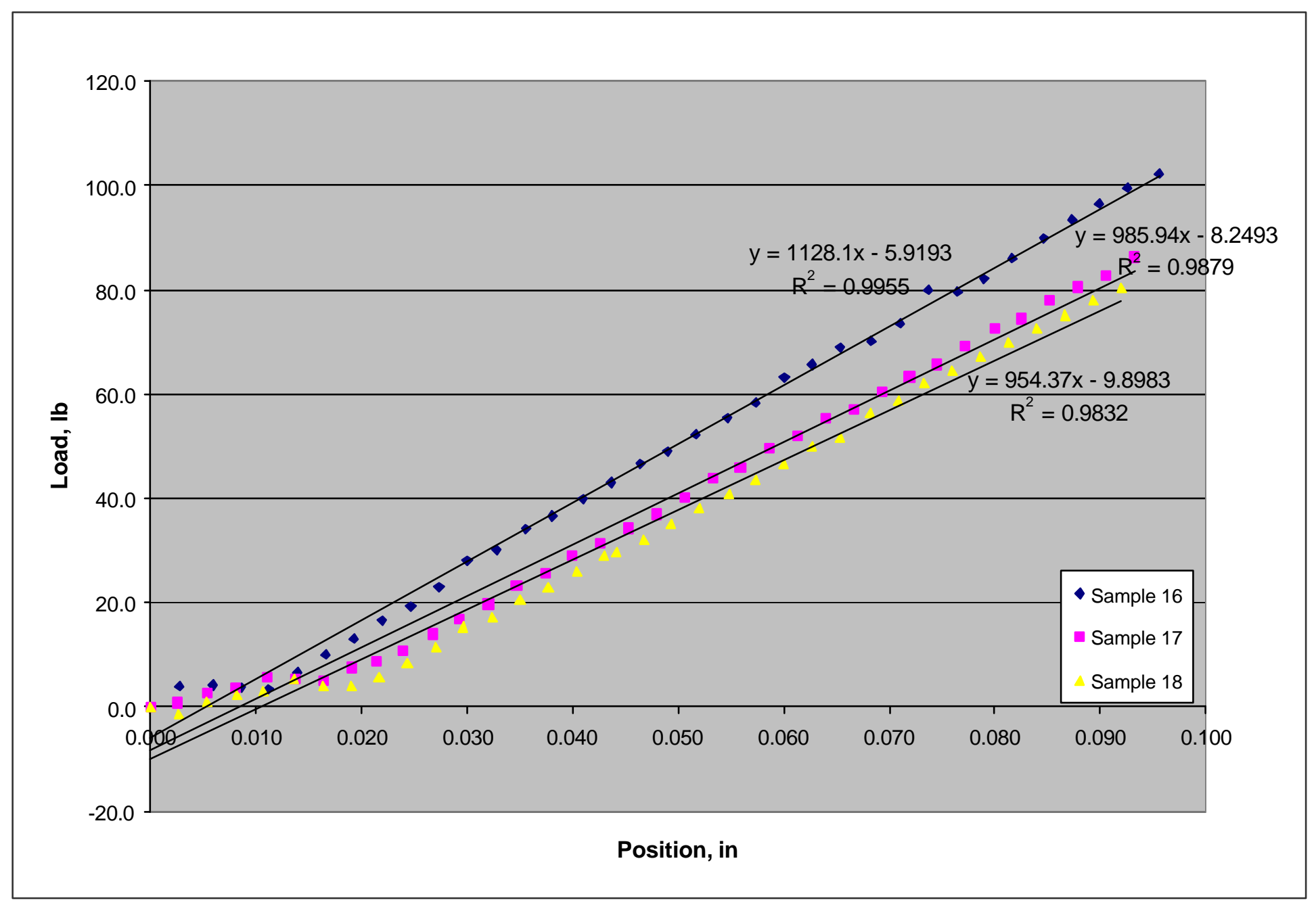

Figure 5-7. Determination of Initial Slope of Bending Tests for Modulus Calculation

(Samples Aged in $25^{\circ} \mathrm{C}$ Water for 3000 Hours, W1-16, 17, 18) 


\subsubsection{Strength of Neat Resin Samples}

The strength data on all the neat resin samples are shown is Figure 5-8. Two processes can affect the strength of the matrix: cross-linking and hydrolysis, both of which are irreversible. Additional cure results in cross-linking and increased strength, while hydrolysis results in a reduction of strength. It is apparent that the neat resin samples were not fully cured, and the degree of cross-linking increased during aging. This was also verified by the DSC, which showed the neat resin still undergoing cure during the first run. Due to the incomplete cure, the samples had the opportunity to further cure during the aging process. The additional cure and cross-linking were enhanced by the aqueous environment, which plasticizes the resin and lowers the Tg. This lowering of the $\mathrm{Tg}$ allows the polymer chain segments to move past one another, facilitating cross-linking. Upon drying the plasticization is reversed, but the chemical structural changes that occurred during the process (cross-linking or hydrolysis) are not.

The effects of cross-linking and hydrolysis are evident in the strength of the neat resin samples. The control samples, tested immediately upon cure at room temperature for 24 hours, are of relatively low strength. However, the control samples that were not tested immediately upon the initial cure are significantly greater in strength. This increase in strength arose because the sample underwent further cure prior to testing. However, it is important to note that the sample was not completely cured at the time of testing. If a post-cure heating process were employed, the degree of cross-linking would further increase, which would result in a greater value of strength.

No difference in strength is observed after the freeze-thaw cycling. Perhaps with a greater number of cycles, adverse effects might have been observed. The samples aged at $25^{\circ} \mathrm{C}$ are lower in strength when compared to the control sample, both the initial and cross-linked. There is also a large error associated with the measurement of strength for these samples. There is also the probability that the samples may not have been completely dry when tested. As previously stated, water in the resin plasticizes the material and lowers the mechanical properties, which return to the original values upon drying if no permanent changes occurred. If subsequent tests were conducted on dry samples aged at $25^{\circ} \mathrm{C}$, the expected result would show no reduction in strength since it is believed plasticization caused the strength reduction for the current data. 


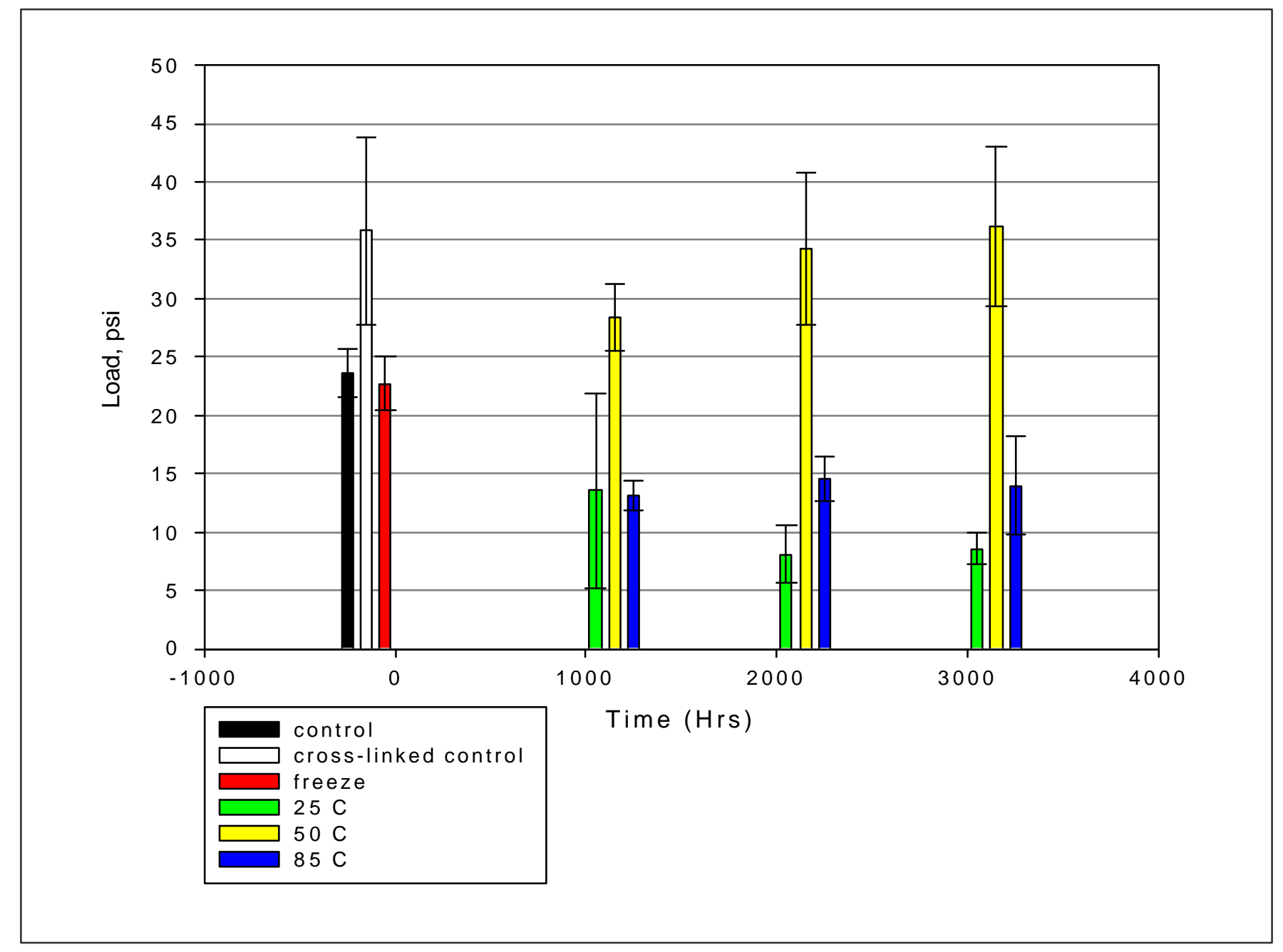

Figure 5-8. Bending Strength of Aged Neat Resin 
The samples aged at $50^{\circ} \mathrm{C}$ showed significant differences in strength than the other samples. The samples aged at $50^{\circ} \mathrm{C}$ had undergone additional cure and crosslinking that increased the strength of the samples. The strength gained through this process mirrors that of the control sample that was allowed to further cure and cross-link prior to testing. Note that two competing processes: hydrolysis and cross-linking are occurring simultaneously for all samples. If only cross-linking had occurred, the strength for the samples aged at $50^{\circ} \mathrm{C}$ would be expected to be greater than that obtained with the unaged samples. Also, since the cross-linked control sample is not fully cured, it is important to note that the strength of the $50^{\circ} \mathrm{C}$ sample may not be the maximum value.

The bending strength of the samples aged at $85^{\circ} \mathrm{C}$ is considerably lower than that of the ones aged at $50^{\circ} \mathrm{C}$, as shown in Figure 5-8. These data suggest that hydrolysis was the more dominant process when the samples were aged at $85^{\circ} \mathrm{C}$. It is believed that they also underwent additional cross-linking, which would increase strength. However, the effects of the cross-linking were negated by hydrolysis.

\subsubsection{Strength of Pultruded Samples}

Results of the bending tests and the ultimate bending strength are shown in Figures 5-9 to 5-13. From these results, it is apparent that the data for both the unaged and aged specimens do not show a dependence on the line speed. This, however, does not rule out the possibly that with higher line speeds, i.e. 24 ipm, differences may appear due to lack of fiber wet-out and increased void fraction. These results are not unexpected since the pultrusion industry currently produces composites at $12 \mathrm{ipm}$. An important conclusion from these tests is that line speeds slower than $12 \mathrm{ipm}$ do not improve physical properties. Table 5-2 provides a comparison of the percent change in the flexural strength of the pultruded samples for the various aging conditions.

It is apparent that the pultruded samples were completely cured, while the neat resin samples were not by noting the difference in the degree of additional cross-linking that occurred during aging. The difference between the pultruded and neat resin samples is the resin used. The neat resin samples were made with a pre-promoted resin that was formulated to cure at room temperature, while the pultruded samples were produced with a resin that required additional heat to fully cure. The pultruded samples were fully cured 


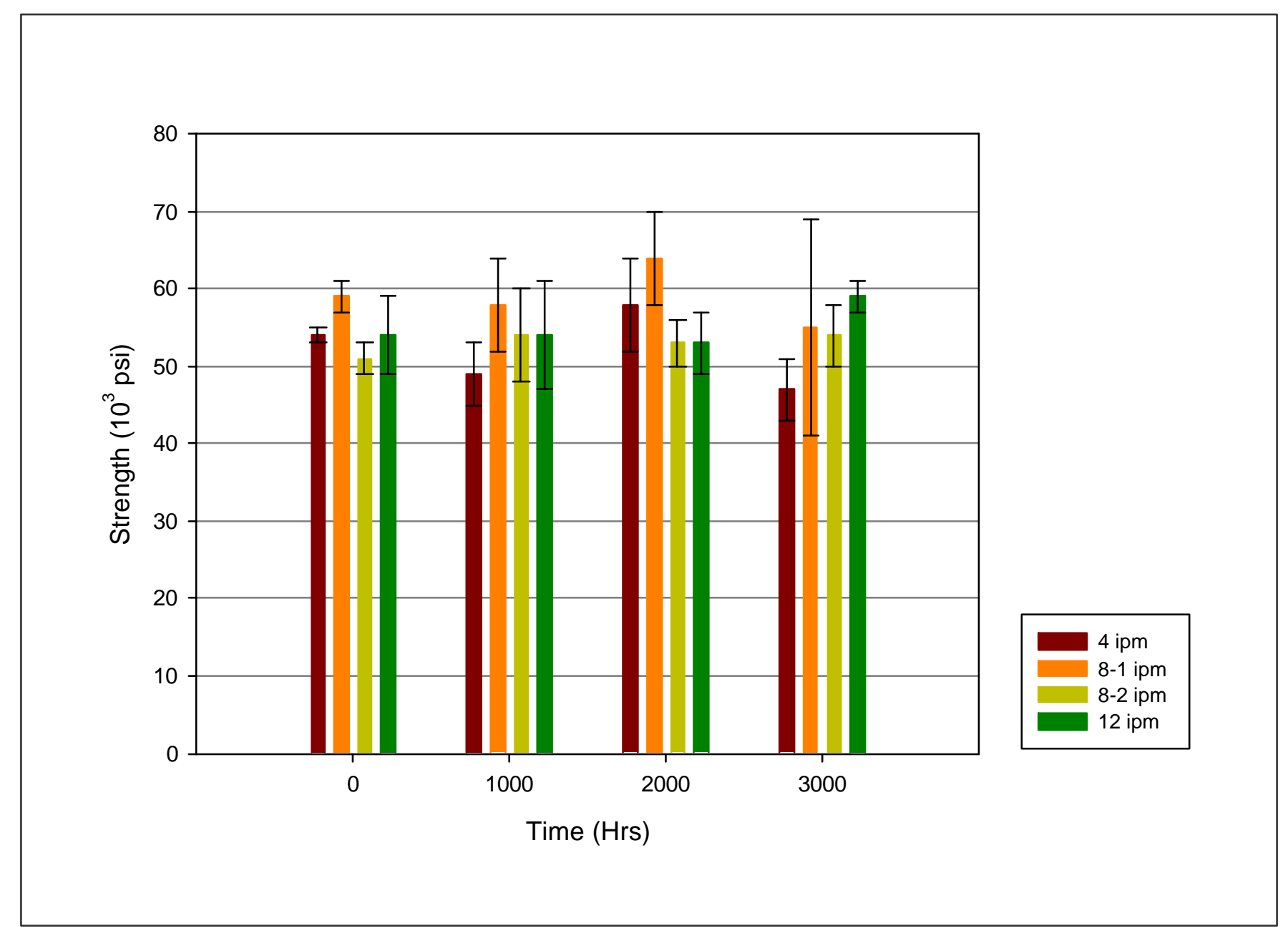

Figure 5-9. Bending Strength of Pultruded Bars Aged in Water at $25^{\circ} \mathrm{C}$. 


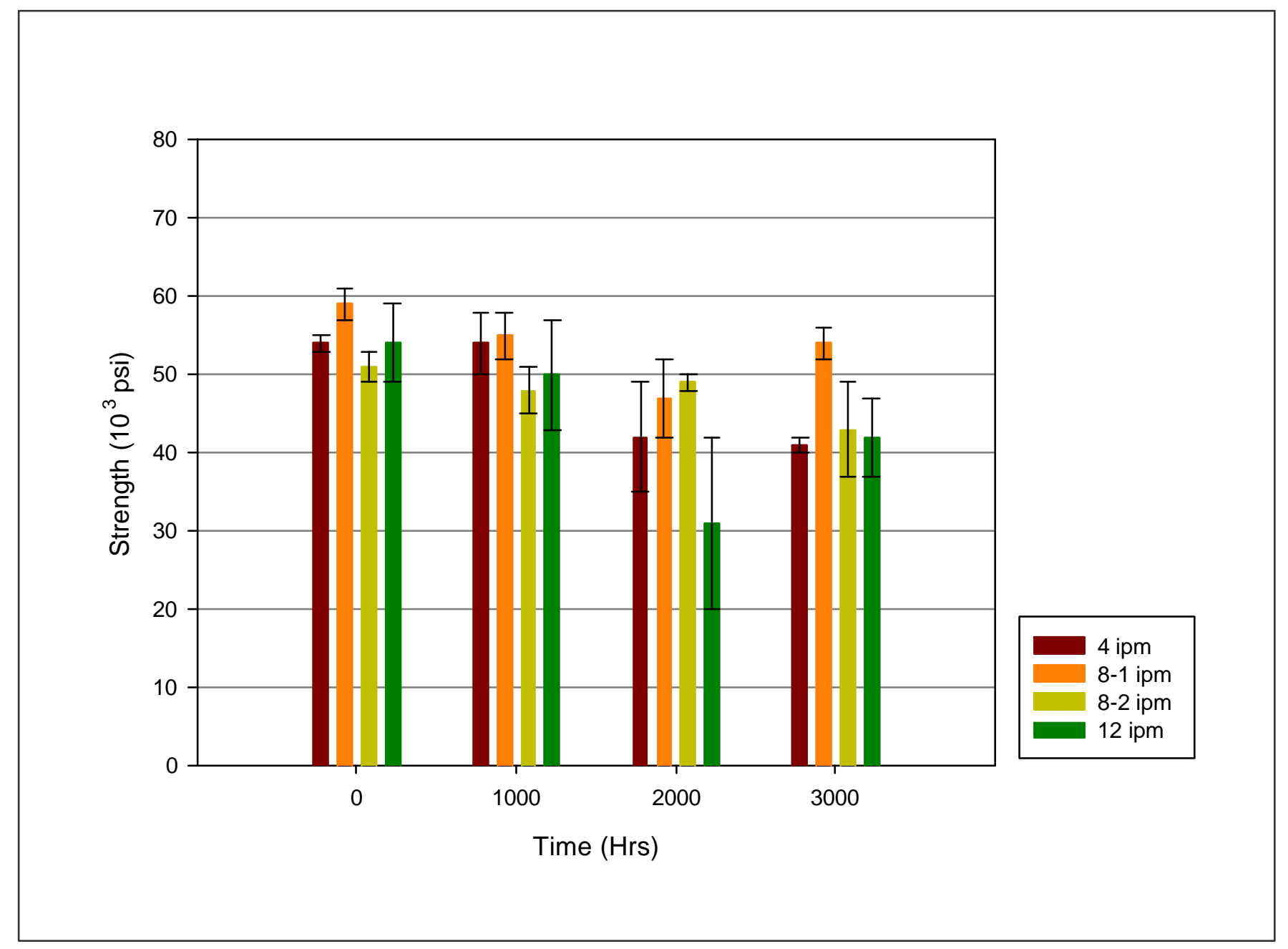

Figure 5-10. Bending Strength of Pultruded Bars Aged in Water at $50^{\circ} \mathrm{C}$ 


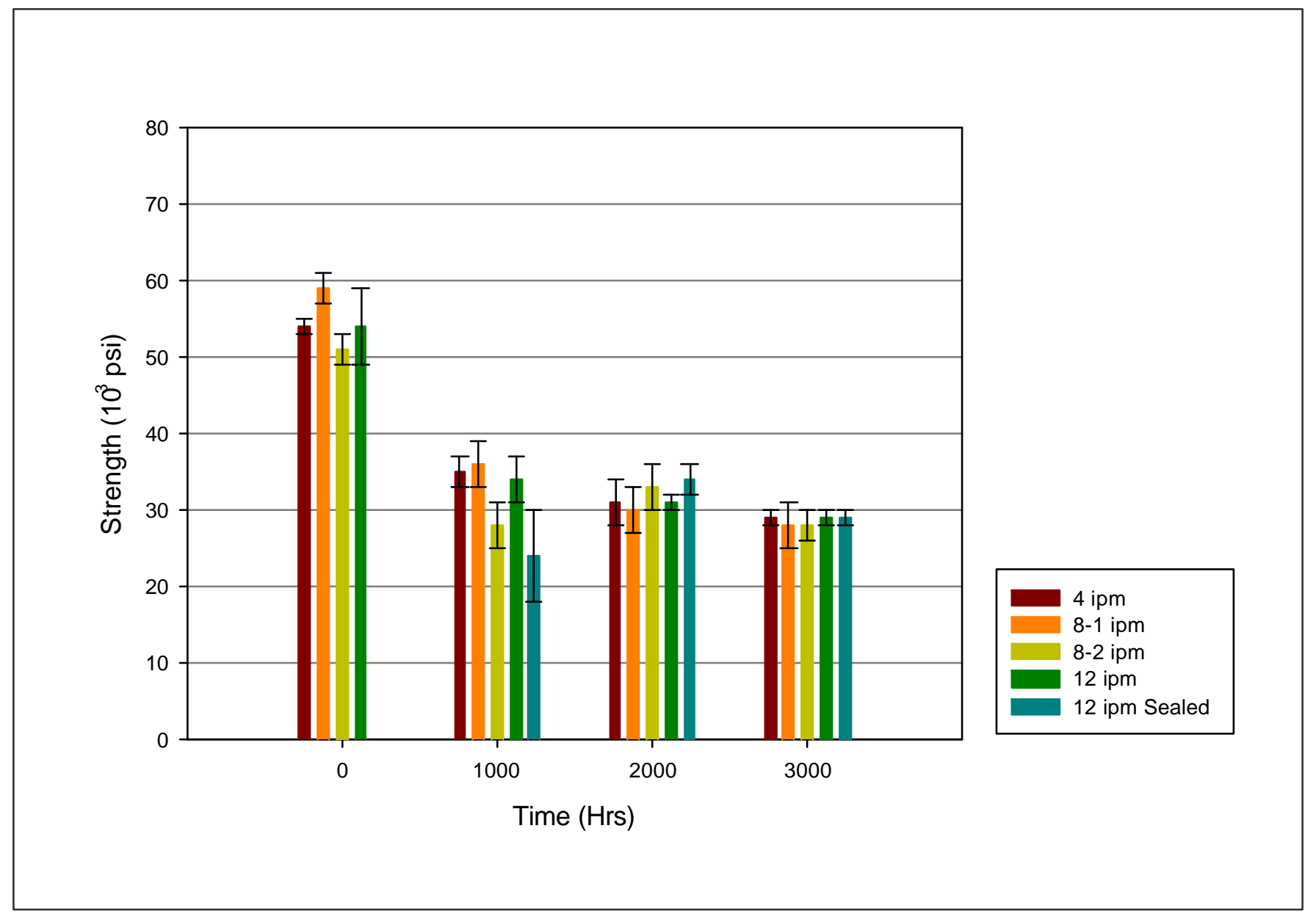

Figure 5-11. Bending Strength of Pultruded Bars Aged in Water at $85^{\circ} \mathrm{C}$ 


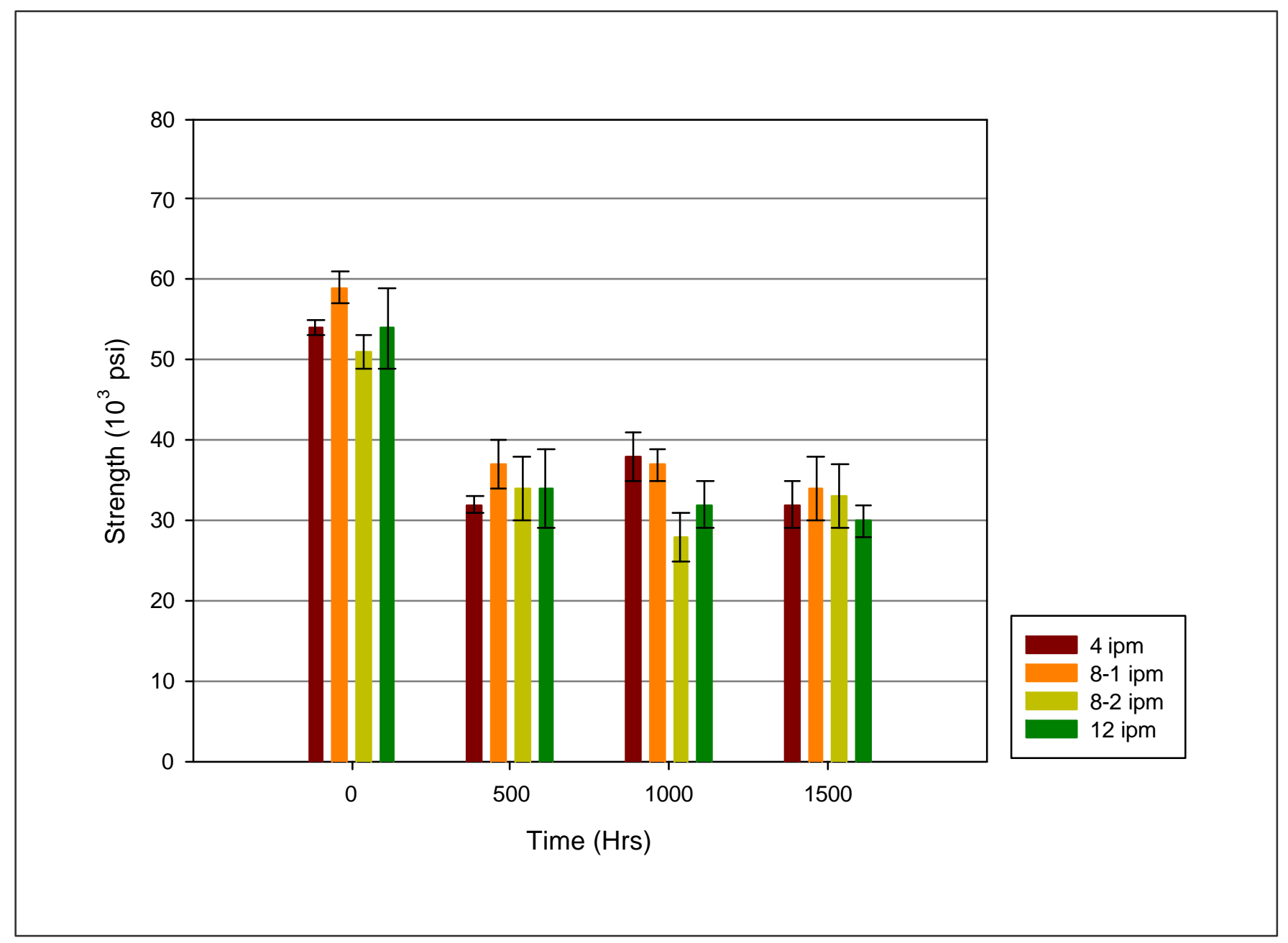

Figure 5-12. Bending Strength of Pultruded Bars Stressed in Water at $85^{\circ} \mathrm{C}$ 


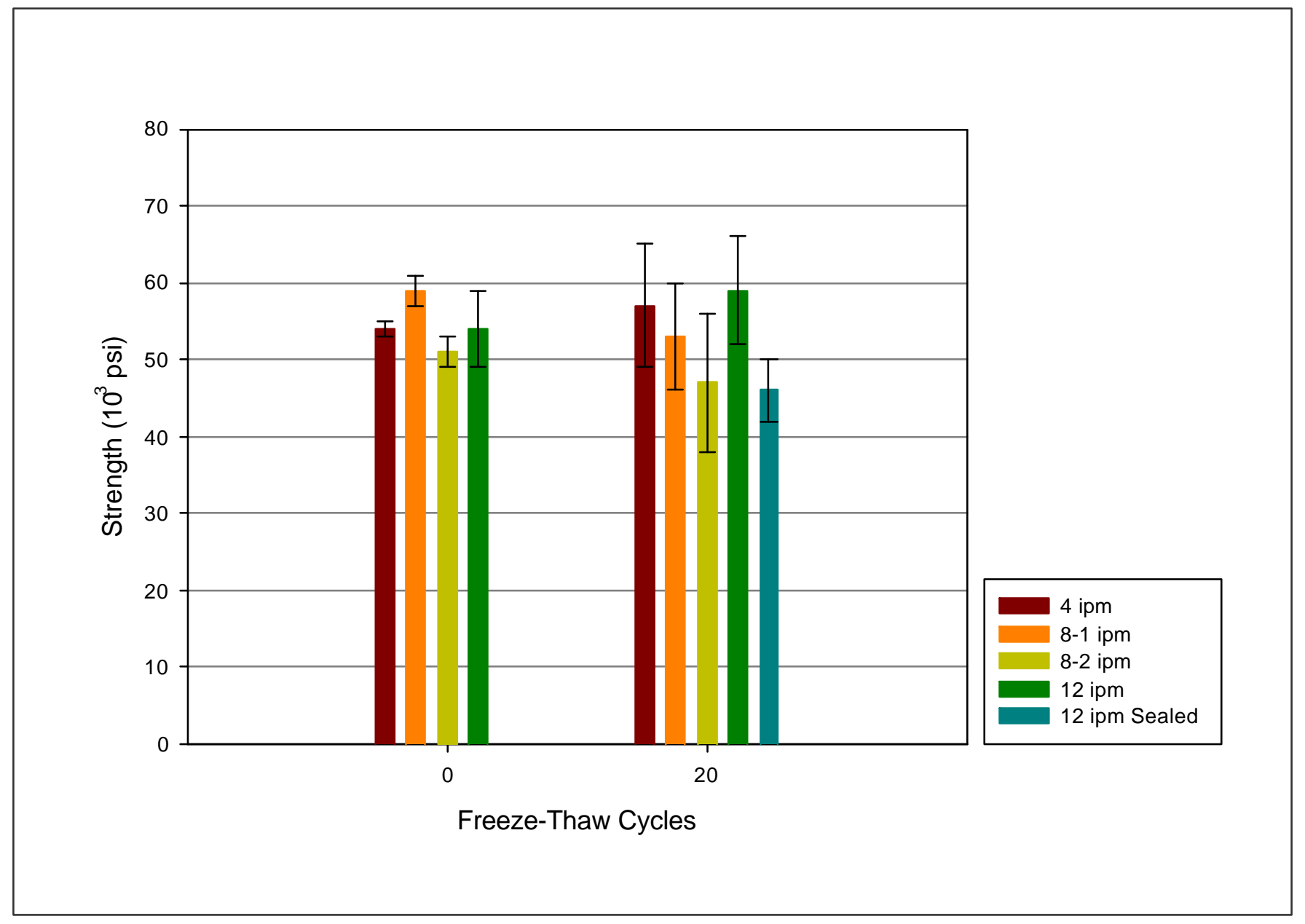

Figure 5-13. Bending Strength of Pultruded Bars Aged by Freeze-Thaw Cycling 
Table 5-2. Percent Change in Flexural Strength for Pultruded Samples (Average for All Line Speeds)

\begin{tabular}{|c|c|c|c|c|c||}
\hline Condition & $\mathbf{5 0 0}$ & $\mathbf{1 0 0 0}$ & $\mathbf{1 5 0 0}$ & $\mathbf{2 0 0 0}$ & $\mathbf{3 0 0 0}$ \\
\hline \hline $\mathbf{2 5}^{\circ} \mathbf{C}$ & - & 0 & - & +5 & +5 \\
\hline $\mathbf{5 0}^{\circ} \mathbf{C}$ & - & -5 & - & -18 & -18 \\
\hline $\mathbf{8 5}^{\circ} \mathbf{C}$ & - & -35 & - & -35 & -47 \\
\hline $\begin{array}{c}\mathbf{8 5}^{\circ} \mathbf{C}-\text { stressed } \\
(\mathbf{4 0 \%} \text { ult. in bending) }\end{array}$ & -35 & -35 & -35 & - & - \\
\hline Freeze-Thaw & 0 & \multicolumn{5}{|c|}{ (20 Cycles) } \\
\hline
\end{tabular}

upon exiting the die. It is believed that the neat resin samples would exhibit the same behavior upon aging if post-curing had been performed.

Just as with the neat resin, the same two processes can affect the strength of the composites by altering the properties of the matrix: cross-linking and hydrolysis, both of which are irreversible. Additional cure results in cross-linking and increased strength, while hydrolysis results in a reduction in strength. In addition, degradation of the fibermatrix interface and the fibers themselves leads to a reduction in the properties of the composite.

For the tests conducted, a decrease in strength was observed with increased temperature in as little as 1000 hours at $85^{\circ} \mathrm{C}$ and 2000 hours at $50^{\circ} \mathrm{C}$. A plateau in the strength loss for exposure to water at $85^{\circ} \mathrm{C}$ occurred for the remaining times tested (2000, $3000 \mathrm{hrs})$. This strength reduction is due to the elevated temperature, which was conducive to degradation of the material, through hydrolysis, and degradation of the interface and fibers. The samples aged at $25^{\circ} \mathrm{C}$ showed no reduction in strength, indicating that hydrolysis or other degradation mechanisms did not occur. No effect was observed from freeze-thaw cycling. This may be due to the small number of cycles to which the samples were subjected. Little difference was observed in strength loss at 
$85^{\circ} \mathrm{C}$ between stressed (40 percent ult.) and unstressed samples. This suggests that the temperature has a greater effect on strength loss than the presence of sustained stress.

No benefit was received from sealing the edges of cut samples before exposure to water. A difference may have been apparent if the samples were not allowed to fully dry prior to testing. The rate of water sorption would be greater for the unsealed samples, which would enhance plasticization. However, this process is reversed upon drying and no effect is observed.

It was also observed that the sample pulled at $8 \mathrm{ipm}$ with reversed die temperature $\left(\mathrm{T}_{1}=325^{\circ} \mathrm{F}, \mathrm{T}_{2}=275^{\circ} \mathrm{F}\right)$ had better retention of mechanical properties. This sample therefore had a better die temperature profile compared to the other samples. Comparisons of die temperature profiles obtained during the pultrusion process are shown in Figures 5-14 to 5-17. The location of the peak die temperature relative to the die exit as well as the exit temperature itself is important to the properties of the material. For the profiles of $4 \mathrm{ipm}$ and $8 \mathrm{ipm}$ temperature reversed, Figures 5-14 and 5-17, the exothermic reaction begins in the middle of the die and has completed prior to the FRP exiting the die. The profiles for the 8 and $12 \mathrm{ipm}$, Figures 5-15 and 5-16, show the reaction starting late in the die and continuing on after the FRP has exited the die. The material should be fully cured prior to exiting the die, where the temperature is suddenly reduced to room temperature. The material may scale and form microcracks if the exit temperature is too high. From these profiles it is apparent that the best temperature profiles are for the slowest pull speed, $4 \mathrm{ipm}$, and for the $8 \mathrm{ipm}$ reversed die temperature. 


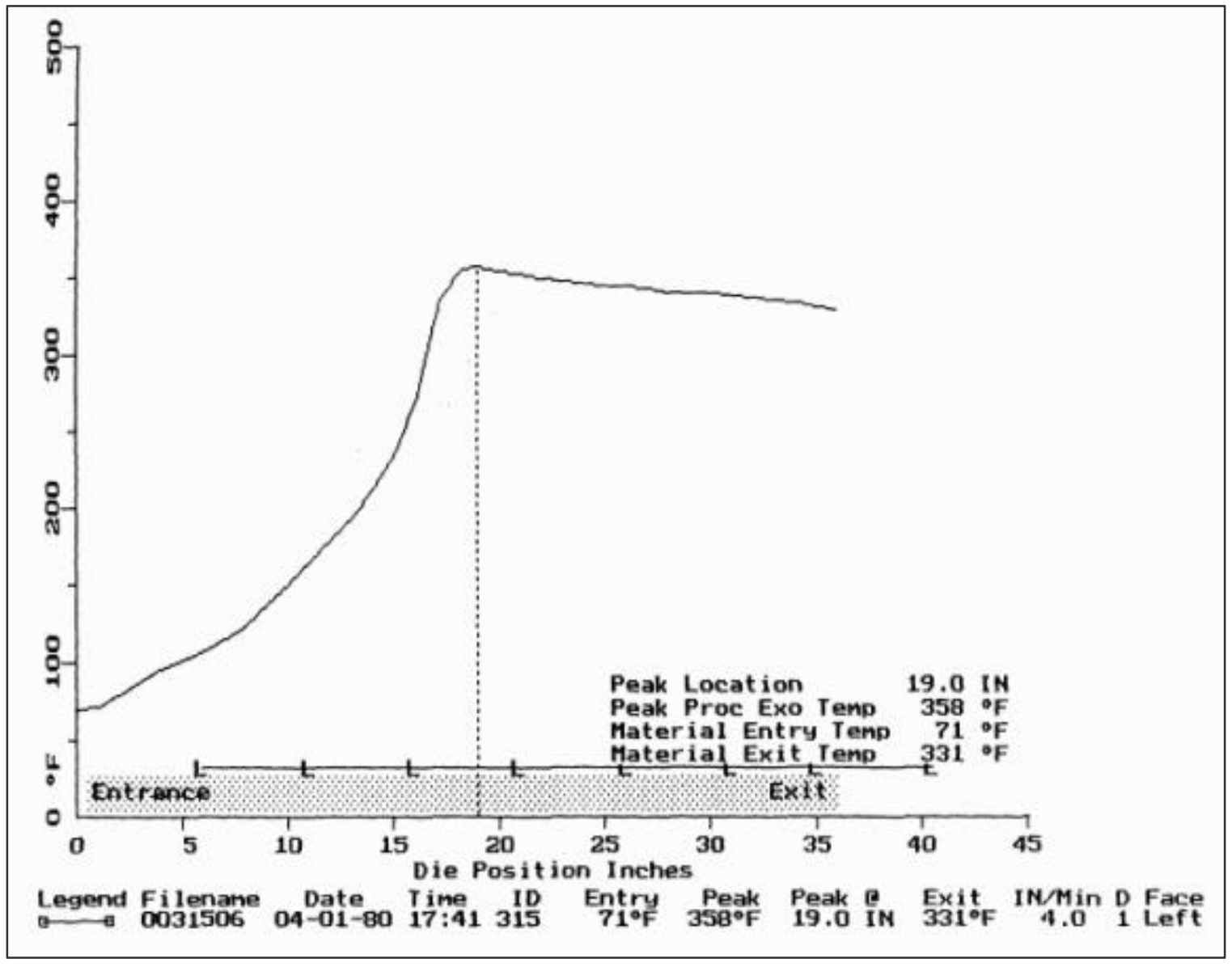

Figure 5-14. Temperature Profile within the Die during

Manufacturing by Pultrusion $\left(4 \mathrm{ipm}, \mathrm{T}_{1}=275^{\circ} \mathrm{F}, \mathrm{T}_{2}=325^{\circ} \mathrm{F}\right)$ 


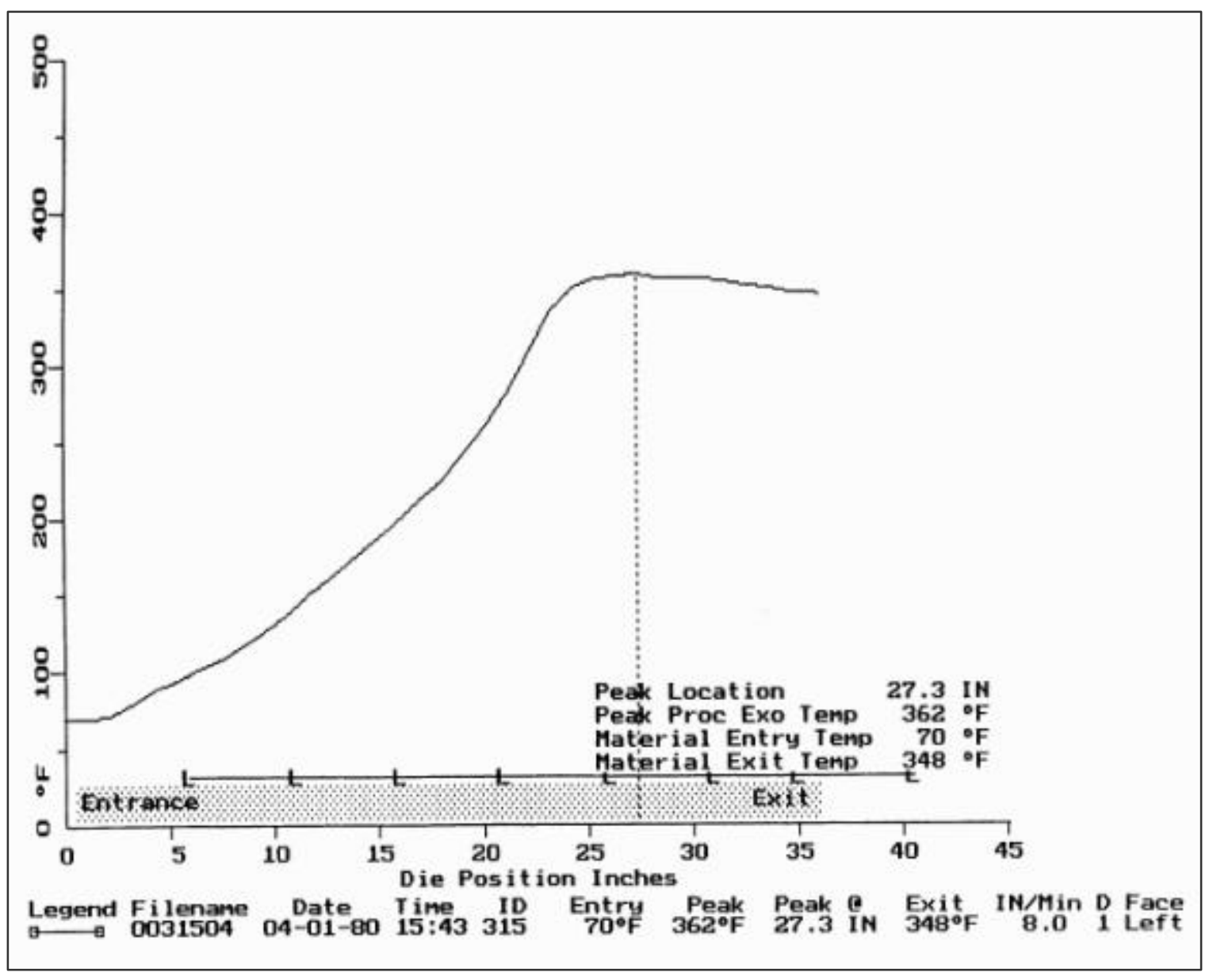

Figure 5-15. Temperature Profile within the Die during

Manufacturing by Pultrusion $\left(8 \mathrm{ipm}, \mathrm{T}_{1}=275^{\circ} \mathrm{F}, \mathrm{T}_{2}=325^{\circ} \mathrm{F}\right)$ 


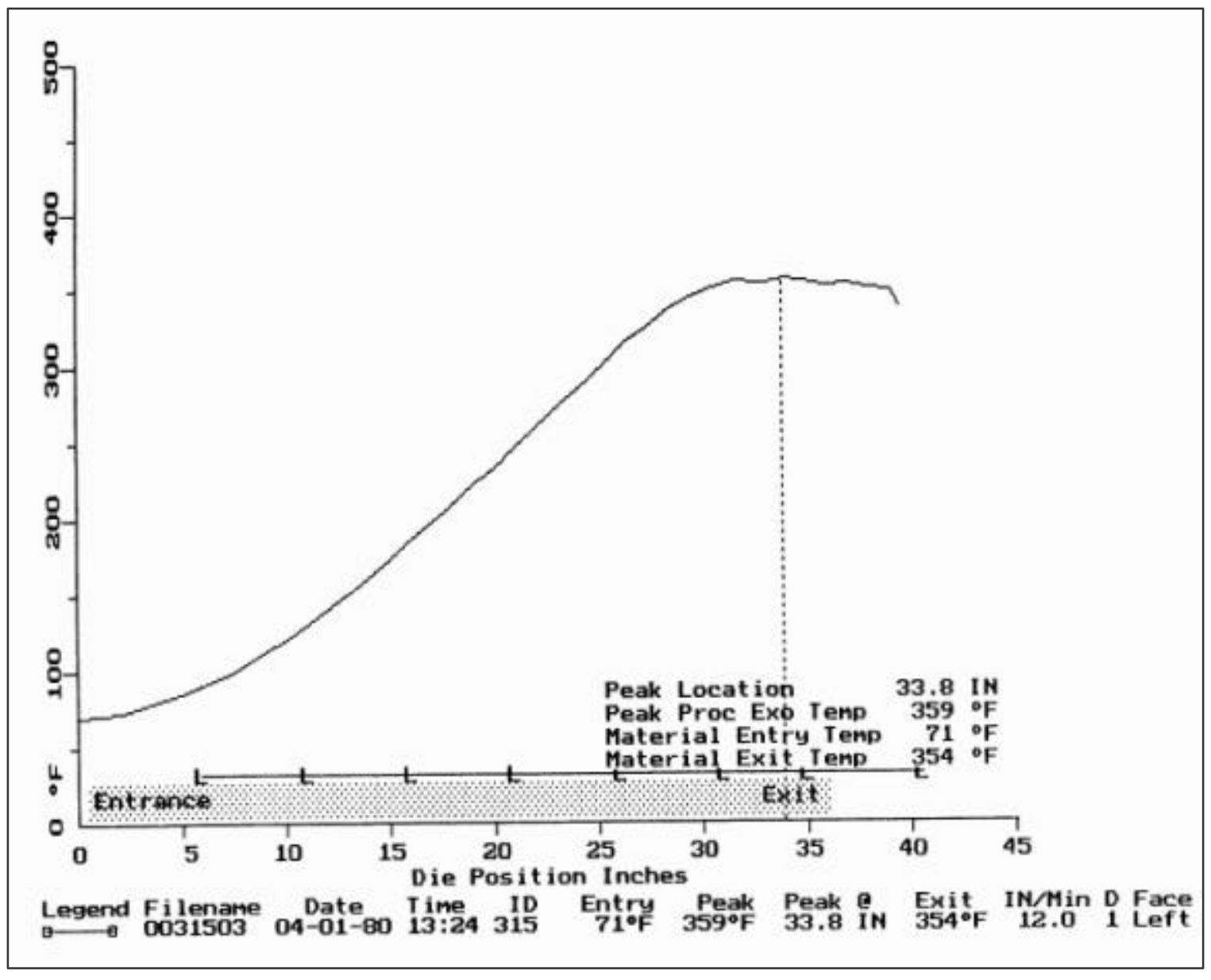

Figure 5-16. Temperature Profile within the Die during

Manufacturing by Pultrusion $\left(12 \mathrm{ipm}, \mathrm{T}_{1}=275^{\circ} \mathrm{F}, \mathrm{T}_{2}=325^{\circ} \mathrm{F}\right)$ 


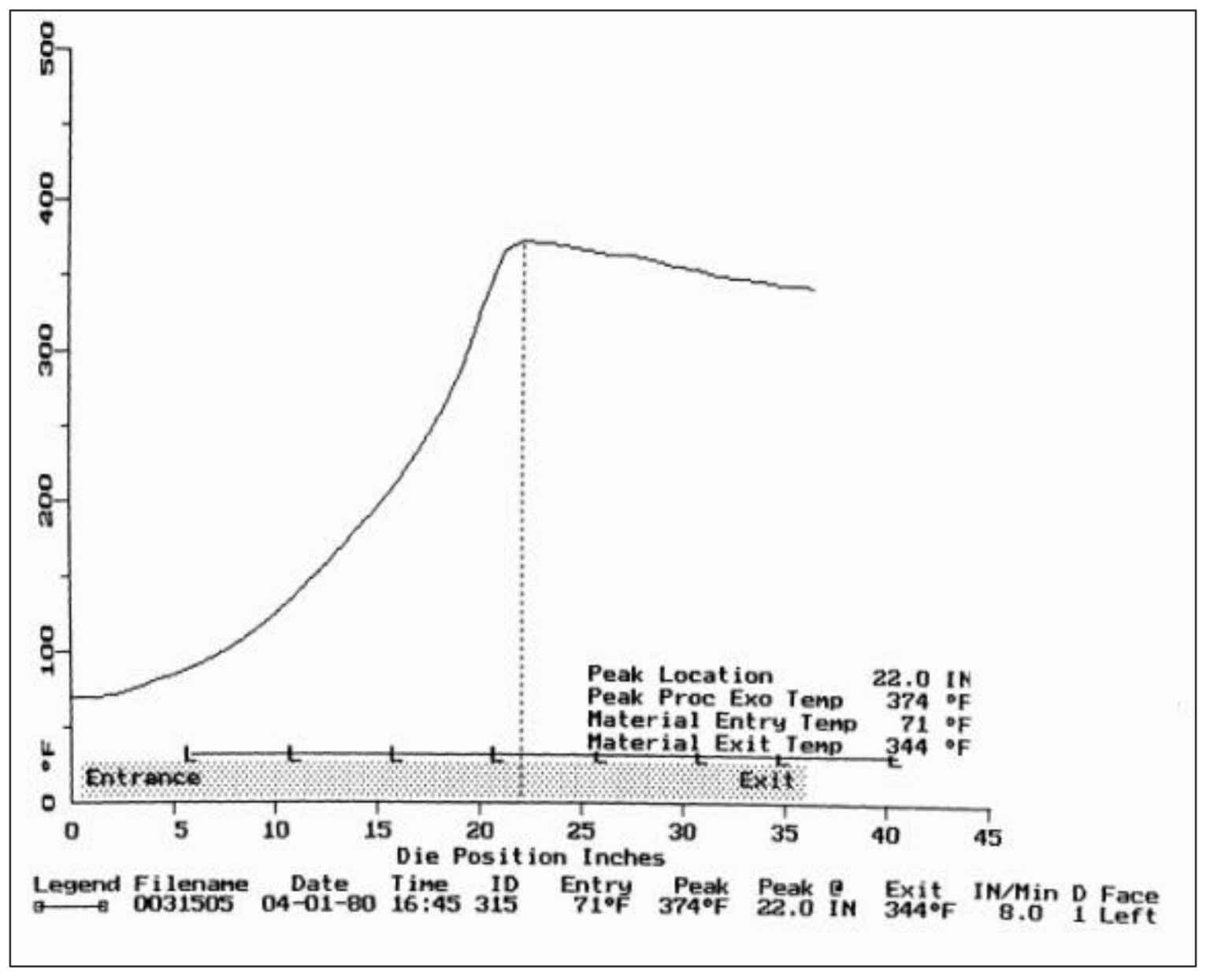

Figure 5-17. Temperature Profile within the Die during

Manufacturing by Pultrusion $\left(8 \mathrm{ipm}, \mathrm{T}_{1}=325^{\circ} \mathrm{F}, \mathrm{T}_{2}=275^{\circ} \mathrm{F}\right.$ ) 


\subsubsection{Stiffness of Pultruded Samples}

Results of the bending tests and modulus of elasticity are shown in Figures 5-18 to 5-22. It is apparent that results for the line speeds obtained $(4,8,12 \mathrm{ipm})$ do not differ in modulus, whether unaged or upon aging. Possibly with higher line speeds, i.e. 24 ipm, differences may appear due to lack of fiber wet-out and increased void fraction. These results are not unexpected since the pultrusion industry currently produces at $12 \mathrm{ipm}$. These tests show that line speeds slower than this do not improve physical properties.

Just as in the strength analysis, two processes affect the composites: cross-linking and hydrolysis, both of which are irreversible. Note that the two processes described mainly affect the properties of the resin and not the fibers. The modulus of a composite is largely a property of the fibers. Degradation of the interface or fibers themselves would produce a significant decrease in the modulus.

From Figure 5-18, an increase in modulus is observed with exposure to water in as little as 1000 hours at $25^{\circ} \mathrm{C}$ due to increased degree of cross-linking. Increased temperature had a greater effect on the increase in modulus. The effect of hydrolysis is not apparent in the modulus of the pultruded samples. Furthermore, degradation of the fibers or fiber-matrix interface is not apparent in the results obtained. Additional cure and cross-linking appear to be the major factor in the changes in modulus.

Once again, no effect was observed with freeze-thaw cycling. This may be due to the small number of cycles to which the samples were subjected. In addition, little difference was observed in stiffness loss at $85^{\circ} \mathrm{C}$ between stressed and unstressed samples, shown in Figures 5-20 and 5-21. Just as with the strength results, this suggests that the temperature has a greater effect on stiffness loss than sustained stress.

No benefit was received from sealing the edges of cut samples before exposure to water. A difference would be apparent if the samples were not allowed to fully dry prior to testing. The rate of water sorption would be greater for the unsealed samples, which

would enhance plasticization, lowering the $\mathrm{Tg}$ and modulus. However, this process is reversed upon drying and no effect is observed. 


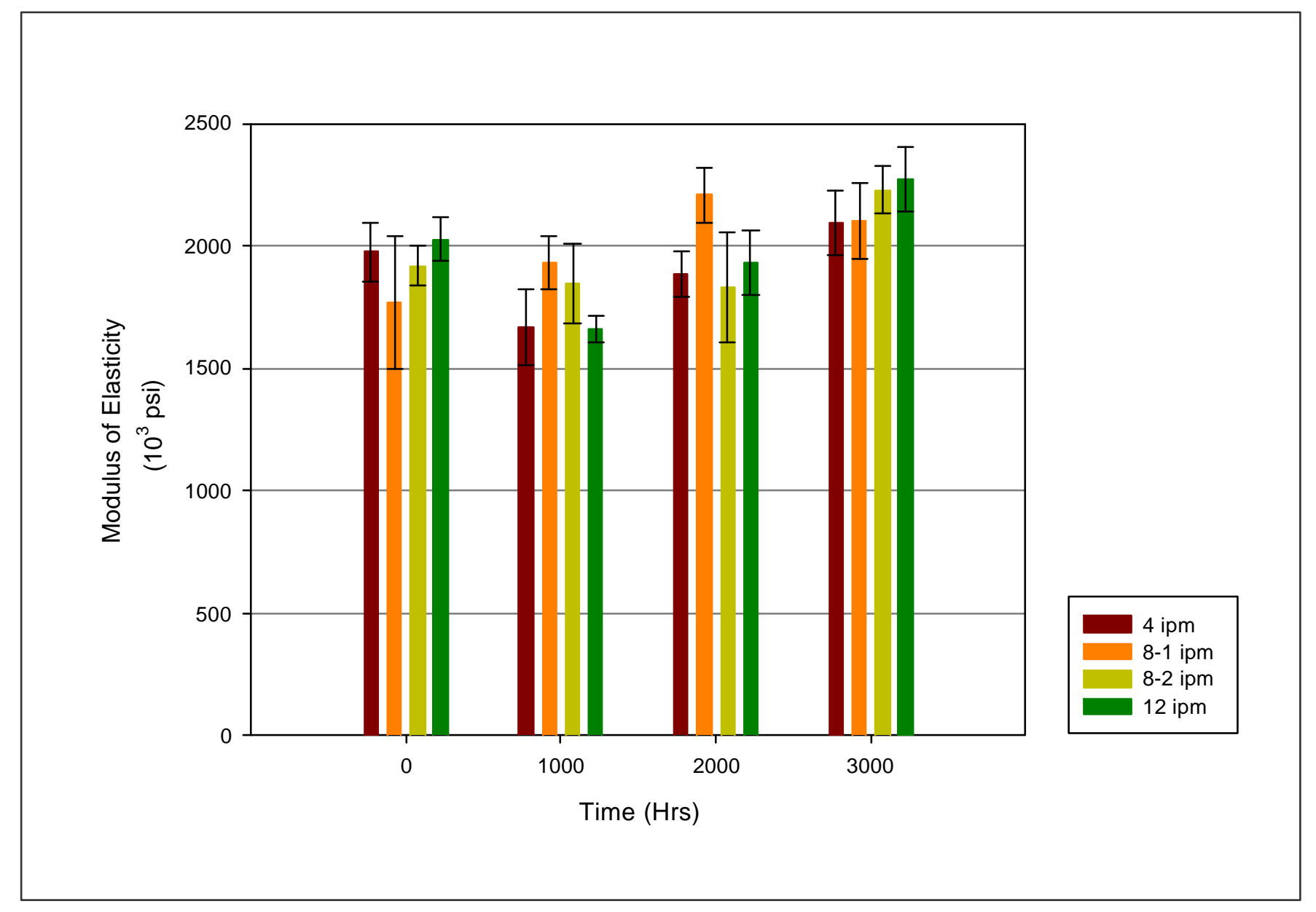

Figure 5-18. Stiffness of Pultruded Bars Aged in Water at $25^{\circ} \mathrm{C}$ 


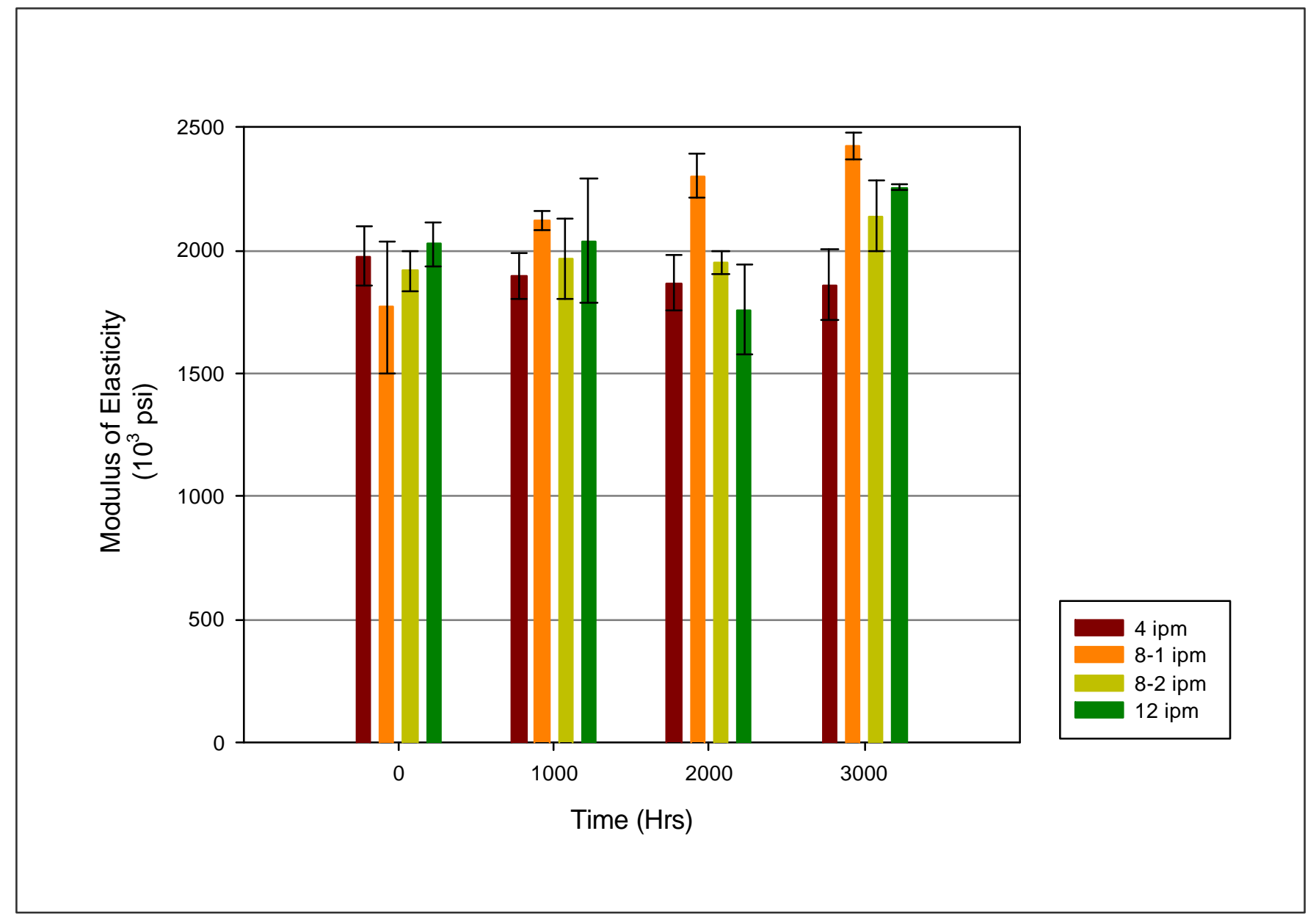

Figure 5-19. Stiffness of Pultruded Bars Aged in Water at $50^{\circ} \mathrm{C}$ 


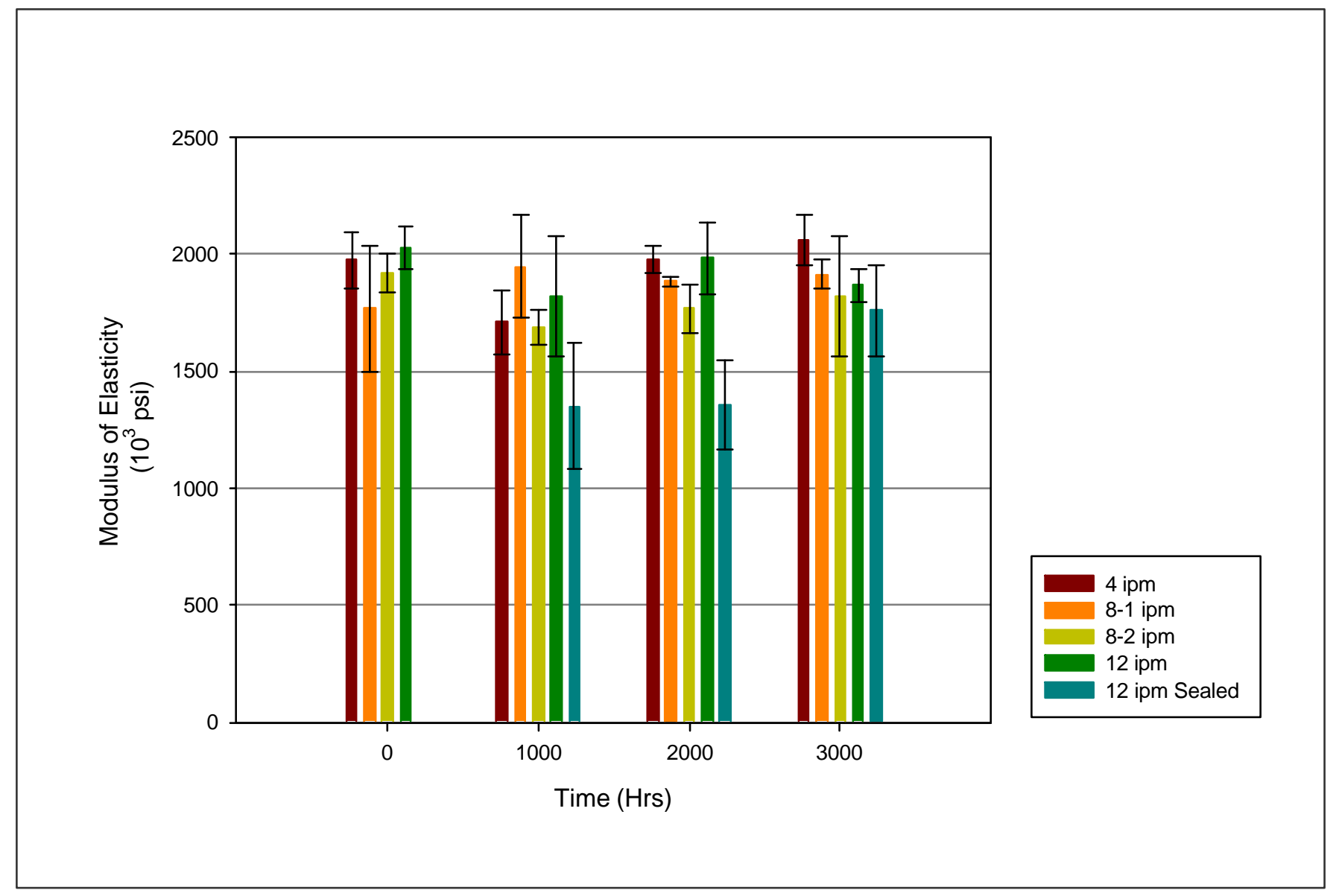

Figure 5-20. Stiffness of Pultruded Bars Aged in Water at $85^{\circ} \mathrm{C}$ 


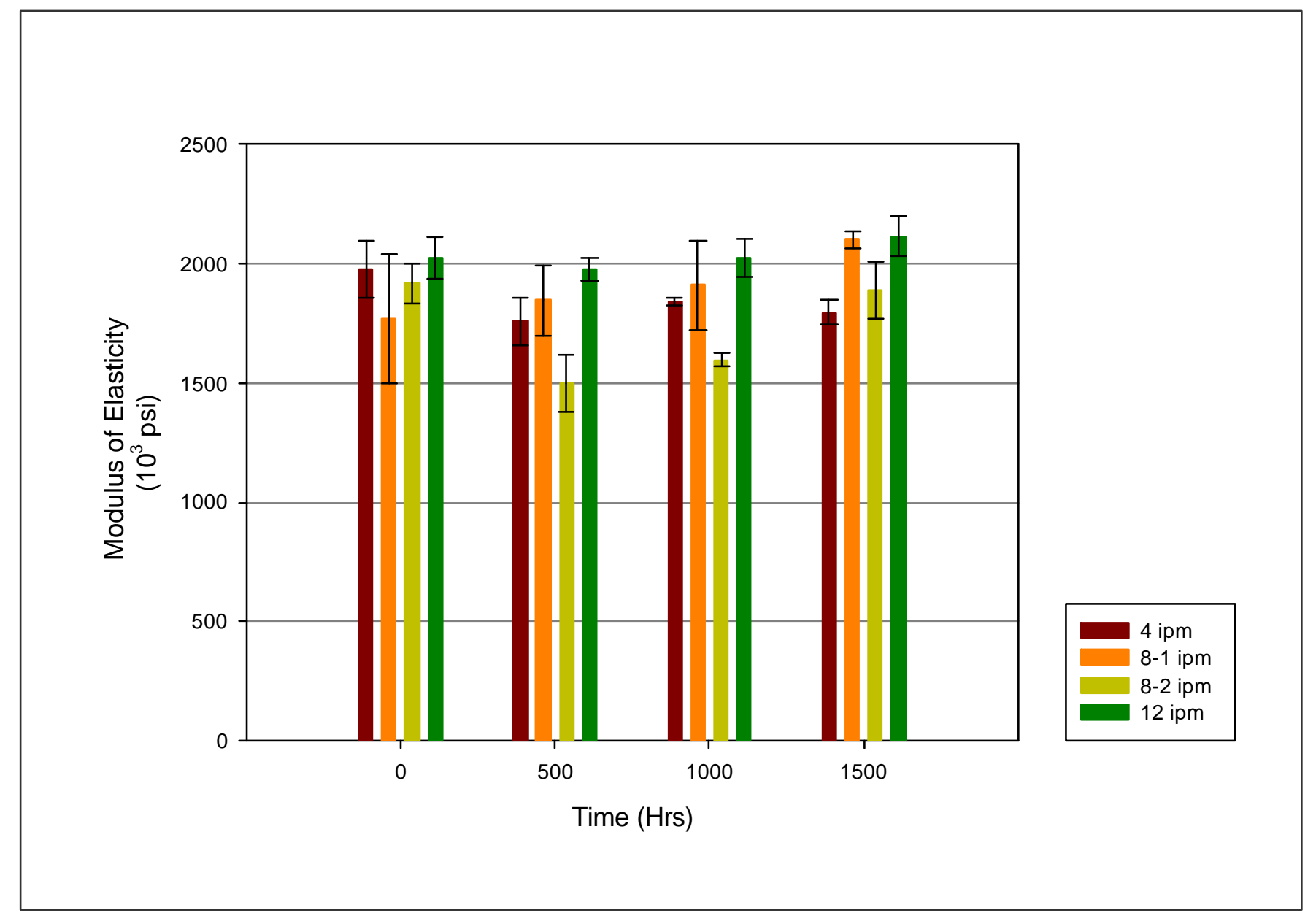

Figure 5-21. Stiffness of Pultruded Bars Stressed in Water at $85^{\circ} \mathrm{C}$ 


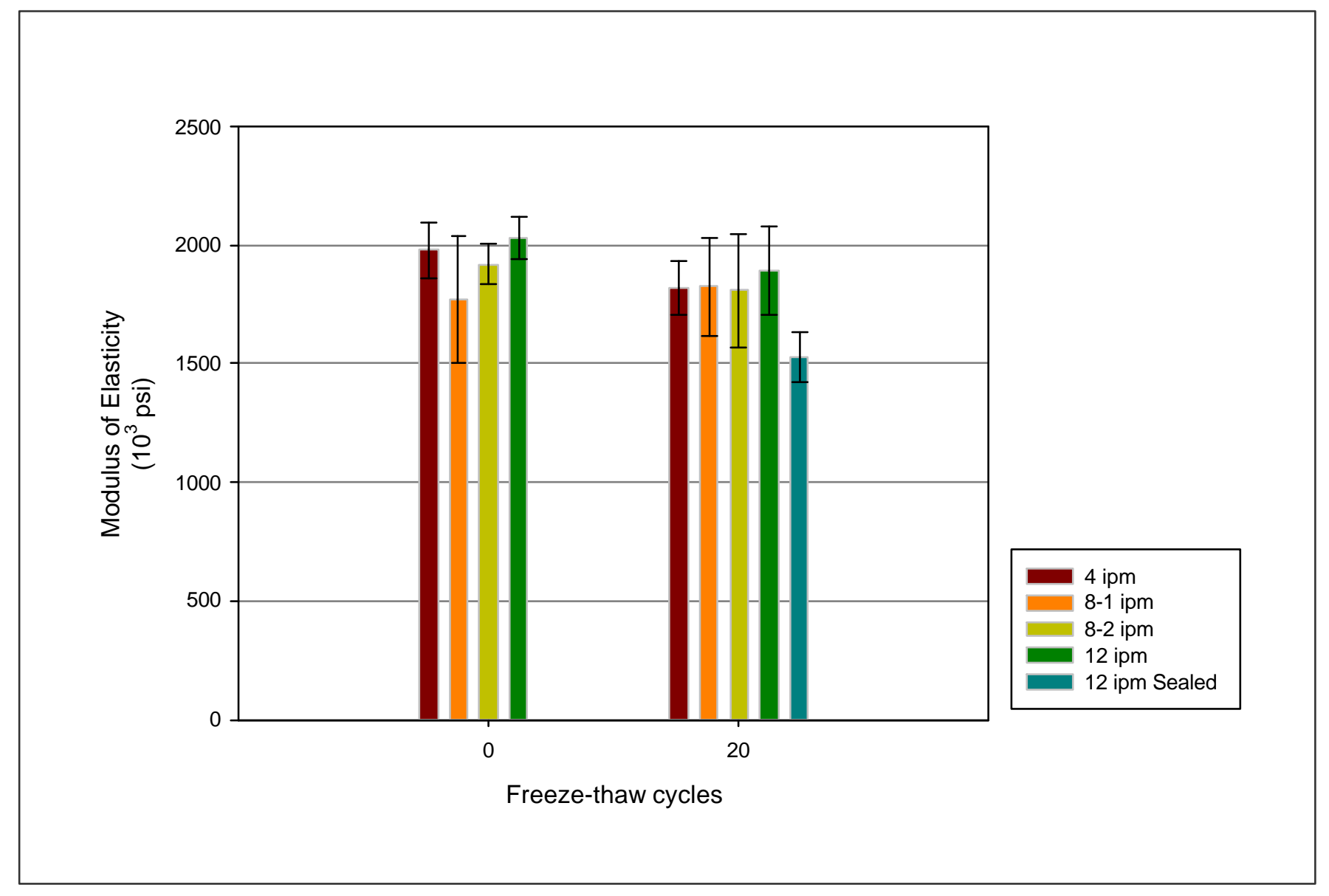

Figure 5-22. Stiffness of Pultruded Bars Aged by Freeze-Thaw Cycling 


\subsubsection{Correlation of Predicted and Experimental Bending Results}

Computer calculations were performed to determine the theoretical strength and stiffness of the pultruded composite material [33, 34]. These predicted results were compared with those obtained experimentally. Through this comparison, the quality of the pultruded part will be established by examining the proximity of the actual properties to those predicted. These results are shown in Table 5-3.

Table 5-3. Correlation of Experimental and Predicted Results for Pultruded Vinyl Ester Composites

\begin{tabular}{||c|c|c|c||}
\hline Composite Properties & $\begin{array}{c}\text { Theoretical } \\
\text { Results }\end{array}$ & $\begin{array}{c}\text { Experimental } \\
\text { Results } \\
\text { (WVU) }\end{array}$ & $\begin{array}{c}\text { Experimental } \\
\text { Results } \\
\text { (Independent) }\end{array}$ \\
\hline \hline Tensile Modulus, psi & $2.89 \mathrm{E}+06$ & --- & $3.50 \mathrm{E}+06$ \\
\hline Bending Modulus, psi & $3.80 \mathrm{E}+06$ & $2.30 \mathrm{E}+06$ & $2.40 \mathrm{E}+06$ \\
\hline $\begin{array}{c}\text { Bending Strength, psi } \\
\text { (experimental) }\end{array}$ & --- & $5.50 \mathrm{E}+04$ & --- \\
\hline $\begin{array}{c}\text { Bending Strength, psi } \\
\text { (from tensile modulus) }\end{array}$ & $5.78 \mathrm{E}+04$ & --- & $7.00 \mathrm{E}+04$ \\
\hline $\begin{array}{c}\text { Bending Strength, psi } \\
\text { (from bending modulus) }\end{array}$ & $7.60 \mathrm{E}+04$ & $4.60 \mathrm{E}+06$ & $4.80 \mathrm{E}+04$ \\
\hline \hline
\end{tabular}

The experimental bending modulus obtained was approximately $60 \%$ of that predicted by the program. However, the predicted tensile modulus was in good agreement with the bending modulus obtained experimentally. In order to determine if the discrepancy was reasonable, independent bending tests were conducted. For the tests conducted for this research, the stiffness was determined from the bending tests. The initial slope of the load-displacement plot was used rather than a strain gauge to determine the modulus of the material. The values obtained through the independent bending tests were slightly greater than those conducted at WVU, but were within a 5 
percent margin of error. Furthermore, independent tension tests were also conducted in which the predicted modulus was achieved. This result was expected, as the stiffness is often greater tested under tension than bending. The strength of the material was predicted from the theoretical modulus by using Equation 5-1.

$$
\text { Strength }=\text { Stress } * \text { Strain }
$$

Where,

Stress $=$ Modulus (predicted or experimental), psi

Strain $=20,000 \mathrm{E}-06$

Since strain gauges were not used in the research, a strain value of 20,000E-06 was used. The value was used as an estimate for the calculation as it is a typical strain result obtained [35]. The predicted strength from the tensile modulus is once again in good agreement with the values obtained experimentally. The predicted bending modulus gives a predicted bending strength that is much greater than that obtained experimentally. The details of the calculation for predicted properties, including equations used and the calculated values are provided in Appendix E.

\subsubsection{Other Results from Bending Tests}

Figures 5-23 and 5-24 show the failure of the pultruded samples during bending tests. The location of failure was consistent in that the cracking began on the bottom face of the sample. This is expected since the bottom face is in tension and will fail first. The stress will be transferred to the center of the sample, where the bulk of the failure is seen. The crack will expand and travel across the center of the sample. Other samples delaminated during the failure, indicating poor adhesion between the layers of the composite. No correlation was found between line speed and failure mode. 


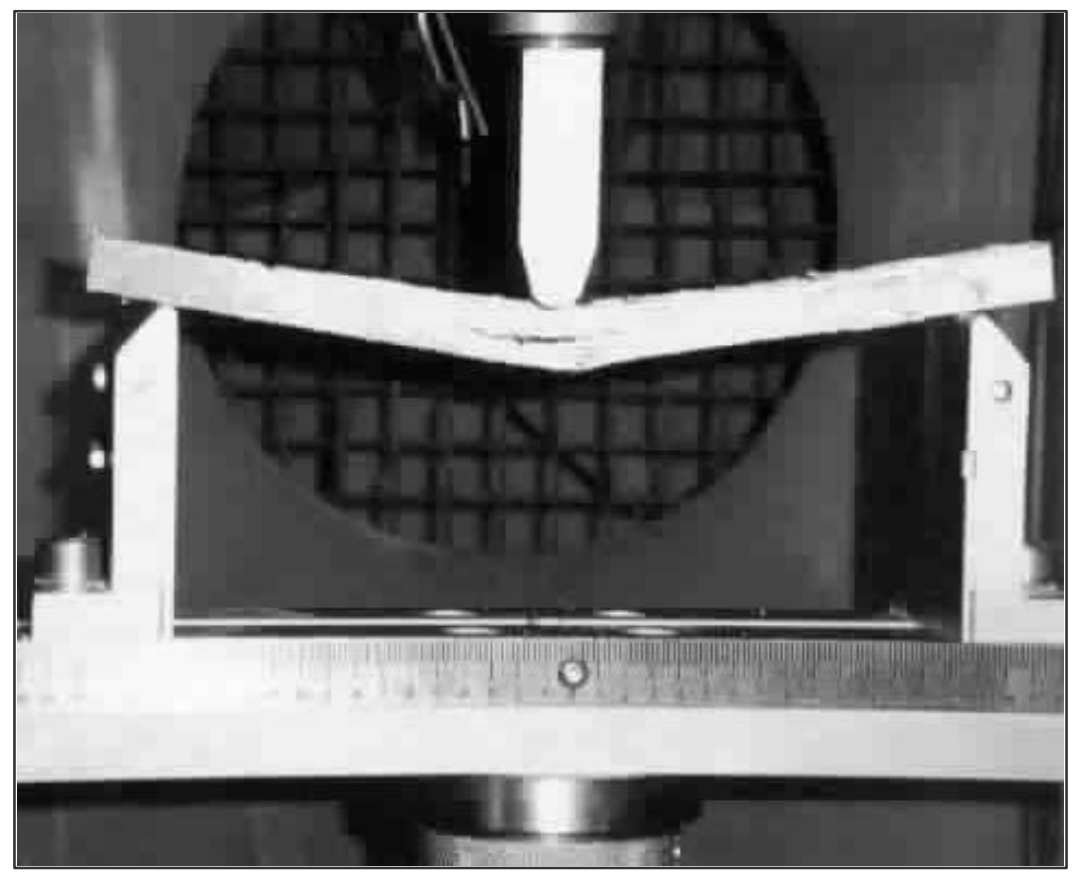

Figure 5-23. Typical Fracture of Pultruded Specimen

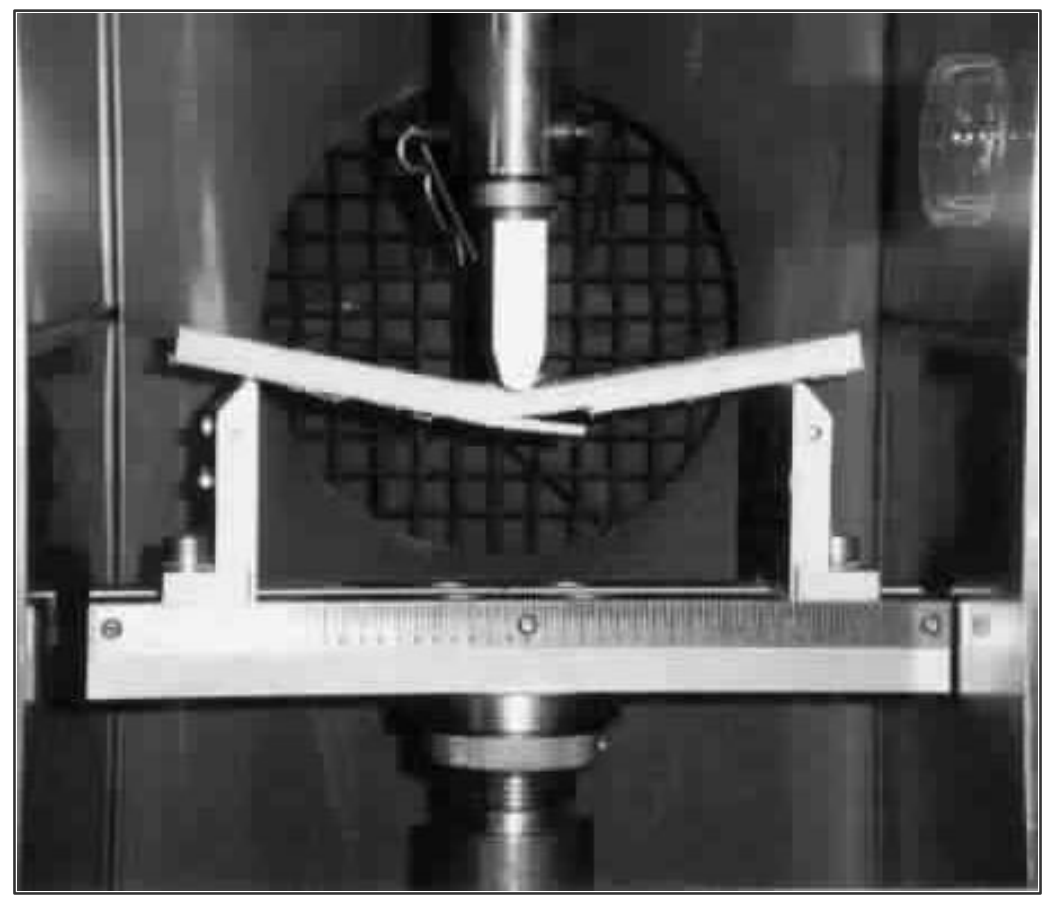

Figure 5-24. Delamination of Pultruded Specimen 


\subsection{Microscopy Results}

\subsubsection{SEM}

The void fraction of the pultruded samples manufactured at various line speeds was analyzed via microscopy tests. A void is considered to be an area in the composite in which resin is absent. Both SEM and optical microscopy were used in the analysis of the pultruded samples. Imaging software, Scion Image ${ }^{\mathrm{TM}}$ from Windows, was used to determine the void fraction of the composite samples [36]. Typical micrographs, representative of all line speeds are shown in Figures 5-25 to 5-30.

Figures 5-25 to 5-27 are micrographs from SEM analysis. Figure 5-25 is of low magnification, 20X, in which the layers and boundaries of fabric and roving of the fiber architecture are easily visible. From this micrograph, it is apparent that the majority of the voids are concentrated in the layers of fabric within the composite. This is most likely due to the difficulty in completely impregnating the resin into the fabric during manufacturing. Each layer of fabric consists of fibers oriented at $90 / 45 /-45^{\circ}$, whereas the roving is unidirectional and not as compact.

Figure 5-26 is a micrograph focusing on the TH-4000 fabric taken at 500X. The area of voids is easily distinguished in this micrograph as the voids appear as holes in the surface. Notice that they appear in the region where the fibers are closely bound. Poor fiber wet-out could be the cause of these voids. The stray surface particles are most likely residual polishing compound. The voids that appear in Figure 5-26 are thought to be manufacturing defects, and not a product of sample preparation. Figure 5-27 is also at 500X, however, no voids are evident in this micrograph. Not all samples analyzed

contained voids. Furthermore, the void content differed for those samples containing voids. However, no correlation was found for void content and line speed. 


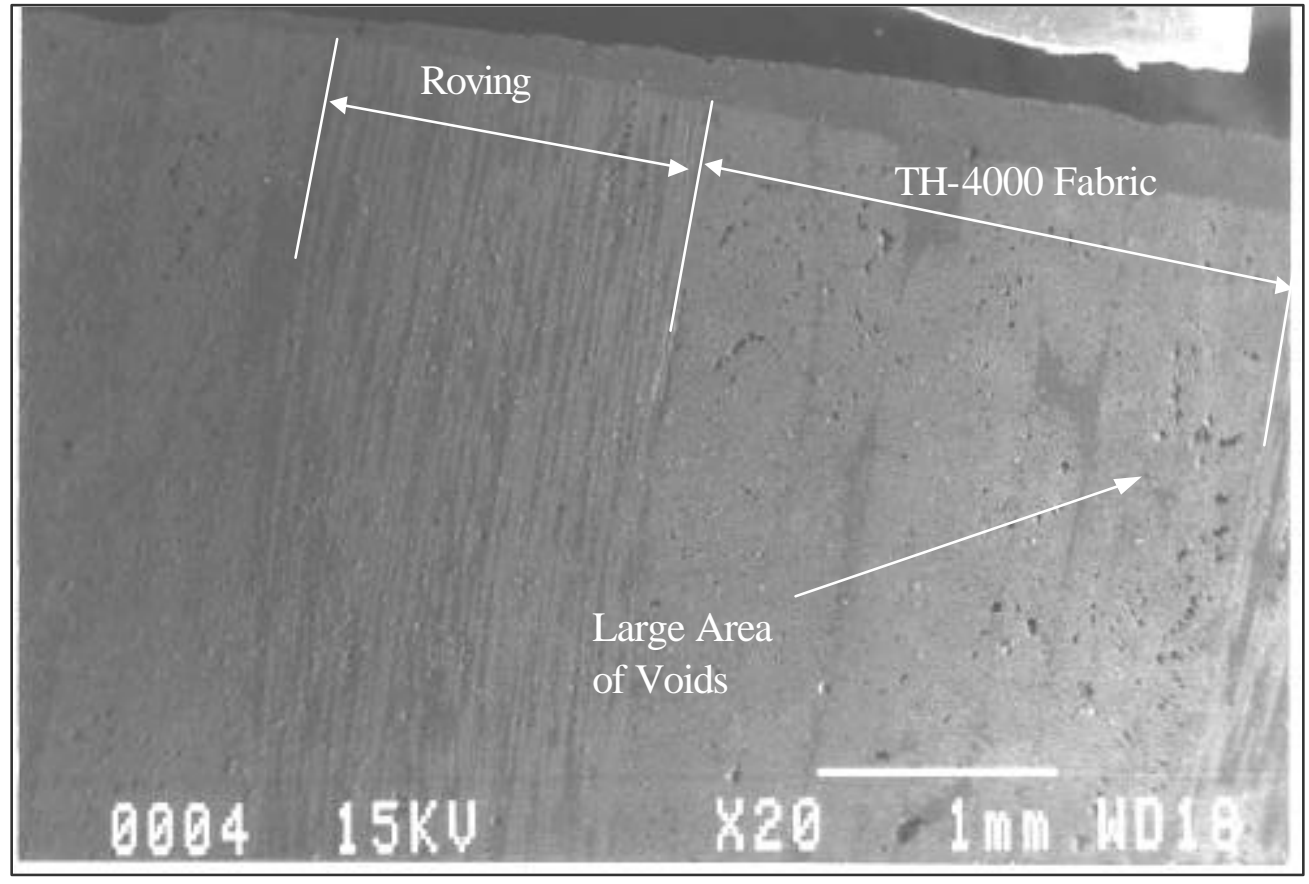

Figure 5-25. SEM of Pultruded Sample at 20X.

Fiber Composition and Apparent Voids Indicated.

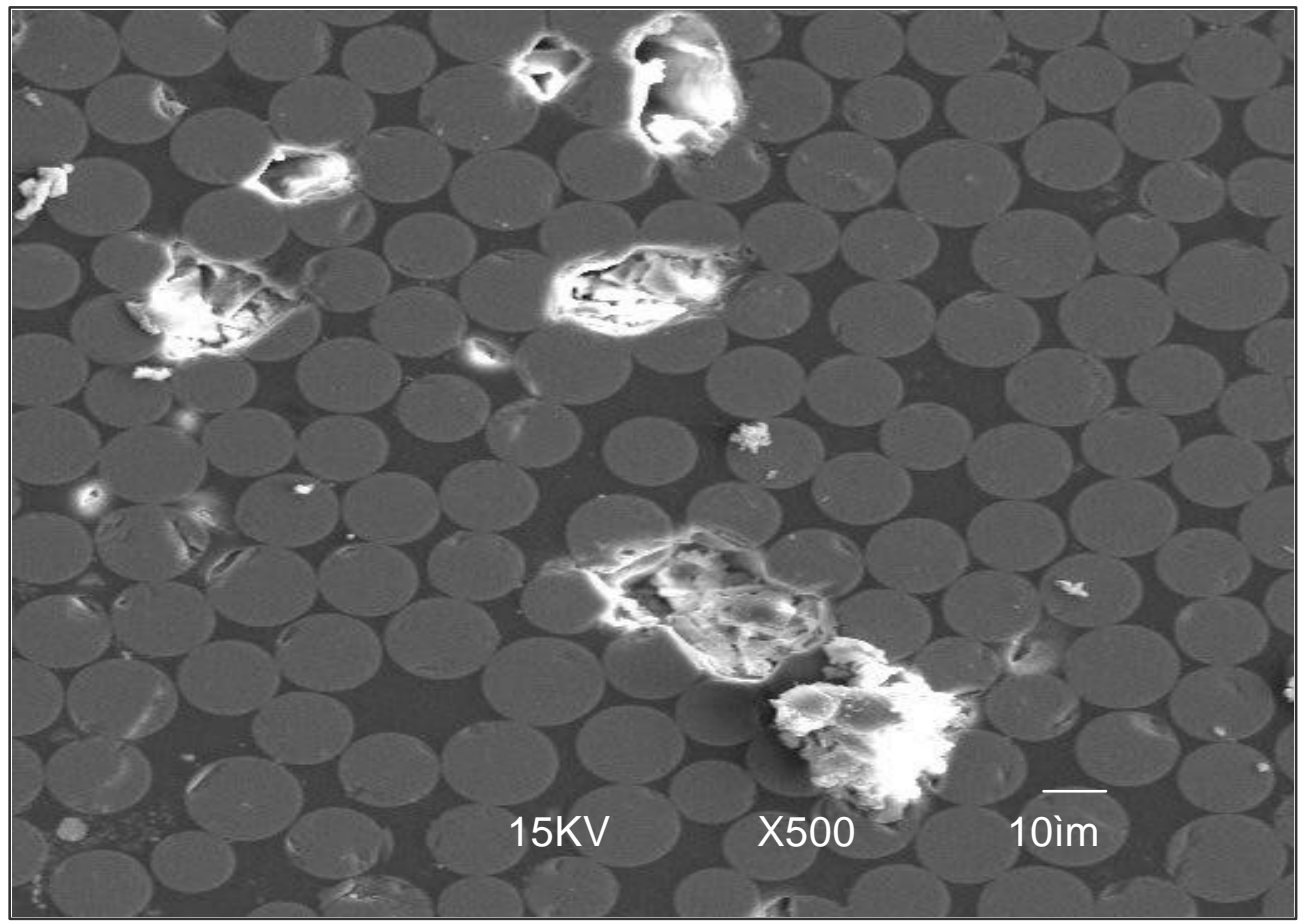

Figure 5-26. SEM of Pultruded Sample at 500X in which Voids are Evident. 


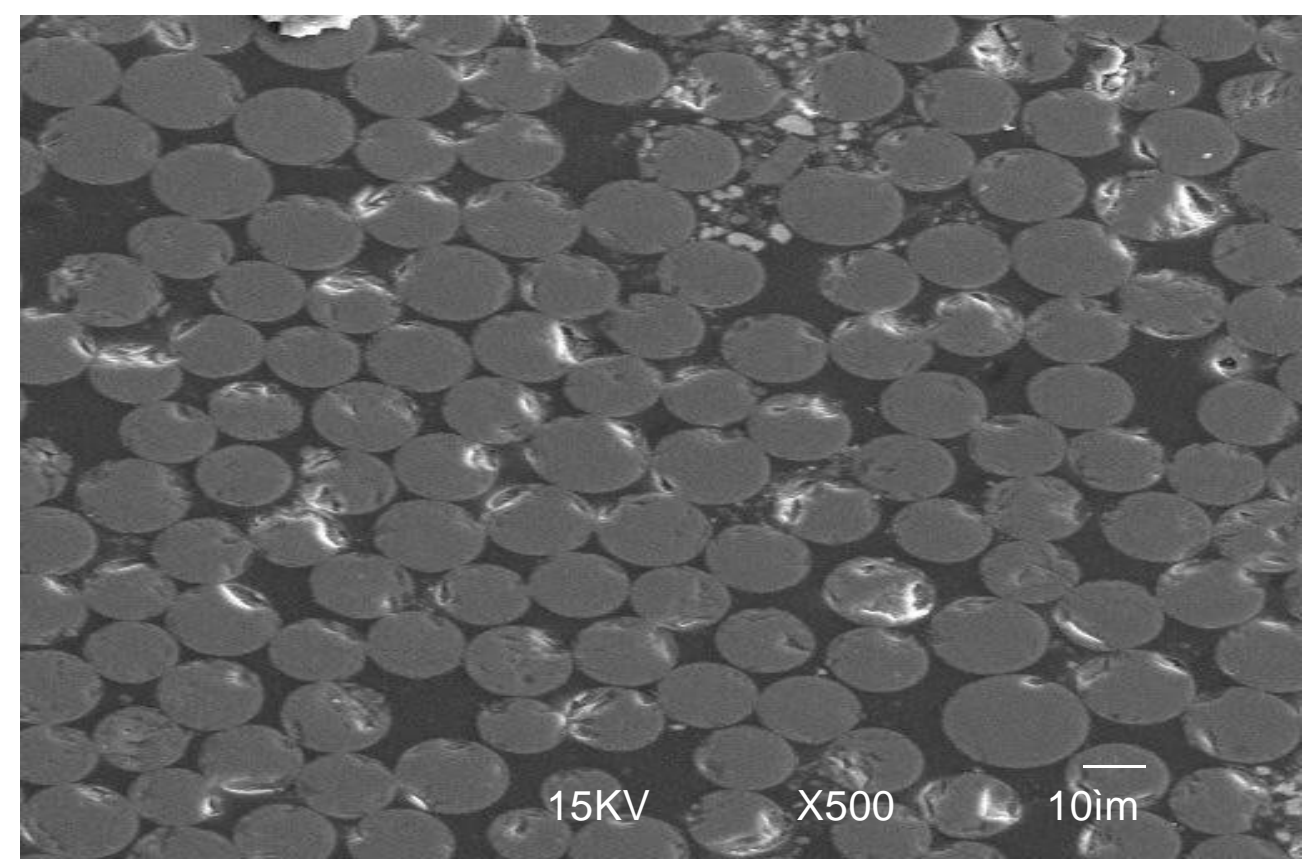

Figure 5-27. SEM of Pultruded Sample at 500X in which No Voids are Evident. 


\subsubsection{Optical Microscopy}

Figures 5-28 to 5-30 are from the analysis by an optical microscope. The micrograph in Figure 5-28 taken at 100X shows the detail of the fiber architecture of the pultruded specimen. The top region is the glass roving, which is parallel to the page. The bottom region is the glass fabric, which is perpendicular to the page. The irregular shaped dark regions, which appear primarily in the fabric, are believed to be voids in the material. The large circular artifacts are the glass microspheres, which are used as filler in the resin.

The micrograph of the pultruded sample taken at 160X is shown in Figure 5-29. No rovings are present in this view, as the fabric and the voids within are of primary interest. Once again, the voids are shown as the darker regions of the micrograph. It is believed that these voids were a flaw that developed during the manufacturing process rather than created by preparing the samples for analysis. Voids can be created by sample preparation. A void would be created during sample preparation if a fiber was broken and inadvertently removed from the matrix.

Figure 5-30 illustrates a flaw in the material that most likely occurred during production. The dark region is a large crack that is surrounded by smaller voids. A flaw such as this may cause premature failure of the material. The error found in the bending tests may be attributed to flaws such as this.

The micrographs presented are representative of all the analysis performed. The average void fraction for all samples, as determined by Scion Image software, was determined to be $1.0 \pm 0.5$ percent [36]. No difference in void fraction was detected for

the different line speeds obtained. It has been determined that strength reduction is observed for void fraction greater than 4 to 5 percent [37]. No strength difference was detected in the different line speeds, which correlates with low void content and little deviation in the void fraction for the pultruded samples. Possibly with higher line speeds, an increase in void fraction would be observed. 


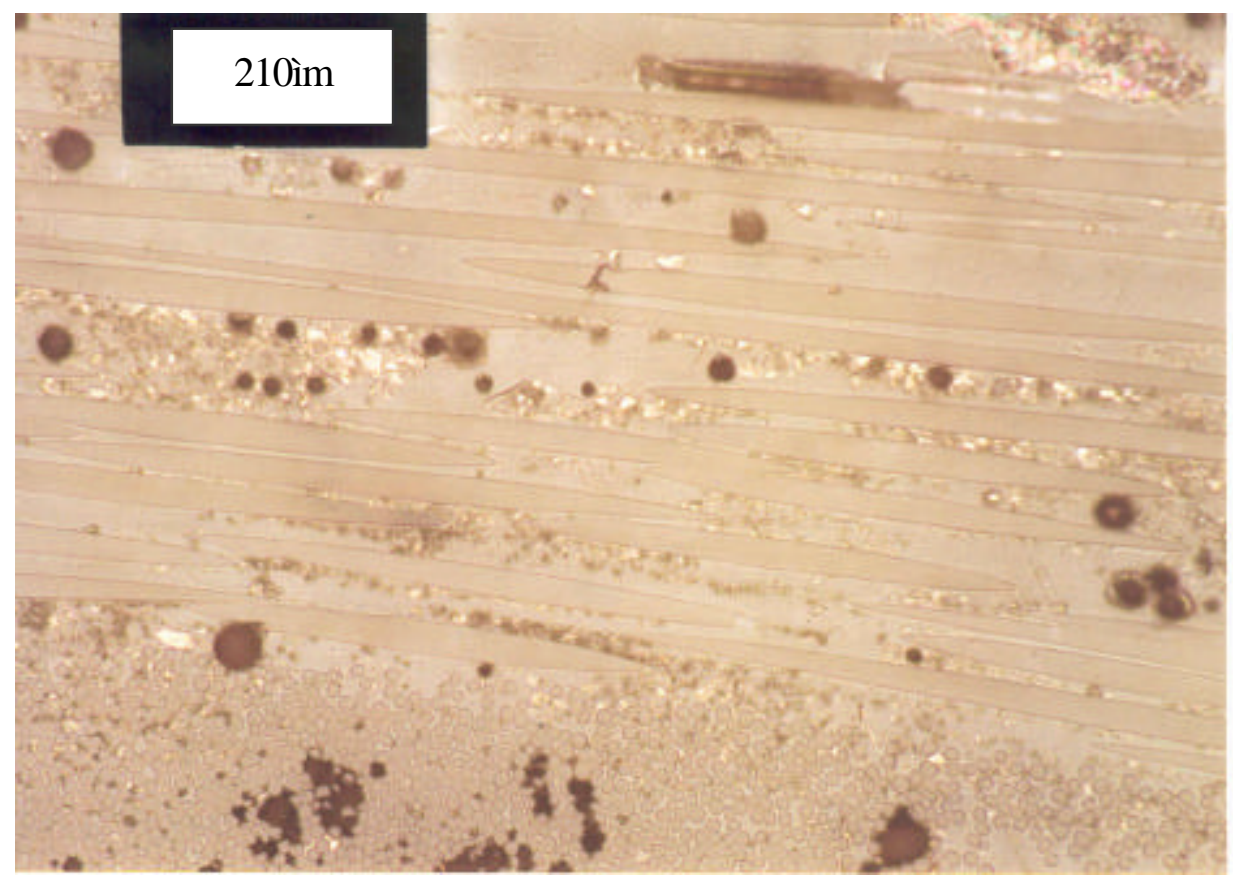

Figure 5-28. View of Pultruded Sample from Optical Microscope

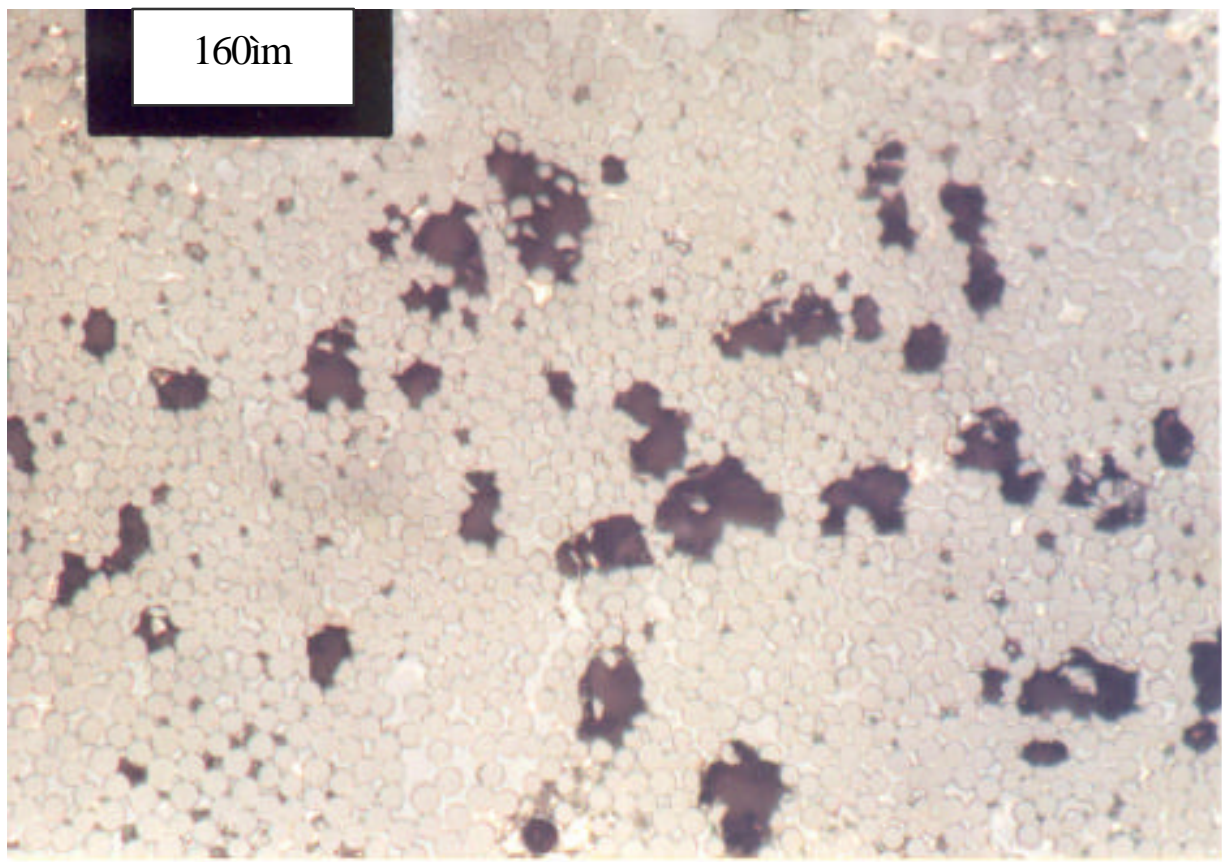

Figure 5-29. View of Voids in Pultruded Sample in Optical Microscope 


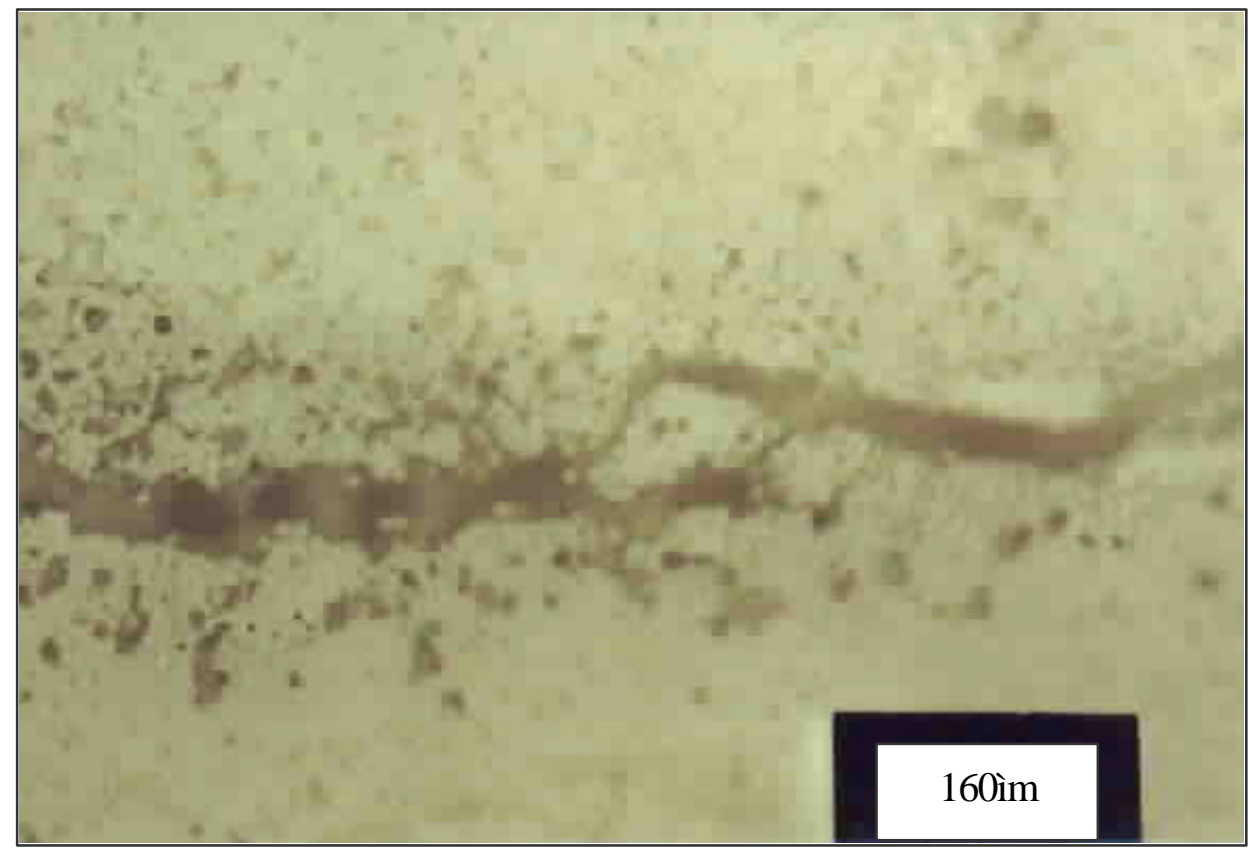

Figure 5-30. View of Crack in Pultruded Sample in Optical Microscope 


\subsection{Water Sorption of Pultruded Samples}

Water sorption is an important parameter in the degradation of polymer composites. The larger the water content, the more probable the occurrence of degradation. Processes such as hydrolysis, which weaken the matrix, occur during immersion in aqueous environments. Degradation of the fiber/matrix interface is another process that occurs in the presence of water.

In order to determine if process conditions, such as line speed, affected water sorption, water sorption during aging was determined. The mass of each sample was taken prior to immersion and immediately upon removal from the aging medium. The mass of each sample was also recorded prior to testing to assure the sample had returned to the original mass. The percent water absorbed was calculated for each line speed for each medium at 1000, 2000, and 3000 hours as described in Chapter 4. Typical results are shown in Figure 5-31 and Figure 5-32. From Figure 5-31, which is for immersion at $25^{\circ} \mathrm{C}$, it is apparent that the line speed had no effect on the percent water absorbed. This was expected since no difference in strength or void fraction was found for the various line speeds. Also as expected, the percent water absorbed increased with increasing temperature of the aging medium. These results are given in Figure 5-32, which is for samples pultruded at $12 \mathrm{ipm}$. Furthermore, the percent water absorbed increased with length of exposure. It appears that the applied stress did not affect the water sorption process in that the percent water absorbed was relatively the same for stressed and unstressed samples. 


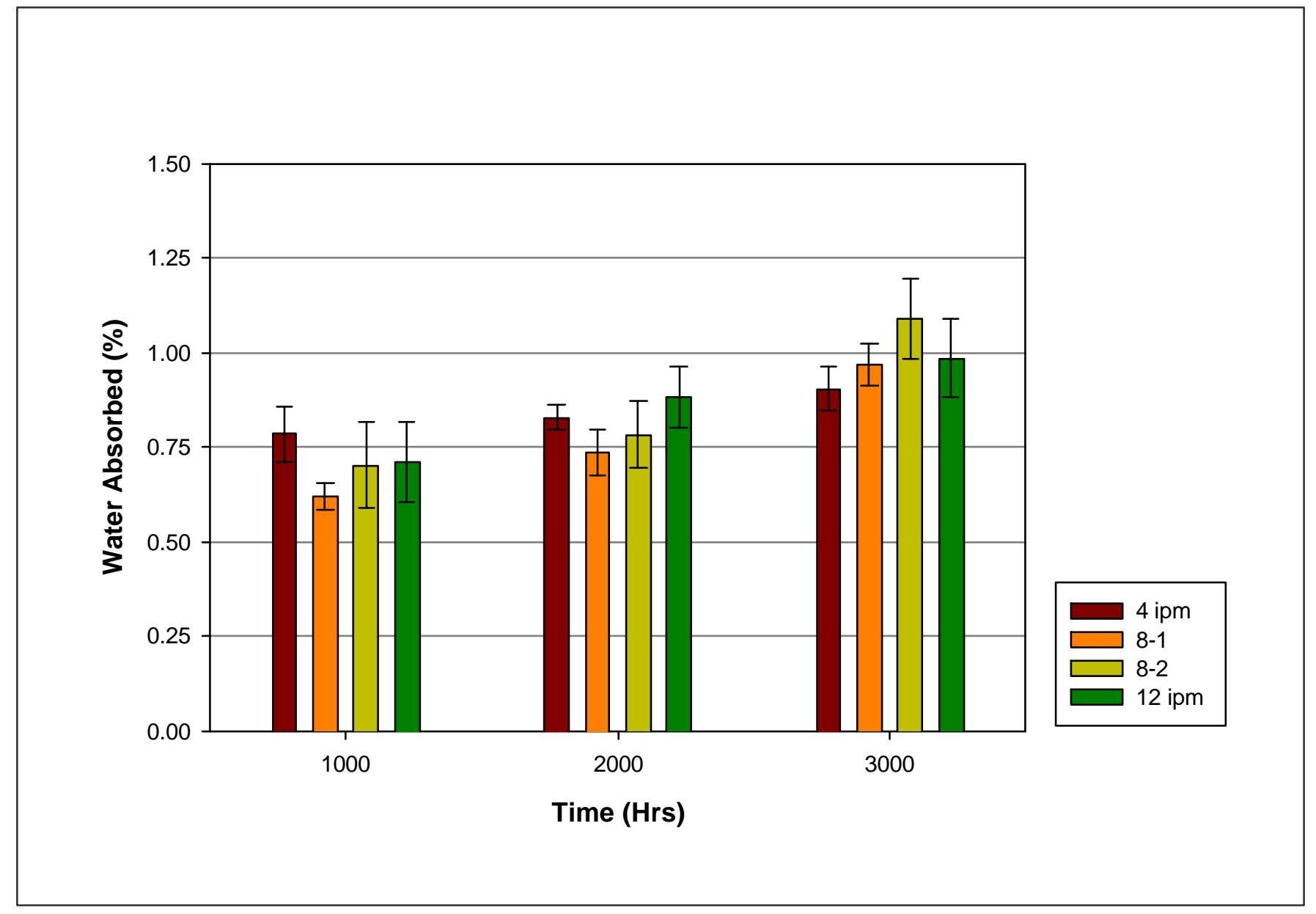

Figure 5-31. Percent Water Absorbed Compared for Different Line Speeds

(Water Temperature of $25^{\circ} \mathrm{C}$ ) 


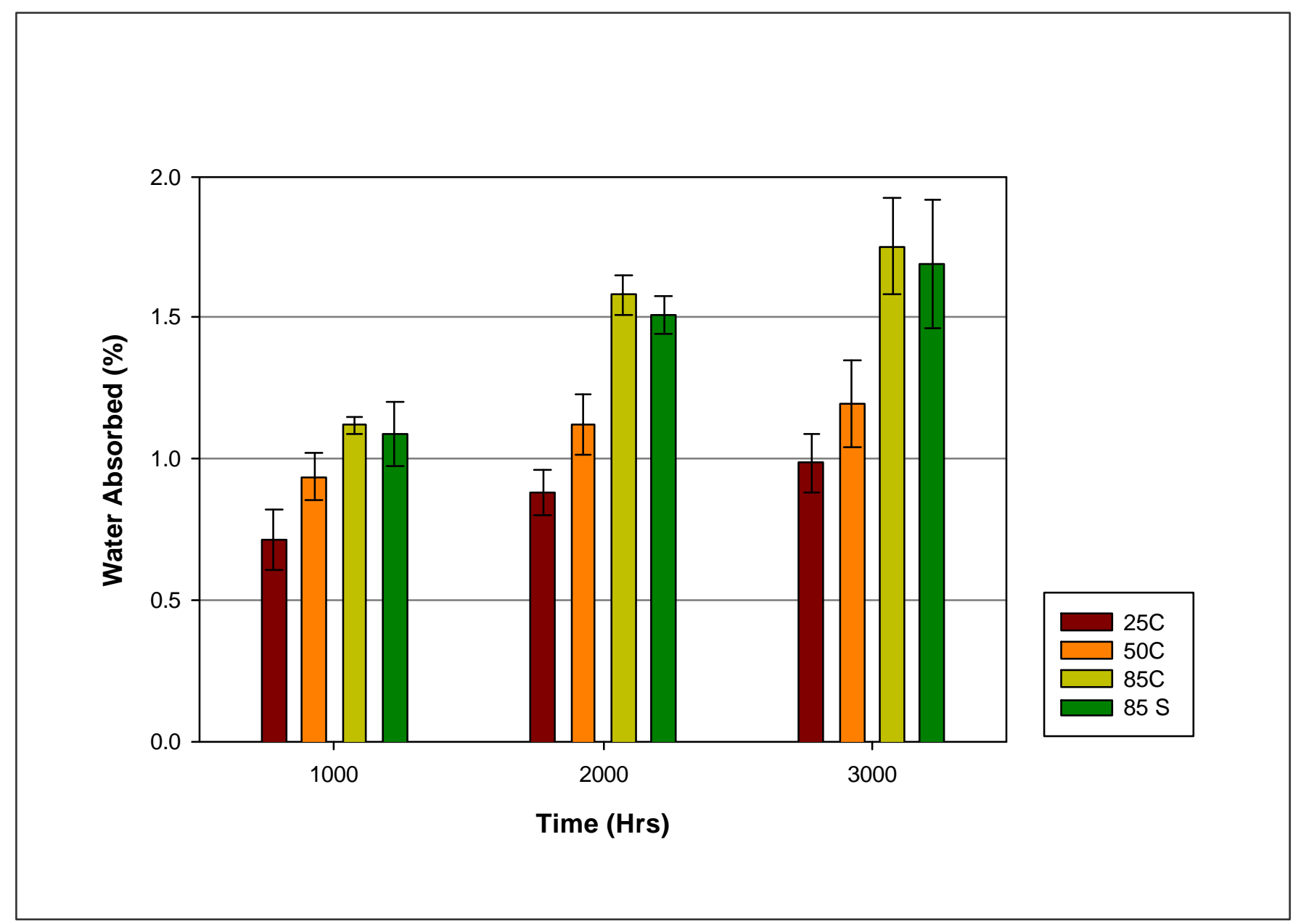

Figure 5-32. Percent Water Absorbed Compared for Different Temperatures

( Line Speed of $12 \mathrm{ipm}$ ) 


\section{CHAPTER 6}

\section{CONCLUSIONS AND RECOMMENDATIONS}

The primary purpose of the research conducted was to study the effect of process conditions, such as line speed and die temperature profile, on the durability and degradation of pultruded vinyl ester/glass composites. The composites were subjected to various environmental conditions and resulting changes in mechanical and physical properties were measured. Based on experimental results from the study, several conclusions can be drawn.

\subsection{Conclusions}

\subsubsection{Effect of Aging on Tg and Storage Modulus}

Based on DMTA results, the $\mathrm{Tg}$ increased within 1000 hours for all samples with the largest increase occurring for samples aged at the higher temperatures. This indicates that the samples undergo additional cross-linking during immersion in water. Also the shape of the tan delta peak becomes narrower with increased water temperature. This suggests that the molecular weight distribution becomes more uniform within the polymer with additional cross-linking. Based on DMTA results, it was found that the storage modulus increased within 1000 hours for all samples with the largest increase occurring at the higher aging temperatures. This increase in stiffness also suggests that additional cross-linking occurred during immersion and correlates with the $\mathrm{Tg}$ results. In the frequency range tested, the material behaves as an elastic solid since the modulus is linear in appearance and has zero slope.

\subsubsection{Effect of Aging on Strength and Stiffness}

Based on bending test results, the flexural strength decreased for all samples, with the largest decrease occurring at the higher aging temperatures. No difference was observed in the flexural strength for the various line speeds obtained. A small increase in strength was noted for the different die temperature profile. No benefit was received from sealing the exposed cut edges of the samples. 
Based on bending test results, it was found that the modulus increased for all samples, with the largest increase occurring at the higher aging temperatures. This indicates that the fibers were not damaged or degraded during the aging process. No difference in the flexural stiffness was observed for the samples with varying line speeds.

\subsubsection{Effect of Line Speed on Void Fraction}

Based on microscopy results, no difference was observed in the void fraction of the pultruded samples. This correlates with the bending test results that also showed no difference in the properties of the samples with varying line speed.

\subsubsection{Effect of Line Speed on Water Sorption}

Based on percent water absorbed calculations, no difference was observed for the pultruded samples. This result correlates with both the bending and microscopy evaluations in which no difference in properties or appearance was noticed for the varying line speeds of the pultruded samples.

\subsection{Recommendations for Future Work}

To determine the extent to which line speed affects the mechanical properties of pultruded composites, samples should be obtained with increased pull speeds. Pull speeds of 18 to $24 \mathrm{ipm}$ may provide some differences in void fraction, fiber wet-out, and degree of cure that would be observed by both flexural and microscopy tests. Aging of samples for longer periods of time would also provide insight to the extent of degradation that may occur within the service life of a structure.

In this research, no clear evidence is present to determine if hydrolysis occurred within the composite sample. Possible tests for hydrolysis could be conducted using thin film samples prepared for analysis via FTIR. These thin film samples could be analyzed both before and after aging to compare the spectra obtained, specifically the $-\mathrm{OH}$ region, in order to determine if hydrolysis occurred. 


\section{BIBLIOGRAPHY}

1. Lopez-Anido, R., Troutman D. T. and Busel J. P., "Fabrication and Installation of Modular FRP Composite Bridge Deck", Proceedings, ICE 98, Nashville, TN, 1998.

2. Makowski, Z. S., "Symbiosis of Architecture and Engineering in the Development of Structure uses of Plastics", Plastics in Material and Structural Engineering, R.A. Bares et al Eds., Elsevier Scientific Publishing Co., New York, 1982, p. $59-72$.

3. High Performance Construction Materials and Systems: An Essential Program for America and Its Infrastructure, Executive Report 93-5011.E, The Civil Engineering Research Foundation, April, 1993.

4. Composites Technology, September/October, 1996, p. 8.

5. Parmar, M. and Boyce, G., "Finding the Hidden Flaw", Engineering, 228, March 1988, p. 14-16.

6. Springer, G. S., "Introduction”, Environmental Effects on Composite Materials, Technomic Publishing Company, Inc., 1, 1981, p. 1-6.

7. Mallick, P. K., "Composites Engineering Handbook", Marcel Dekker, New York, 1997.

8. Tsai, S. W., "Environmental Factors in the Design of Composite Materials", Mechanics of Composite Materials, Proc. of the 5th Symp. on Naval Str. Mech., Philadelphia, Pergamon Press, 1967, p. 749-767.

9. Loos, A. C. and Springer, G. S., "Moisture Absorption of Graphite-Epoxy Composition Immersed in Liquids and Humid Air", Environmental Effect on Composite Materials, Technomic Publishing Company, Inc., 1, 1981, p. 34-50.

10. Prian, L. and Barkatt, A., "Degradation Mechanism of Fiber-reinforced Plastics and Its Implications to Prediction of Long-term Behavior", Journal of Materials Science, 34, August 1999, p. 3977-89.

11. Springer, G. S., Sanders, B. A., and Tung, R. W., "Environmental Effect on Glass Fiber Reinforced Polyester and Vinylester Composites", Environmental Effects on Composite Materials, Technomic Publishing Company, Inc., 1, 1981, p. 126-144. 
12. Buck, S. E., Lischer, D. W. and Nemat-Nasser, S., "The Durability of EGlass/Vinyl Ester Composite Materials Subjected to Environmental Conditioning and Sustained Loading", Journal of Composite Materials, 32, 1998, p. 874-92.

13. Fried, N., "Degradation of Composite Materials: The Effect of Water on GlassReinforced Plastics", Mechanics of Composite Materials: Proceedings of the 5th Symposium on Naval Str. Mech., Philadelphia, Pergamon Press, 1967, p. 813-827.

14. Gorji, M. and Mirzadeh, F., "Theoretical Prediction of the Thermoelastic Properties and Thermal Stresses in Unidirectional Composites", Journal of Reinforced Plastics and Composites, 8, May 1989, p. 233-258.

15. Dewimille, B. and Bundsell, A. R., "Accelerated Aging of a Glass FiberReinforced Epoxy Resin in Water”, Composites, Jan. 1983, p. 35-40.

16. Ciriscioli, P. R., Lee, W. I., Peterson, D. G., Springer, G. S., and Tang, J. M, "Accelerated Environmental Testing of Composites", Environmental Effects on Composite Materials, Technomic Publishing Company, Inc., 3, 1988, p. 35-50.

17. Schultheisz, C. R., Schutte, C. L., McDonough, W. G., Macturk, K. S., Kondagunta, S., and Hunston, D. L., "Effect of Temperature and Fiber Coating on the Strength of E-Glass Fibers and the E-Glass/Epoxy Interface for Single-Fiber Fragmentation Samples Immersed in Water", Fiber, Matrix, and Interface Properties, ASTM-STP, American Society for Testing and Materials, 1996, p.103131.

18. Schulteisz, C. R., McDonough, W. G., Kondagunta, S., Schutte, C. L., Macturk, K. S., McAuliffe, M., and Hunston, D. L., "Effect of Moisture on E-Glass/Epoxy Interfacial and Fiber Strength", Composite Materials: Testing and Design, American Society for Testing and Materials, 13, 1997, p. 257-286.

19. Nguyen, T., Aouadi, K., and Chin, J. W., "Effect of Civil Engineering Environments on Interfacial Properties of Polymer/Glass Fiber Composites", 4th International Conference on Composites Engineering, 1997, p. 725-726.

20. Chin, J. W., Nyguyen, T., and Aouadi, K., "Effects of Environmental Exposure on Fiber-Reinforced Plastic (FRP) Materials Used in Construction", Journal of Composites Technology and Research, 19, 1997, p. 205-213.

21. Ghasemzadeh, S., Kajorncheappunngam, S., Gupta, R. K., and Gangarao, H. V.S., "Durability of Glass-Epoxy-Wood Hybrid Composites for Rehabilitation of Railroad Cross-ties", Durability of FRP Composites for Construction, Proceedings, CDCC-98, Sherbrooke, Canada, Aug 1998, p. 81-93. 
22. Liao, K., Schultheisz, C. R., Hunston, D. L., and Brinson, L. C., "Environmental Fatigue of Pultruded Glass-Fiber-Reinforced Composites", Composite Materials: Fatigue and Fracture, Seventh Symposium ASTM STP 1330, R. B. Bucinelle, Ed., American Society for Testing and Materials, 1998.

23. Haramis, J., Verghese, K. N. E., and Lesko, J. J., "Freeze-Thaw Durability of Composites for Civil Infrastructure", Antec 2000, p. 3184-88.

24. Norris, J. F., Crowder, J. R., and Probert, C., "The Weathering of GlassReinforced Polyester under Stress - Short Term Behavior", Composites, July, 1976, p. 165-172.

25. The Weathering of Plastics Materials in the Tropics: 7 Evaluation of the Weathering Behavior of a Variety of Glass Reinforced Polyester and Epoxy Systems, Procurement Executive, Ministry of Defense/British Federation Joint Working Party on the Aging and Weathering of Polymers and Composites, 1982.

26. Gomez, J. and Casto, B., "Freeze-Thaw Durability of Composite Materials", Fiber Composites in Infrastructure, Proceedings of the First International Conference on Composites in Infrastructure, H. Saadatmanesh and M.R. Ehsani Eds, Tucson, AZ, 15-17 January, 1996, p. 947-955.

27. Holloway, L., "Handbook of Polymer Composites for Engineers", Woodhead Publishing Ltd., Cambridge, 1994.

28. http://www.fibrolux.com/structuralprofiles

29. ASTM D 790-92, "Test Methods for Flexural Properties of Unreinforced and Reinforced Plastics and Electrical Insulation Materials", The 1995 Book of ASTM Standards, 8.01, p. 155-164.

30. Kumar, A. and Gupta, R. K., "Fundamentals of Polymers", McGraw-Hill, New York, 1998.

31. Kajorncheappunngam, S., "The Effects of Environmental Aging on the Durability of Glass/Epoxy Composites", Ph.D. Dissertation, Dept. of Chemical Eng., West Virginia University, 1999.

32. Dowdy, S. and Wearden, S., "Statistics for Research", $2^{\text {nd }}$ Ed., John Wiley \& Sons, New York, 1991.

33. Shekar, V., "Advancement in FRP Composites Using 3-D Stitched Fabrics and Enhancement in FRP Bridge Deck Component Properties", Master's Thesis, Dept. of Civil and Environ. Eng., West Virginia University, 2000. 
34. Barbero, E. J., "Introduction to Composite Materials Design", Taylor \& Francis, Philadelphia, 1999.

35. Shekar, V., West Virginia University, Personal Communication, 2000.

36. GangaRao, H., West Virginia University, Personal Communication, 2000.

37. Mallick, P. K., "Fiber-reinforced Composites, Materials, Manufacturing and Design", 2nd Ed., Marcel Dekker, New York, 1994. 


\section{APPENDIX A}

\section{BASIC DEFINITIONS AND PROPERTIES OF FIBERS AND RESINS}

\section{A.1 Introduction}

The use of composite materials in structural applications and in the construction industry has increased significantly in recent years. Fiber-reinforced composite materials offer mechanical properties that are comparable to or exceed many traditional materials. Properties of FRPs including low specific gravity, high strength to weight ratio, high modulus to weight ratio, and high fatigue damage tolerance make them desirable as structural materials. They are widely used in aircraft and space structures, automotive and sporting goods, and marine applications. The types of resins and fibers used in the composite industry are discussed further below [37].

\section{A.2 Fibers}

Fibers are the principal structural component in a fiber-reinforced composite material. They support the majority of the load acting on a composite structure. However, the properties of a composite laminate such as compressive strength and modulus, tensile strength and modulus, specific gravity, fatigue strength, electrical and thermal conductivities and cost are influenced not only by the amount of fiber, but also by the orientation of the fibers. The most commonly used fibers in composites are glass, carbon and aramid fibers, which are discussed further below.

\section{A.2.1 Glass fibers}

Glass fibers are the most common of all reinforcing fibers for polymeric matrix composites. They have high tensile strength, chemical resistance and insulating properties and are inexpensive compared to most other fibers. The disadvantages are their low tensile modulus, relatively high specific gravity, low fatigue resistance and sensitivity to abrasion with handling due to high hardness.

There are two commonly used types of glass fibers in the FRP industry: E-glass and S-glass. E-glass has the lowest cost of all commercially available reinforcing fibers and is therefore the most widely used. S-glass was originally developed for aircraft 
components and missile casings; it has the highest tensile strength among all the fibers in use.

The internal structure of glass fibers is a three dimensional network of silicon, oxygen and other atoms like boron and aluminum arranged in a random fashion. Thus glass fibers are amorphous and isotropic in nature.

\section{A.2.2 Carbon (graphite) fibers}

Carbon fibers have exceptionally high tensile strength to weight, tensile modulus to weight ratio, and very low linear thermal expansion, in addition to high fatigue strengths. In general, the low modulus fibers have lower specific gravity, lower cost, higher tensile and compressive strengths and higher tensile strength to failure than the high modulus fibers. The disadvantages of carbon fibers are low impact resistance and high electrical conductivity and high cost. They are used mostly in the aerospace industry where weight saving is considered more important than cost.

Carbon fibers contain a blend of amorphous carbon and graphitic carbon. Highly anisotropic physical and mechanical properties of the fiber result from the arrangement of carbon atoms in the planes, the forces between the planes, and the bonds between the atoms in a plane.

\section{A.2.3 Kevlar 49 fibers}

Kevlar 49 fibers are highly crystalline aramid or aromatic polyamide fibers that have the lowest specific gravity and the highest tensile strength-to-weight ratio among the current reinforcing fibers. They have low linear thermal expansion that is utilized in designing low thermal expansion composite printed circuit boards. The major disadvantages of aramid fiber-reinforced composites are their low compressive strengths and difficulty in cutting or machining. They are used in marine and aerospace applications where light weight, high tensile strength and resistance to impact damage are important.

The repeat unit in Kevlar fiber molecules contains an amide group and an aromatic ring, which gives it a higher chain stiffness or modulus and also better chemical and thermal stability over other commercial organic fibers, such as nylons. Table A-1 
lists the typical properties of the various fibers [27]. Table A-2 compares the fibers on the basis of cost, heat resistance, toughness, and impact resistance.

Table A-1. Fiber Properties [27]

\begin{tabular}{|l|r|r|r|r|}
\hline Properties & Kevlar & Carbon & S-2-Glass & E-Glass \\
\hline Density (mg/cc) & 1.45 & 1.73 & 2.46 & 2.56 \\
\hline Tensile strength (ksi) & 510 & 535 & 595 & 445 \\
\hline Strain to failure (\%) & 2.55 & 1.5 & 4.8 & 4.3 \\
\hline Tensile modulus (msi) & 18 & 33.9 & 12 & 11.7 \\
\hline Specific tensile strength $\left(\right.$ in $\left.^{*} 10^{6}\right)$ & 10 & 7.4 & 6.6 & 4.8 \\
\hline Specific tensile modulus $\left(\right.$ in $\left.^{6} 10^{6}\right)$ & 3.45 & 5.4 & 1.4 & 1.2 \\
\hline
\end{tabular}

Table A-2. Fiber Comparison [27]

\begin{tabular}{|l|l|l|l|l|}
\hline & Best & & & Worst \\
\hline Cost & E-Glass & S-2-Glass & Kevlar & Graphite \\
\hline Heat resistance & S-2-Glass & E-Glass & Graphite & Kevlar \\
\hline Toughness & Kevlar & S-2-Glass & E-Glass & Graphite \\
\hline Impact Resistance & Kevlar & S-2-Glass & E-Glass & Graphite \\
\hline
\end{tabular}

\section{A.3 Resins}

Though the resin supports a minor part of the tensile load acting on a composite structure, it has a major influence on inter-laminar shear and in-plane shear properties of the composite material. These properties are important design considerations for structures under bending and torsional loads. The resin matrix also influences compressive strength of the composite material by supporting fibers from buckling under compressive load. Further, physical and thermal characteristics of the matrix including viscosity, melting point and curing temperature influence defects in a composite and the ease of processing. For high performance composites in structural applications, 
thermoset polymers such as epoxies, vinyl esters and polyesters are most widely used. The following discussion presents a brief summary of these resins.

\section{A.3.1 Epoxies}

Epoxy resins have epoxide groups which are three-membered rings containing one oxygen atom and two carbon atoms. The starting materials for the preparation of an epoxy resin are low molecular weight organic liquids. Starting materials may be mixed with other ingredients such as diluents to reduce viscosity, and flexibilizers to modify the strength of the cured epoxy matrix.

An epoxy has many advantages over other thermoset resins:

- A wide variation of properties such as tensile strength, tensile modulus, specific gravity, coefficient of thermal expansion, etc. because a large number of starting materials, curing agents and modifiers are available.

- Low volumetric shrinkage and absence of volatile matters during cure.

- Excellent resistance to chemicals and solvents.

- Excellent adhesion to a wide variety of fillers, fibers and other substrates.

The principal disadvantages of epoxy resins are relatively high cost and long cure time. Epoxy resins are principally used in aerospace, aircraft and structural applications.

\section{A.3.2 Polyesters}

Unsaturated polyester resins that contain a number of $\mathrm{C}=\mathrm{C}$ bonds are the starting materials for polyester matrices. The resin is typically prepared by reacting maleic anhydride and ethylene glycol or propylene glycol. The resulting liquid is dissolved in a reactive diluent such as styrene that reduces viscosity and acts as a cross-linking agent. The amount and type of diluent influence the properties and processing characteristics of polyester resins.

The advantages of polyester resins are low viscosity, fast cure time and low cost; however, their properties are generally inferior than those of epoxies. The principal disadvantage of polyesters is their high volumetric shrinkage. Polyester resins are mostly used in automotive, marine, chemical and electrical applications. 


\section{A.3.3 Polyurethanes}

Polyurethanes are produced by the addition polymerization of isocyanate molecules with organic molecules like alcohols. The resulting linear polymer is later cross-linked. Depending on the degree of cross-linking, urethanes behave as thermoplastic polymers, thermosetting polymers or elastomers. Polyurethanes have extremely high abrasion resistance and tear strength, excellent shock absorption, resistance to many solvents and excellent resistance to oxygen aging. The major disadvantage is the limited life in high-humidity and high-temperature conditions. Polyurethanes are widely used in fibers, coatings, insulation, mattresses, foams for furniture, and other exterior applications.

\section{A.3.4 Vinyl esters}

Unsaturated vinyl ester resin is produced by the reaction of an unsaturated carboxylic acid and an epoxy resin. The resulting resin is dissolved in a styrene monomer for cross-linking at $\mathrm{C}=\mathrm{C}$ bonds at the ends of the molecule and also to reduce viscosity. Vinyl ester resins have excellent tensile strength and chemical resistance, low viscosity and low curing time. The principal disadvantage is high volumetric shrinkage, which is higher than that for parent epoxy resins. They are typically used in aerospace and other exterior applications.

Typical mechanical properties of the various resins are listed in Table A-3.

Table A-3. Resin Properties [27]

\begin{tabular}{|l|c|c|c|}
\hline Properties & Polyester & Vinyl Ester & Epoxy \\
\hline Specific gravity & $1.1-1.4$ & $1.12-1.32$ & $1.2-1.3$ \\
\hline Tensile strength (Mpa) & $34.5-103.5$ & $73-81$ & $55-130$ \\
\hline Tensile modulus (Gpa) & $2.1-3.45$ & $3-3.5$ & $2.75-4.10$ \\
\hline Cure Shrinkage (\%) & $5.0-12.0$ & $5.4-10.3$ & $1.0-5.0$ \\
\hline
\end{tabular}




\section{APPENDIX B STRESS FIXTURES AND TEFLONTM RESIN MOLD FABRICATION}

\section{B.1 Stress Fixtures}

The fixtures for the application of stress during environmental conditioning had to meet several requirements. One of these was chemical resistance of the material to the environment to assure the material itself did not affect the aging of the composite samples, such as by altering the $\mathrm{pH}$ of the aging medium. The material also had to be workable and strong. For these reasons, aluminum plates were used in conjunction with stainless steel hardware (see Figure B-1). The thickness of the top plate was 1/4" while that of the bottom plate was $1 \frac{12}{2}$ to assure adequate strength. Another issue was conforming to the guidelines set by the ASTM standard, D-790. A span of 6" with center loading had to be met. The plates were 8" square and were milled to provide a secure bond for the supporting and loading rods, which were also aluminum. Once the plates were milled, the rods were attached to the plate with epoxy and drilled. Three holes, $5 / 16$ " in diameter, were drilled per plate to provide access for stress application. The holes were drilled in the center of the plate at equal distances along a straight line. Two samples were stressed per bolt to provide accommodation for six samples per fixture. Belleville washers provided the stress due to a concave shape that when compressed applied a calibrated load. Two washers were used in opposing position to assure that a constant load was applied in case of deformation of the sample. 

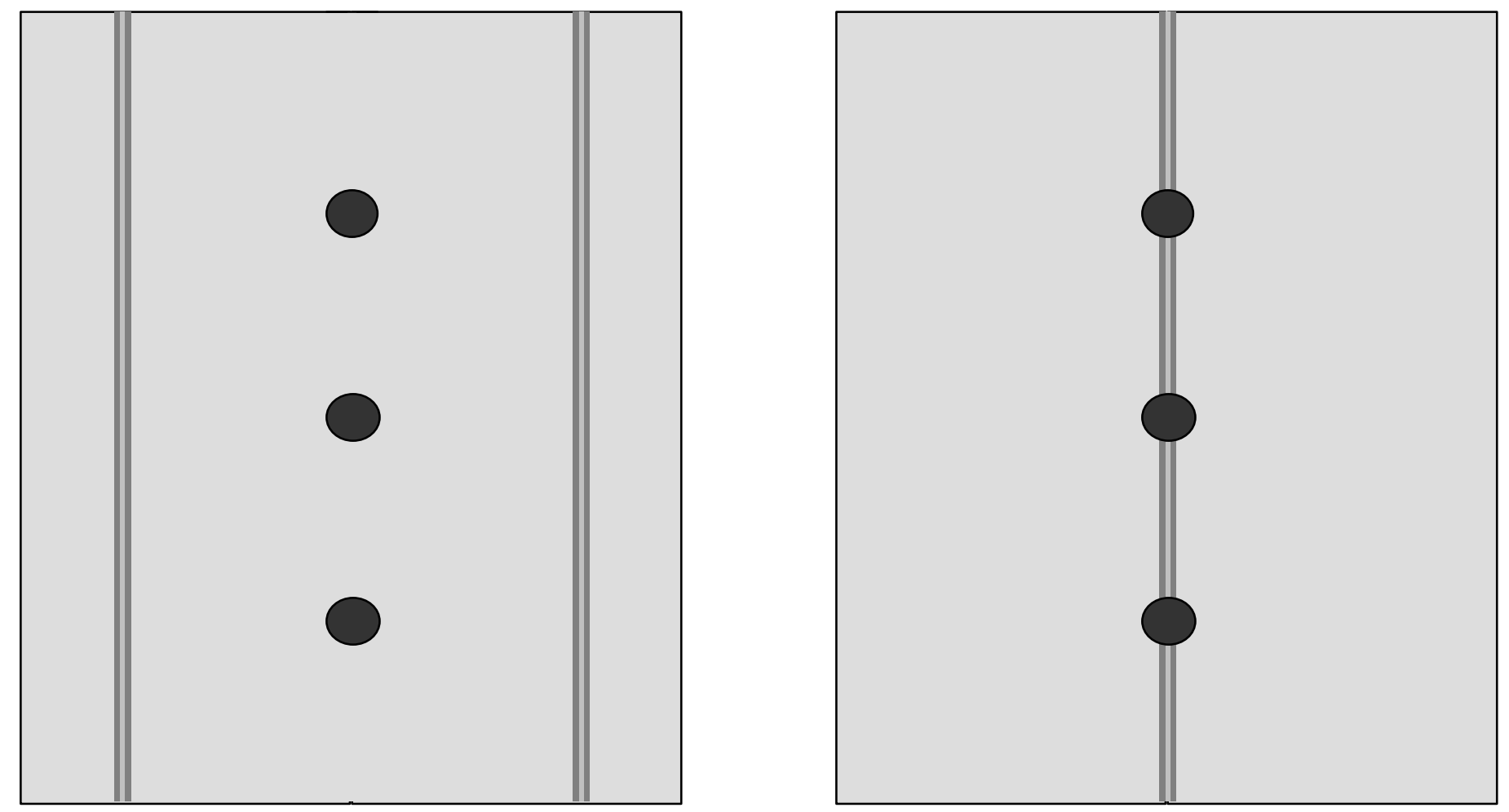

Top Plate

Figure B-1. Aluminum Stress Fixtures 


\section{B.2 Teflon® Resin Molds}

The molds for the manufacturing of neat resin samples had to meet several requirements. The material had to release the cast bar with ease after cure as well as be workable. For these reasons, Teflon ${ }^{\circledR}$ sheets were used. In order to maintain the liquid resin in the mold cavity, pressure was applied to the edge of the mold with clamps. Another issue was conforming to the size guidelines of the equipment used to analyze the samples. The top Teflon ${ }^{\circledR}$ sheet had a thickness of $1 / 16$ ", the thickness of the desired bar. The bottom Teflon ${ }^{\circledR}$ sheet had a thickness of $1 / 8$ " to provide a sturdy mold. The top plate was milled to provide 5 cavities per mold. A diagram of the mold is shown in Figure B-2 below.

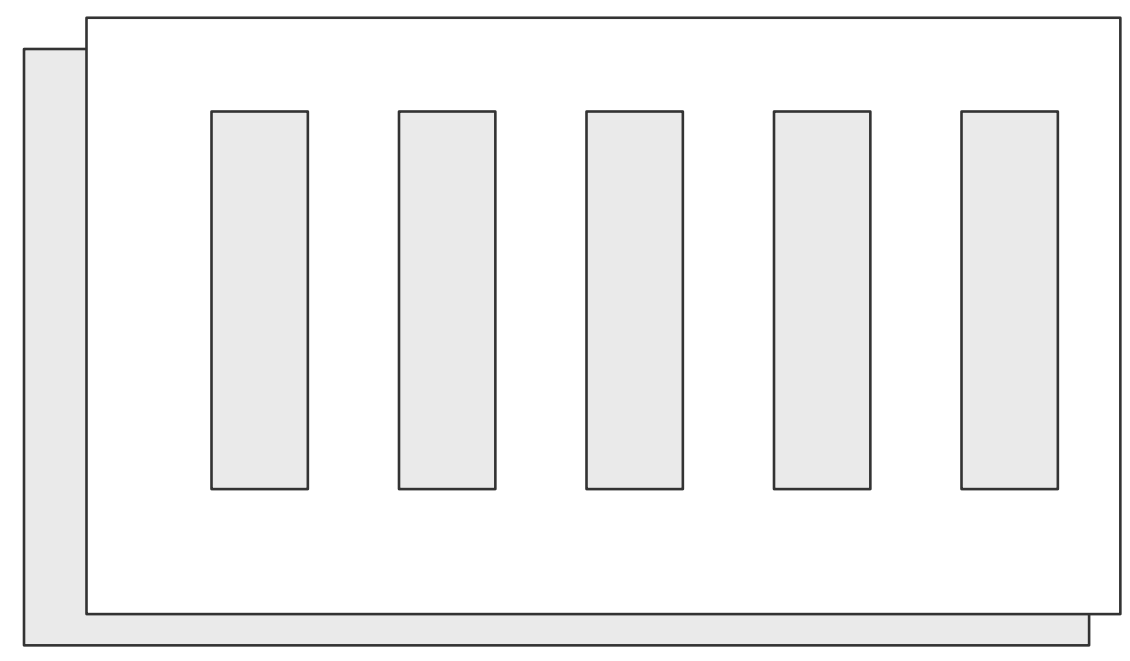

Figure B-2. Teflon ${ }^{\circledR}$ Molds 


\section{APPENDIX C}

\section{DERIVATION OF EQUATIONS USED IN DESTRUCTIVE TESTS}

\section{C.1 Bending Strength}

The derivation of the equations used to calculate the bending strength follow. The variables for the derivations are illustrated in schematic of a 3-point bending test and rectangular sample, Figures C-1 and C-2.

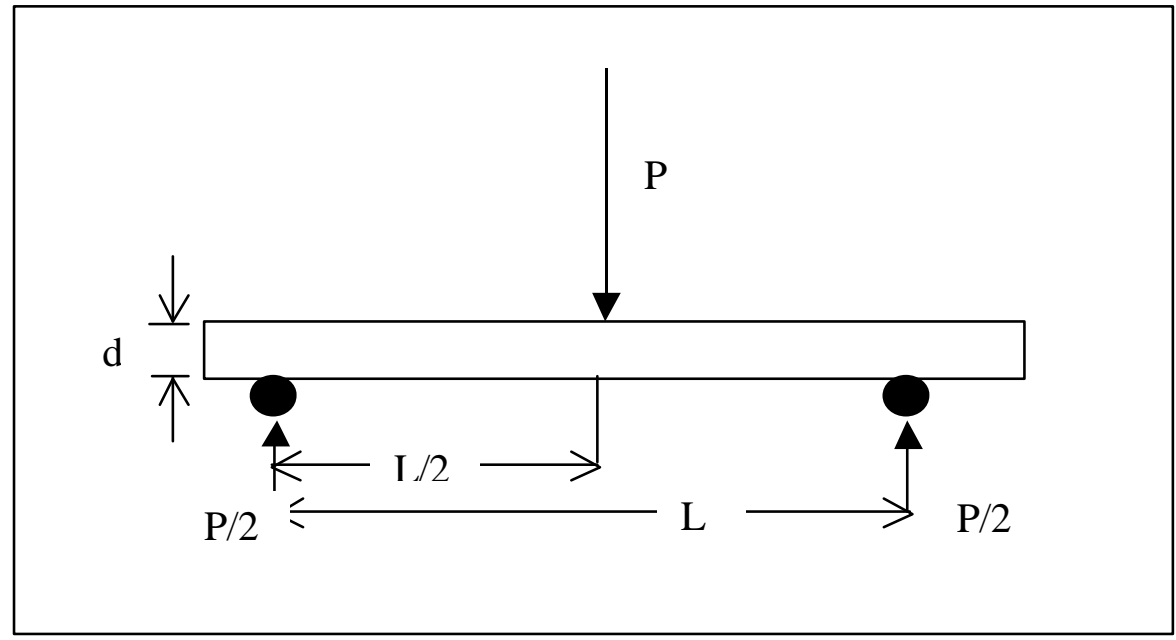

Figure C-1. Diagram of 3-point Bend Test

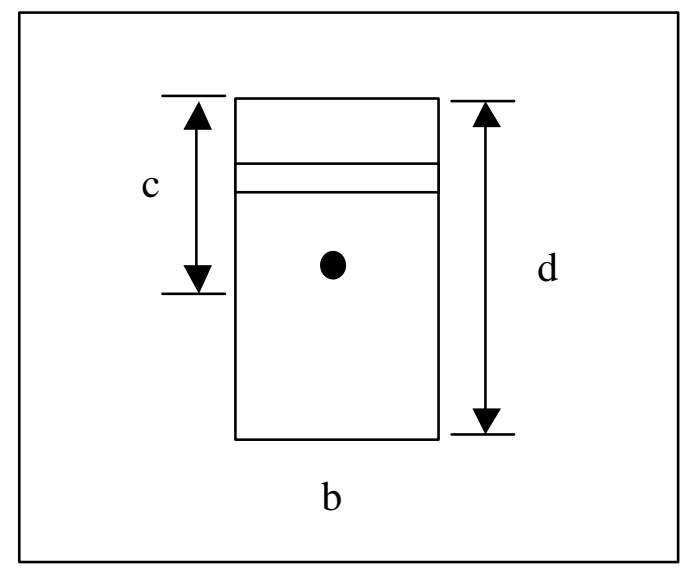

Figure C-2. Diagram of Rectangular Beam Sample 


$$
\begin{gathered}
S=\frac{3 P L}{2 b d^{2}} \\
E=\frac{m L^{3}}{4 b d^{3}}
\end{gathered}
$$

Where,

$$
\begin{aligned}
& \mathrm{S}=\text { stress in outer fibers at midspan, psi } \\
& \mathrm{P}=\text { load at given point, } \mathrm{lb}_{\mathrm{f}} \\
& \mathrm{L}=\text { support span, in } \\
& \mathrm{b}=\text { width of beam tested, in } \\
& \mathrm{d}=\text { depth of beam tested, in } \\
& \mathrm{E}_{\mathrm{B}}=\text { modulus of elasticity in bending, psi } \\
& \mathrm{m}=\text { slope of tangent to initial straight-line portion of load-deflection curve, } \mathrm{lb}_{\mathrm{f}} / \text { in } \\
& \mathrm{I}=\text { moment of Inertia for rectangular beam } \mathrm{x}^{\mathrm{n}} \\
& \mathrm{C}=\text { distance from center of } \mathrm{x}^{\mathrm{n}} \text { to the depth above where stress computed }
\end{aligned}
$$$$
I=\frac{1}{12} b d^{3} \text { for rectangular beam }
$$$$
\text { Moment @ } \mathrm{L}=\frac{P}{2}\left(\frac{L}{2}\right)=\frac{P L}{4}
$$$$
S=\frac{M C}{I}=\frac{P L}{4} *\left(\frac{d / 2}{b d^{3} / 12}\right)
$$$$
S=\frac{P L}{4} * \frac{d}{2} * \frac{12}{b d^{3}}
$$

$$
\therefore S=\frac{3 P L}{2 b d^{2}}
$$




\section{C.2 Bending Stiffness}

The derivation of the equations used to calculate the bending stiffness follow. The data obtained from a bending test would have the general appearance of Figure C- 3 .

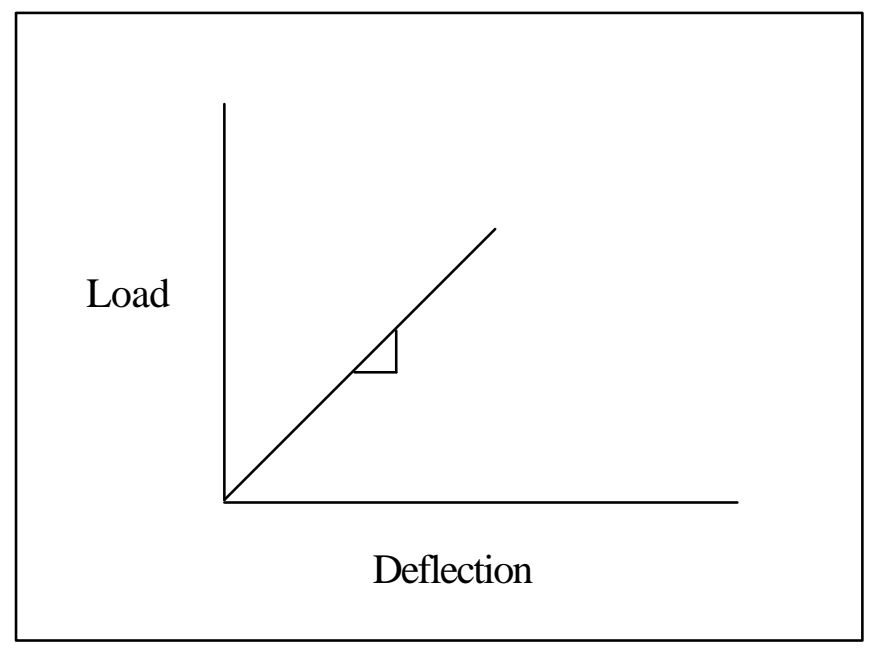

Figure C-3. Load-displacement diagram

For a simply supported beam with concentrated load in the middle, displacement is equivalent to deflection, $\Delta$.

$$
\begin{aligned}
& \Delta=\frac{P L^{3}}{48 E I} \\
& E=\left(\frac{P}{\Delta}\right) \frac{L^{3}}{48\left(\frac{b d^{3}}{12}\right)} \\
& \frac{P}{\Delta}=m \\
& \therefore E=\frac{m L^{3}}{4 b d^{3}}
\end{aligned}
$$




\section{APPENDIX D}

\section{SUMMARY OF EXPERIMENTS}

Details for the numbering and testing of samples are provided in Tables D-1 through D-4. These numbers correspond with the experimental data given in Tables D-5 through D-13.

Table D-1. Preparation and Testing via 3-pt. Bending

\begin{tabular}{|c|c|c|c|}
\hline Control & & & \\
\hline Resin & $1,2,3$ & & \\
\hline Pultrude $_{4}$ & $7,8,9$ & & \\
\hline Pultrude $8 \mathrm{~T} 1$ & $10,11,12$ & & \\
\hline Pultrude $8 \mathrm{~T} 2$ & $13,14,15$ & & \\
\hline Pultrude $_{12}$ & $16,17,18$ & & \\
\hline Total & 18 & & \\
\hline Water $25^{\circ} \mathrm{C}$ & $1000 \mathrm{hr}$ & $2000 \mathrm{hr}$ & $3000 \mathrm{hr}$ \\
\hline Resin (W1_1-9) & $1,2,3$ & $4,5,6$ & $7,8,9$ \\
\hline Pultruded $4\left(\mathrm{~W} 1 \_10-18\right)$ & $10,11,12$ & $13,14,15$ & $16,17,18$ \\
\hline Pultrude 8T1(W1_19-27) & $19,20,21$ & $22,23,24$ & $25,26,27$ \\
\hline Pultruded 8T2 (W1_28-36) & $28,29,30$ & $31,32,33$ & $34,35,36$ \\
\hline 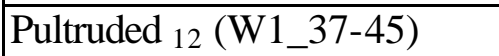 & $37,38,39$ & $40,41,42$ & $43,44,45$ \\
\hline Total & 15 & 15 & 15 \\
\hline Water $50^{\circ} \mathrm{C}$ & $1000 \mathrm{hr}$ & $2000 \mathrm{hr}$ & $3000 \mathrm{hr}$ \\
\hline Resin (W2_1-9) & $1,2,3$ & $4,5,6$ & $7,8,9$ \\
\hline Pultruded ${ }_{4}\left(\mathrm{~W} 2 \_10-18\right)$ & $10,11,12$ & $13,14,15$ & $16,17,18$ \\
\hline Pultrude 8T1 (W2_19-27) & $19,20,21$ & $22,23,24$ & $25,26,27$ \\
\hline Pultruded 8T2 (W2_28-36) & $28,29,30$ & $31,32,33$ & $34,35,36$ \\
\hline Pultruded 12 (W2_37-45) & $37,38,39$ & $40,41,42$ & $43,44,45$ \\
\hline Total & 15 & 15 & 15 \\
\hline Water $85^{\circ} \mathrm{C}$ & $1000 \mathrm{hr}$ & $2000 \mathrm{hr}$ & $3000 \mathrm{hr}$ \\
\hline Resin (W3_1-9) & $1,2,3$ & $4,5,6$ & $7,8,9$ \\
\hline Pultruded ${ }_{4}\left(\mathrm{~W} 3 \_10-18\right)$ & $10,11,12$ & $13,14,15$ & $16,17,18$ \\
\hline Pultrude 8T1 (W3_19-27) & $19,20,21$ & $22,23,24$ & $25,26,27$ \\
\hline Pultruded 8T2 (W3_28-36) & $28,29,30$ & $31,32,33$ & $34,35,36$ \\
\hline Pultruded 12 (W3_37-45) & $37,38,39$ & $40,41,42$ & $43,44,45$ \\
\hline Pultruded 12 sealed (W3_46-54) & $46,47,48$ & $49,50,51$ & $52,53,54$ \\
\hline Total & 18 & 18 & 18 \\
\hline
\end{tabular}


Table D-1. Preparation and Testing via 3-pt. Bending, continued

\begin{tabular}{|c|c|c|c|}
\hline Freeze-Thaw & 20 cycles & & \\
\hline $\operatorname{Resin}(\mathrm{F} 1-3)$ & $1,2,3$ & & \\
\hline Pultrude $_{4}$ (F7-9) & $7,8,9$ & & \\
\hline Pultrude $8 \mathrm{~T} 1$ (F10-12) & $10,11,12$ & & \\
\hline Pultrude $_{8 \mathrm{~T} 2}(\mathrm{~F} 13-15)$ & $13,14,15$ & & \\
\hline Pultrude $_{12}(\mathrm{~F} 16-18)$ & $16,17,18$ & & \\
\hline Pultrude $_{12 \text {-sealed }}(\mathrm{F} 19-21)$ & $19,20,21$ & & \\
\hline Total & 21 & & \\
\hline $40 \%$ Ult. Flexural Stress & $1000 \mathrm{hr}$ & $2000 \mathrm{hr}$ & $3000 \mathrm{hr}$ \\
\hline Pultruded $_{4}$ (S19-27) & $19,20,21$ & $22,23,24$ & $25,26,27$ \\
\hline Pultruded $_{8 \mathrm{~T} 1}(\mathrm{~S} 28-36)$ & $28,29,30$ & $31,32,33$ & $34,35,36$ \\
\hline Pultrude 8т2 (S37-45) & $37,38,39$ & $40,41,42$ & $43,44,45$ \\
\hline Pultruded $_{12}\left(\mathrm{~S}_{40} 46-54\right)$ & $46,47,48$ & $49,50,51$ & $52,53,54$ \\
\hline Total & 18 & 18 & 18 \\
\hline
\end{tabular}

Table D-2. Preparation and Testing via RMS-800 non-destructive tests

\begin{tabular}{|l|c|c|}
\hline & Resin & Composite \\
\hline Control & 2 & 2 \\
\hline Water $25 \mathrm{C}, 1000 \mathrm{hr}$ & 2 & 2 \\
\hline Water $50 \mathrm{C}, 1000 \mathrm{hr}$ & 2 & 2 \\
\hline Water $85 \mathrm{C}, 1000 \mathrm{hr}$ & 2 & 2 \\
\hline
\end{tabular}

Table D-3. Preparation and Testing via Optical Microscopy

\begin{tabular}{|l|l|}
\hline \multicolumn{1}{|c|}{ Optical } & \\
\hline Pultruded $_{4}$ (O 1-2) & 2 \\
\hline Pultruded $_{\text {8T1 }}$ (O 3-4) & 2 \\
\hline Pultrude $8 \mathrm{~T} 2$ (O 5-6) (O 7-8) & 2 \\
\hline Pultruded $_{12}$ (Otal & 2 \\
\hline Total & 8 \\
\hline
\end{tabular}


Table D-4. Preparation and Testing via Scanning Electron Microscopy

\begin{tabular}{|l|l|}
\hline \multicolumn{1}{|c|}{ SEM } & \\
\hline Pultruded $_{4}$ (M 1-2) & 2 \\
\hline Pultruded $_{\text {8T1 }}$ (M 3-4) & 2 \\
\hline Pultrude $_{\text {8T2 }}$ (M 5-6) & 2 \\
\hline Pultruded $_{12}$ (M 7-8) & 2 \\
\hline Total & 8 \\
\hline
\end{tabular}

Table D-5. Load, Slope, $\mathbf{R}^{2}$ from Bending Tests (Control)

\begin{tabular}{|c|c|c|c|c|}
\hline \multicolumn{2}{|c|}{ Control (no Aging) } & & & \\
\hline Sample & Line Speed & Load & Slope & Correlation Coeff. \\
\hline & (ipm) & (lb) & (lb/in) & $(---)$ \\
\hline \hline 1 & neat & & - & - \\
\hline 2 & neat & & - & - \\
\hline 3 & neat & & - & - \\
\hline Average & neat & & - & - \\
\hline 7 & 4 & 428 & 1026.0 & 0.9896 \\
\hline 8 & 4 & 434 & 997.2 & 0.9856 \\
\hline 9 & 4 & 412 & 871.1 & 0.9855 \\
\hline Average & $\mathbf{4}$ & $\mathbf{4 2 5}$ & $\mathbf{9 6 5}$ & - \\
\hline 10 & 8.1 & $282 * *$ & 767 & 0.9657 \\
\hline 11 & 8.1 & 452 & 744 & 0.9461 \\
\hline 12 & 8.1 & 471 & 1078 & 0.9926 \\
\hline Average & $\mathbf{8 . 1}$ & $\mathbf{4 6 1}$ & $\mathbf{8 6 3}$ & - \\
\hline 13 & 8.2 & 420 & 983 & 0.9841 \\
\hline 14 & 8.2 & 373 & 874 & 0.9863 \\
\hline 15 & 8.2 & 394 & 953 & 0.9924 \\
\hline Average & $\mathbf{8 . 2}$ & $\mathbf{3 9 6}$ & $\mathbf{9 3 7}$ & - \\
\hline 16 & 12 & 454 & 950 & 0.9795 \\
\hline 17 & 12 & 358 & 958 & 0.9787 \\
\hline 18 & 12 & 451 & 1061 & 0.9894 \\
\hline Average & $\mathbf{1 2}$ & $\mathbf{4 2 1}$ & $\mathbf{9 9 0}$ & - \\
\hline
\end{tabular}


Table D-6. Load, Slope, $\mathbf{R}^{2}$ from Bending Tests (Freeze-Thaw)

\begin{tabular}{|c|c|c|c|c|}
\hline \multicolumn{2}{|c|}{ Aged with Freeze-Thaw } & & \\
\hline Sample & Line Speed & Load & Slope & Correlation Coeff. \\
\hline \hline & (ipm) & (lb) & (lb/in) & $(---)$ \\
\hline 1 & neat & 39 & - & - \\
\hline 2 & neat & 52 & - & - \\
\hline 3 & neat & 46 & - & - \\
\hline Average & neat & $\mathbf{4 6}$ & - & - \\
\hline 7 & 4 & 347 & 822 & 0.9862 \\
\hline 8 & 4 & 504 & 977 & 0.9749 \\
\hline 9 & 4 & 490 & 866 & 0.9605 \\
\hline Average & $\mathbf{4}$ & $\mathbf{4 4 7}$ & $\mathbf{8 8 8}$ & - \\
\hline 10 & 8.1 & 458 & 1050 & 0.9805 \\
\hline 11 & 8.1 & 328 & 849 & 0.9693 \\
\hline 12 & 8.1 & 451 & 771 & 0.9290 \\
\hline Average & $\mathbf{8 . 1}$ & $\mathbf{4 1 2}$ & $\mathbf{8 9 0}$ & - \\
\hline 13 & 8.2 & 419 & 1074 & 0.9789 \\
\hline 14 & 8.2 & 257 & 777 & 0.9712 \\
\hline 15 & 8.2 & 433 & 798 & 0.9421 \\
\hline Average & $\mathbf{8 . 2}$ & $\mathbf{3 7 0}$ & $\mathbf{8 8 3}$ & - \\
\hline 16 & 12 & 514 & 834 & 0.9344 \\
\hline 17 & 12 & 368 & 864 & 0.9670 \\
\hline 18 & 12 & 501 & 1071 & 0.9840 \\
\hline Average & $\mathbf{1 2}$ & $\mathbf{4 6 1}$ & $\mathbf{9 2 3}$ & - \\
\hline 19 & 12 -sealed & 352 & 745.0 & 0.8747 \\
\hline 20 & 12 -sealed & 322 & 695.8 & 0.9777 \\
\hline 21 & 12 -sealed & 413 & 795.3 & 0.9494 \\
\hline Average & $\mathbf{1 2 - s e a l e d ~}$ & $\mathbf{3 6 2}$ & $\mathbf{7 4 5}$ & - \\
\hline & & & & \\
\hline
\end{tabular}

Table D-7. Load, Slope, $\mathbf{R}^{2}$ from Bending Tests $\left(25^{\circ} \mathrm{C}\right)$

\begin{tabular}{|c|c|c|c|c|c|}
\hline \multicolumn{2}{|c|}{ Aged at 25C } & & & & \\
\hline Sample & Line Speed & Time Aged & Load & Slope & $\begin{array}{l}\text { Correlation } \\
\text { Coeff }\end{array}$ \\
\hline \hline & (ipm) & (hours) & (lb) & (lb/in) & $(---)$ \\
\hline 1 & neat & 1000 & 54 & - & - \\
\hline 2 & neat & 1000 & 14 & - & - \\
\hline 3 & neat & 1000 & 13 & - & - \\
\hline Average & neat & $\mathbf{1 0 0 0}$ & $\mathbf{2 7}$ & - & - \\
\hline 4 & neat & 2000 & 22 & - & - \\
\hline 5 & neat & 2000 & 17 & - & - \\
\hline 6 & neat & 2000 & 9 & - & - \\
\hline
\end{tabular}




\begin{tabular}{|c|c|c|c|c|c|}
\hline Average & neat & 2000 & 16 & - & - \\
\hline 7 & neat & 3000 & 18 & - & - \\
\hline 8 & neat & 3000 & 20 & - & - \\
\hline 9 & neat & 3000 & 15 & - & - \\
\hline Average & neat & 3000 & 18 & - & - \\
\hline 10 & 4 & 1000 & 365 & 717 & 0.9785 \\
\hline 11 & 4 & 1000 & 439 & 927 & 0.9838 \\
\hline 12 & 4 & 1000 & 353 & 796 & 0.9653 \\
\hline Average & 4 & 1000 & 386 & 813 & - \\
\hline 13 & 4 & 2000 & 493 & 871 & 0.9784 \\
\hline 14 & 4 & 2000 & 384 & 993 & 0.9910 \\
\hline 15 & 4 & 2000 & 488 & 895 & 0.9678 \\
\hline Average & 4 & 2000 & 455 & 920 & - \\
\hline 16 & 4 & 3000 & 399 & 1128 & 0.9955 \\
\hline 17 & 4 & 3000 & 317 & 986 & 0.9879 \\
\hline 18 & 4 & 3000 & 379 & 954 & 0.9832 \\
\hline Average & 4 & 3000 & 365 & 1023 & - \\
\hline 19 & 8.1 & 1000 & 509 & 886 & 0.9673 \\
\hline 20 & 8.1 & 1000 & 386 & 917 & 0.9809 \\
\hline 21 & 8.1 & 1000 & 463 & 1028 & 0.9884 \\
\hline Average & 8.1 & 1000 & 453 & 944 & - \\
\hline 22 & 8.1 & 2000 & 574 & 1166 & 0.9935 \\
\hline 23 & 8.1 & 2000 & 473 & 1016 & 0.9873 \\
\hline 24 & 8.1 & 2000 & 446 & 1052 & 0.9857 \\
\hline Average & 8.1 & 2000 & 498 & 1078 & - \\
\hline 25 & 8.1 & 3000 & 250 & 923 & 0.9941 \\
\hline 26 & 8.1 & 3000 & 504 & 1139 & 0.9955 \\
\hline 27 & 8.1 & 3000 & 530 & 1019 & 0.9639 \\
\hline Average & 8.1 & 3000 & 428 & 1027 & - \\
\hline 28 & 8.2 & 1000 & 496 & 968 & 0.9905 \\
\hline 29 & 8.2 & 1000 & 407 & 962 & 0.9877 \\
\hline 30 & 8.2 & 1000 & 361 & 769 & 0.9926 \\
\hline Average & 8.2 & 1000 & 421 & 900 & - \\
\hline 31 & 8.2 & 2000 & 383 & 1028 & 0.9903 \\
\hline 32 & 8.2 & 2000 & 413 & 724 & 0.9780 \\
\hline 33 & 8.2 & 2000 & 452 & 933 & 0.9764 \\
\hline Average & 8.2 & 2000 & 416 & 895 & - \\
\hline 34 & 8.2 & 3000 & 459 & 1145 & 0.9991 \\
\hline 35 & 8.2 & 3000 & 434 & 1107 & 0.9914 \\
\hline 36 & 8.2 & 3000 & 370 & 1013 & 0.9905 \\
\hline Average & 8.2 & 3000 & 421 & 1088 & - \\
\hline 37 & 12 & 1000 & 412 & 772 & 0.9656 \\
\hline 38 & 12 & 1000 & 346 & 810 & 0.9757 \\
\hline 39 & 12 & 1000 & 500 & 846 & 0.9712 \\
\hline Average & 12 & 1000 & 419 & 810 & - \\
\hline
\end{tabular}




\begin{tabular}{|c|c|c|c|c|c|}
\hline 40 & 12 & 2000 & 403 & 992 & 0.9837 \\
\hline 41 & 12 & 2000 & 458 & 836 & 0.9557 \\
\hline 42 & 12 & 2000 & 376 & 999 & 0.9934 \\
\hline Average & $\mathbf{1 2}$ & $\mathbf{2 0 0 0}$ & $\mathbf{4 1 2}$ & $\mathbf{9 4 2}$ & - \\
\hline 43 & 12 & 3000 & 457 & 1122 & 0.9914 \\
\hline 44 & 12 & 3000 & 486 & 1194 & 0.9967 \\
\hline 45 & 12 & 3000 & 443 & 1010 & 0.9919 \\
\hline Average & $\mathbf{1 2}$ & $\mathbf{3 0 0 0}$ & $\mathbf{4 6 2}$ & $\mathbf{1 1 0 9}$ & - \\
\hline
\end{tabular}

Table D-8. Load, Slope, $\mathbf{R}^{2}$ from Bending Tests $\left(50^{\circ} \mathrm{C}\right)$

\begin{tabular}{|c|c|c|c|c|c|}
\hline \multicolumn{2}{|c|}{ Aged at 50C } & \multirow[b]{2}{*}{ Time Aged } & \multirow[b]{2}{*}{ Load } & \multirow[b]{2}{*}{ Slope } & \multirow[b]{2}{*}{$\begin{array}{l}\text { Correlation } \\
\text { Coeff } \\
\end{array}$} \\
\hline Sample & Line Speed & & & & \\
\hline & (ipm) & (hours) & (lb) & (lb/in) & (---) \\
\hline 1 & neat & 1000 & 48 & - & - \\
\hline 2 & neat & 1000 & 61 & - & - \\
\hline 3 & neat & 1000 & 61 & - & - \\
\hline Average & neat & 1000 & 57 & - & - \\
\hline 4 & neat & 2000 & 89 & - & - \\
\hline 5 & neat & 2000 & 64 & - & - \\
\hline 6 & neat & 2000 & 52 & - & - \\
\hline Average & neat & 2000 & 68 & - & - \\
\hline 7 & neat & 3000 & 59 & - & - \\
\hline 8 & neat & 3000 & 86 & - & - \\
\hline 9 & neat & 3000 & 72 & - & - \\
\hline Average & neat & 3000 & 72 & - & - \\
\hline 10 & 4 & 1000 & 399 & 936 & 0.9887 \\
\hline 11 & 4 & 1000 & 466 & 982 & 0.9823 \\
\hline 12 & 4 & 1000 & 391 & 858 & 0.9843 \\
\hline Average & 4 & 1000 & 419 & 925 & - \\
\hline 13 & 4 & 2000 & 377 & 911 & 0.9843 \\
\hline 14 & 4 & 2000 & 242 & 835 & 0.9882 \\
\hline 15 & 4 & 2000 & 368 & 991 & 0.9928 \\
\hline Average & 4 & 2000 & 329 & 912 & - \\
\hline 16 & 4 & 3000 & 308 & 974 & 0.9870 \\
\hline 17 & 4 & 3000 & 315 & 794 & 0.9497 \\
\hline 18 & 4 & 3000 & 331 & 957 & 0.9926 \\
\hline Average & 4 & 3000 & 318 & 908 & - \\
\hline 19 & 8.1 & 1000 & 471 & 1011 & 0.9754 \\
\hline 20 & 8.1 & 1000 & 405 & 1062 & 0.9853 \\
\hline 21 & 8.1 & 1000 & 421 & 1036 & 0.9767 \\
\hline Average & 8.1 & 1000 & 432 & 1036 & - \\
\hline 22 & 8.1 & 2000 & 419 & 1196 & 0.9970 \\
\hline
\end{tabular}




\begin{tabular}{|c|c|c|c|c|c|}
\hline 23 & 8.1 & 2000 & 369 & 1090 & 0.9890 \\
\hline 24 & 8.1 & 2000 & 303 & 1087 & 0.9955 \\
\hline Average & 8.1 & 2000 & 364 & 1124 & - \\
\hline 25 & 8.1 & 3000 & 434 & 1177 & 0.9951 \\
\hline 26 & 8.1 & 3000 & 428 & 1153 & 0.9915 \\
\hline 27 & 8.1 & 3000 & 398 & 1227 & 0.9909 \\
\hline Average & 8.1 & 3000 & 420 & 1186 & - \\
\hline 28 & 8.2 & 1000 & 389 & 995 & 0.9861 \\
\hline 29 & 8.2 & 1000 & 407 & 1050 & 0.9892 \\
\hline 30 & 8.2 & 1000 & 339 & 836 & 0.9773 \\
\hline Average & 8.2 & 1000 & 378 & 961 & - \\
\hline 31 & 8.2 & 2000 & 395 & 952 & 0.9831 \\
\hline 32 & 8.2 & 2000 & 379 & 921 & 0.9836 \\
\hline 33 & 8.2 & 2000 & 376 & 986 & 0.9872 \\
\hline Average & 8.2 & 2000 & 384 & 953 & - \\
\hline 34 & 8.2 & 3000 & 350 & 1037 & 0.9905 \\
\hline 35 & 8.2 & 3000 & 261 & 950 & 0.9922 \\
\hline 36 & 8.2 & 3000 & 387 & 1147 & 0.9890 \\
\hline Average & 8.2 & 3000 & 333 & 1045 & - \\
\hline 37 & 12 & 1000 & 440 & 1169 & 0.9909 \\
\hline 38 & 12 & 1000 & 423 & 999 & 0.9763 \\
\hline 39 & 12 & 1000 & 297 & 819 & 0.9795 \\
\hline Average & 12 & 1000 & 387 & 996 & - \\
\hline 40 & 12 & 2000 & 158 & 779 & 0.9993 \\
\hline 41 & 12 & 2000 & 183 & 791 & 0.9894 \\
\hline 42 & 12 & 2000 & 387 & 1004 & 0.9821 \\
\hline Average & 12 & 2000 & 243 & 858 & - \\
\hline 43 & 12 & 3000 & 265 & 1112 & 0.9994 \\
\hline 44 & 12 & 3000 & 346 & 1092 & 0.9890 \\
\hline 45 & 12 & 3000 & 362 & 1102 & 0.9881 \\
\hline Average & 12 & 3000 & 324 & 1102 & - \\
\hline
\end{tabular}

Table D-9. Load, Slope, $\mathbf{R}^{2}$ from Bending Tests $\left(85^{\circ} \mathrm{C}\right)$

\begin{tabular}{|c|c|c|c|c|c|}
\hline \multicolumn{2}{|c|}{ Aged at 85C } & & & & \\
\hline Sample & Line Speed & Time Aged & Load & Slope & $\begin{array}{l}\text { Correlation } \\
\text { Coeff. }\end{array}$ \\
\hline \hline & (ipm) & (hours) & (lb) & (lb/in) & (---) \\
\hline 1 & neat & 1000 & 28 & - & - \\
\hline 2 & neat & 1000 & 28 & - & - \\
\hline 3 & neat & 1000 & 22 & - & - \\
\hline Average & neat & $\mathbf{1 0 0 0}$ & $\mathbf{2 6}$ & - & - \\
\hline
\end{tabular}




\begin{tabular}{|c|c|c|c|c|c|}
\hline 4 & neat & 2000 & 34 & - & - \\
\hline 5 & neat & 2000 & 23 & - & - \\
\hline 6 & neat & 2000 & 30 & - & - \\
\hline Average & neat & 2000 & 29 & - & - \\
\hline 7 & neat & 3000 & 38 & - & - \\
\hline 8 & neat & 3000 & 15 & - & - \\
\hline 9 & neat & 3000 & 31 & - & - \\
\hline Average & neat & 3000 & 28 & - & - \\
\hline 10 & 4 & 1000 & 269 & 731 & 0.9736 \\
\hline 11 & 4 & 1000 & 300 & 912 & 0.9820 \\
\hline 12 & 4 & 1000 & 250 & 863 & 0.9834 \\
\hline Average & 4 & 1000 & 273 & 836 & - \\
\hline 13 & 4 & 2000 & 280 & 935 & 0.9819 \\
\hline 14 & 4 & 2000 & 244 & 1012 & 0.9893 \\
\hline 15 & 4 & 2000 & 210 & 953 & 0.9990 \\
\hline Average & 4 & 2000 & 245 & 967 & - \\
\hline 16 & 4 & 3000 & 231 & 1088 & 0.9937 \\
\hline 17 & 4 & 3000 & 226 & 991 & 0.9804 \\
\hline 18 & 4 & 3000 & 216 & 940 & 0.9886 \\
\hline Average & 4 & 3000 & 224 & 1006 & - \\
\hline 19 & 8.1 & 1000 & 318 & $1674 * *$ & 0.9852 \\
\hline 20 & 8.1 & 1000 & 254 & 877.0 & 0.9823 \\
\hline 21 & 8.1 & 1000 & 266 & 1027.0 & 0.9909 \\
\hline Average & 8.1 & 1000 & 279 & 952 & - \\
\hline 22 & 8.1 & 2000 & 208 & 925.3 & 0.9856 \\
\hline 23 & 8.1 & 2000 & 221 & 932.6 & 0.9844 \\
\hline 24 & 8.1 & 2000 & 266 & 901.8 & 0.9843 \\
\hline Average & 8.1 & 2000 & 231 & 920 & - \\
\hline 25 & 8.1 & 3000 & 187 & 967.1 & 0.9775 \\
\hline 26 & 8.1 & 3000 & 237 & 955.6 & 0.9835 \\
\hline 27 & 8.1 & 3000 & 237 & 885.3 & 0.9709 \\
\hline Average & 8.1 & 3000 & 220 & 936 & - \\
\hline 28 & 8.2 & 1000 & 231 & 880.1 & 0.9869 \\
\hline 29 & 8.2 & 1000 & 243 & 780.8 & 0.9389 \\
\hline 30 & 8.2 & 1000 & 181 & 809.0 & 0.9896 \\
\hline Average & 8.2 & 1000 & 218 & 823 & - \\
\hline 31 & 8.2 & 2000 & 228 & 846.2 & 0.9751 \\
\hline 32 & 8.2 & 2000 & 258 & 803.7 & 0.9502 \\
\hline 33 & 8.2 & 2000 & 285 & 942.5 & 0.9761 \\
\hline Average & 8.2 & 2000 & 257 & 864 & - \\
\hline 34 & 8.2 & 3000 & 240 & 1083.1 & 0.9902 \\
\hline 35 & 8.2 & 3000 & 186 & 842.0 & 0.9916 \\
\hline 36 & 8.2 & 3000 & 219 & 742.7 & 0.9939 \\
\hline Average & 8.2 & 3000 & 215 & 889 & - \\
\hline 37 & 12 & 1000 & 296 & 1083.1 & 0.9951 \\
\hline
\end{tabular}




\begin{tabular}{|c|c|c|c|c|c|}
\hline 38 & 12 & 1000 & 248 & 842.0 & 0.9905 \\
\hline 39 & 12 & 1000 & 247 & 742.7 & 0.9651 \\
\hline Average & $\mathbf{1 2}$ & $\mathbf{1 0 0 0}$ & $\mathbf{2 6 4}$ & $\mathbf{8 8 9}$ & - \\
\hline 40 & 12 & 2000 & 242 & 986.2 & 0.9850 \\
\hline 41 & 12 & 2000 & 224 & 854.8 & 0.9759 \\
\hline 42 & 12 & 2000 & 253 & 1064.7 & 0.9887 \\
\hline Average & $\mathbf{1 2}$ & $\mathbf{2 0 0 0}$ & $\mathbf{2 4 0}$ & $\mathbf{9 6 9}$ & - \\
\hline 43 & 12 & 3000 & 213 & 874.5 & 0.9661 \\
\hline 44 & 12 & 3000 & 231 & 895.6 & 0.9775 \\
\hline 45 & 12 & 3000 & 234 & 965.9 & 0.9892 \\
\hline Average & $\mathbf{1 2}$ & $\mathbf{3 0 0 0}$ & $\mathbf{2 2 6}$ & $\mathbf{9 1 2}$ & - \\
\hline 46 & 12 -sealed & 1000 & 152 & 622 & 0.9785 \\
\hline 47 & 12 -sealed & 1000 & 151 & 497 & 0.9622 \\
\hline 48 & 12 -sealed & 1000 & 269 & 862 & 0.9545 \\
\hline Average & $\mathbf{1 2}$-sealed & $\mathbf{1 0 0 0}$ & $\mathbf{1 9 1}$ & $\mathbf{6 6 1}$ & - \\
\hline 49 & 12 -sealed & 2000 & 282 & 809 & 0.9628 \\
\hline 50 & 12 -sealed & 2000 & 243 & 615 & 0.9417 \\
\hline 51 & 12 -sealed & 2000 & 268 & 560 & 0.9598 \\
\hline Average & $\mathbf{1 2}$-sealed & $\mathbf{2 0 0 0}$ & $\mathbf{2 6 5}$ & $\mathbf{6 6 1}$ & - \\
\hline 52 & 12 -sealed & 3000 & 237 & 820 & 0.9622 \\
\hline 53 & 12 -sealed & 3000 & 209 & 752 & 0.9187 \\
\hline 54 & 12 -sealed & 3000 & 235 & 1009 & 0.9939 \\
\hline Average & $\mathbf{1 2}$-sealed & $\mathbf{3 0 0 0}$ & $\mathbf{2 2 7}$ & $\mathbf{8 6 0}$ & - \\
\hline & & & & & \\
\hline
\end{tabular}

Table D-10. Load, Slope, $\mathbf{R}^{2}$ from Bending Tests (Stressed at $85^{\circ} \mathrm{C}$ )

\begin{tabular}{|c|c|c|c|c|c|}
\hline \multicolumn{2}{|c|}{ Aged at 85C with Stress Applied } & & & Slope & $\begin{array}{l}\text { Correlation } \\
\text { Coeff. }\end{array}$ \\
\hline Sample & Line Speed & Time Aged & Load & & (---) \\
\hline \hline & (ipm) & (hours) & (lb) & (lb/in) & 0.9822 \\
\hline 19 & 4 & 1000 & 235 & 777 & 0.9946 \\
\hline 20 & 4 & 1000 & 252 & 899 & 0.9912 \\
\hline 21 & 4 & 1000 & 260 & 899 & - \\
\hline Average & $\mathbf{4}$ & $\mathbf{1 0 0 0}$ & $\mathbf{2 4 9}$ & $\mathbf{8 5 8}$ & 0.9894 \\
\hline 22 & 4 & 2000 & 276 & 899 & 0.9886 \\
\hline 23 & 4 & 2000 & 270 & 909 & 0.9787 \\
\hline 24 & 4 & 2000 & 335 & 889 & - \\
\hline Average & $\mathbf{4}$ & $\mathbf{2 0 0 0}$ & $\mathbf{2 9 4}$ & $\mathbf{8 9 9}$ & 0.9836 \\
\hline 25 & 4 & 3000 & 281 & 854 & 0.9866 \\
\hline 26 & 4 & 3000 & 257 & 863 & - \\
\hline 27 & 4 & 3000 & 217 & 916 & 0.9888 \\
\hline Average & $\mathbf{4}$ & $\mathbf{3 0 0 0}$ & $\mathbf{2 5 2}$ & $\mathbf{8 7 8}$ & -9766 \\
\hline 28 & 8.1 & 1000 & 320 & 899 & 0.9717 \\
\hline 29 & 8.1 & 1000 & 269 & 801 & \\
\hline
\end{tabular}




\begin{tabular}{|c|c|c|c|c|c|}
\hline 30 & 8.1 & 1000 & 267 & 1003 & 0.9934 \\
\hline Average & 8.1 & 1000 & 285 & 901 & - \\
\hline 31 & 8.1 & 2000 & 304 & 1070 & 0.9920 \\
\hline 32 & 8.1 & 2000 & 263 & 820 & 0.9810 \\
\hline 33 & 8.1 & 2000 & 292 & 907 & 0.9882 \\
\hline Average & 8.1 & 2000 & 287 & 932 & - \\
\hline 34 & 8.1 & 3000 & 252 & 1023 & 0.9888 \\
\hline 35 & 8.1 & 3000 & 228 & 1001 & 0.9881 \\
\hline 36 & 8.1 & 3000 & 311 & 1054 & 0.9668 \\
\hline Average & 8.1 & 3000 & 264 & 1026 & - \\
\hline 37 & 8.2 & 1000 & 240 & 822 & 0.9894 \\
\hline 38 & 8.2 & 1000 & 316 & 664 & 0.9290 \\
\hline 39 & 8.2 & 1000 & 246 & 705 & 0.9625 \\
\hline Average & 8.2 & 1000 & 268 & 730 & - \\
\hline 40 & 8.2 & 2000 & 182 & 757 & 0.9928 \\
\hline 41 & 8.2 & 2000 & 223 & 788 & 0.9788 \\
\hline 42 & 8.2 & 2000 & 248 & 794 & 0.9882 \\
\hline Average & 8.2 & 2000 & 218 & 780 & - \\
\hline 43 & 8.2 & 3000 & 237 & 867 & 0.9850 \\
\hline 44 & 8.2 & 3000 & 231 & 884 & 0.9910 \\
\hline 45 & 8.2 & 3000 & 306 & 1016 & 0.9833 \\
\hline Average & 8.2 & 3000 & 258 & 922 & - \\
\hline 46 & 12 & 1000 & 291 & 986 & 0.9981 \\
\hline 47 & 12 & 1000 & 302 & 983 & 0.9885 \\
\hline 48 & 12 & 1000 & 207 & 925 & 0.9899 \\
\hline Average & 12 & 1000 & 267 & 965 & - \\
\hline 49 & 12 & 2000 & 236 & 951 & 0.9728 \\
\hline 50 & 12 & 2000 & 294 & 964 & 0.9725 \\
\hline 51 & 12 & 2000 & 221 & 1054 & 0.9912 \\
\hline Average & 12 & 2000 & 250 & 990 & - \\
\hline 52 & 12 & 3000 & 261 & 1097 & 0.9808 \\
\hline 53 & 12 & 3000 & 209 & 1004 & 0.9936 \\
\hline 54 & 12 & 3000 & 235 & 999 & 0.9914 \\
\hline Average & 12 & 3000 & 235 & 1033 & - \\
\hline
\end{tabular}


Table D-11. Strength Data from Bending Tests of Pultruded Samples

\begin{tabular}{|c|c|c|c|c|c|c|c|}
\hline & & \multicolumn{2}{|l|}{ lb } & \multicolumn{2}{|l|}{ psi } & \multicolumn{2}{|l|}{$10^{3} \mathrm{psi}$} \\
\hline & & Load, $\mathbf{P}$ & error & Strength & error & Strength & error \\
\hline \multicolumn{8}{|l|}{ CONTROL } \\
\hline & 4 & |424.7| & $\mid 7.8$ & |54360 & |999 & $\mid 54$ & $\overline{1}$ \\
\hline & $8 \mathrm{~T} 1$ & 461.5 & 13.9 & 59068 & 1781 & 59 & 2 \\
\hline & $8 \mathrm{~T} 2$ & 395.6 & 16.6 & 50633 & 2124 & 51 & 2 \\
\hline & 12 & 421.0 & 38.7 & 53890 & 4956 & 54 & 5 \\
\hline \multicolumn{8}{|l|}{ WATER 25} \\
\hline \multirow[t]{4}{*}{1000} & 4 & 385.8 & 33.1 & 49376 & 4242 & 49 & 4 \\
\hline & $8 \mathrm{~T} 1$ & 452.6 & 43.8 & |57933 & 5603 & 58 & 6 \\
\hline & $8 \mathrm{~T} 2$ & 421.1 & 48.5 & 53897 & 6203 & 54 & 6 \\
\hline & 12 & 419.3 & \begin{tabular}{|l|}
54.7 \\
\end{tabular} & 53672 & 6999 & 54 & 7 \\
\hline \multirow[t]{4}{*}{2000} & 4 & 455.1 & 43.4 & 58251 & 5549 & 58 & 6 \\
\hline & $8 \mathrm{~T} 1$ & 497.9 & 47.6 & 63728 & 6092 & 64 & 6 \\
\hline & $8 \mathrm{~T} 2$ & 415.7 & 24.5 & 53209 & 3142 & 53 & 3 \\
\hline & 12 & 412.5 & 29.5 & 52798 & 3780 & 53 & 4 \\
\hline \multirow[t]{4}{*}{3000} & 4 & 364.9 & 30.2 & 46705 & 3861 & 47 & 4 \\
\hline & $8 \mathrm{~T} 1$ & 428.0 & 109.7 & 54788 & 14038 & 55 & 14 \\
\hline & $8 \mathrm{~T} 2$ & 420.9 & 32.6 & 53879 & |4177 & 54 & 4 \\
\hline & 12 & 462.0 & 15.5 & 59141 & 1988 & 59 & 2 \\
\hline \multicolumn{8}{|l|}{ WATER 50} \\
\hline \multirow[t]{4}{*}{1000} & 4 & 418.7 & 29.0 & |53589 & 3706 & 54 & 4 \\
\hline & $8 \mathrm{~T} 1$ & 432.4 & 24.4 & 55348 & 3122 & 55 & 3 \\
\hline & $8 \mathrm{~T} 2$ & 378.1 & 24.9 & 48401 & 3191 & 48 & 3 \\
\hline & 12 & 386.8 & 55.1 & 49516 & 7051 & 50 & 7 \\
\hline \multirow[t]{4}{*}{2000} & 4 & 329.0 & 53.3 & 42114 & 6829 & 42 & 7 \\
\hline & $8 \mathrm{~T} 1$ & 363.7 & 41.2 & 46552 & 5276 & 47 & 5 \\
\hline & $8 \mathrm{~T} 2$ & 383.5 & 7.0 & 49088 & 902 & 49 & 1 \\
\hline & 12 & 242.8 & 88.8 & 31076 & 11367 & 31 & 11 \\
\hline \multirow[t]{4}{*}{3000} & 4 & 318.2 & $\begin{array}{l}8.4 \\
\end{array}$ & 40731 & \begin{tabular}{|l|}
1071 \\
\end{tabular} & 41 & 1 \\
\hline & $8 \mathrm{~T} 1$ & 420.1 & 13.6 & 53777 & 1747 & 54 & 2 \\
\hline & $8 \mathrm{~T} 2$ & 332.5 & 45.8 & 42563 & 5868 & 43 & 6 \\
\hline & 12 & 324.3 & 36.9 & 41509 & 4719 & 42 & 5 \\
\hline \multicolumn{8}{|l|}{ WATER 75} \\
\hline \multirow[t]{5}{*}{101000} & 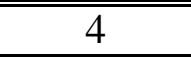 & 272.8 & \begin{tabular}{|c|}
17.9 \\
\end{tabular} & 34918 & 2294 & \begin{tabular}{|c|}
35 \\
\end{tabular} & $\overline{2}$ \\
\hline & $8 \mathrm{~T} 1$ & 279.3 & 23.9 & 35752 & 3061 & 36 & 3 \\
\hline & $8 \mathrm{~T} 2$ & 218.2 & 23.4 & 27935 & 2997 & 28 & 3 \\
\hline & 12 & 263.7 & 19.9 & 33749 & 2546 & 34 & 3 \\
\hline & $\begin{array}{c}12- \\
\text { SEALED }\end{array}$ & 190.6 & 48.1 & 24399 & 6154 & 24 & 6 \\
\hline \multirow[t]{2}{*}{2000} & resin & & & & & & \\
\hline & 4 & 245.0 & 24.8 & 31355 & 3170 & 31 & \\
\hline
\end{tabular}




\begin{tabular}{|r|c|r|r|r|r|r|r|r|}
\hline & $8 \mathrm{~T} 1$ & & 231.4 & 21.6 & 29618 & 2765 & 30 & 3 \\
\hline & $8 \mathrm{~T} 2$ & & 257.1 & 20.2 & 32903 & 2588 & 33 & 3 \\
\hline & 12 & & 239.6 & 10.4 & 30670 & 1326 & 31 & 1 \\
\hline & $12-$ & & 264.7 & 13.9 & 33884 & 1783 & 34 & 2 \\
\hline SEALED & & & & & & & \\
\hline 3000 & resin & & & & & & & \\
\hline & 4 & & 224.2 & 5.5 & 28701 & 708 & 29 & 1 \\
\hline & $8 T 1$ & & 219.9 & 20.4 & 28152 & 2617 & 28 & 3 \\
\hline & $8 T 2$ & & 214.9 & 19.2 & 27508 & 2453 & 28 & 2 \\
\hline & 12 & & 226.1 & 8.3 & 28941 & 1065 & 29 & 1 \\
\hline & $12-$ & & 227.1 & 11.3 & 29063 & 1444 & 29 & 1 \\
\hline SEALED & & & & & & & \\
\hline \hline STRESSED & & & & & & & & \\
\hline 500 & 4 & & 249.1 & 8.8 & 31887 & 1132 & 32 & 1 \\
\hline & $8 T 1$ & & 285.5 & 21.3 & 36539 & 2721 & 37 & 3 \\
\hline & $8 T 2$ & & 267.5 & 29.7 & 34240 & 3797 & 34 & 4 \\
\hline & 12 & & 267.0 & 36.7 & 34180 & 4701 & 34 & 5 \\
\hline 1000 & 4 & & 293.7 & 25.2 & 37597 & 3223 & 38 & 3 \\
\hline & $8 T 1$ & & 286.7 & 14.9 & 36696 & 1904 & 37 & 2 \\
\hline & $8 T 2$ & & 217.6 & 23.7 & 27857 & 3037 & 28 & 3 \\
\hline & 12 & & 250.4 & 27.0 & 32047 & 3452 & 32 & 3 \\
\hline 1500 & 4 & & 252.0 & 23.0 & 32253 & 2950 & 32 & 3 \\
\hline & $8 T 1$ & & 263.8 & 30.0 & 33761 & 3844 & 34 & 4 \\
\hline & $8 T 2$ & & 258.0 & 29.5 & 33027 & 3776 & 33 & 4 \\
\hline & 12 & & 235.2 & 18.2 & 30101 & 2330 & 30 & 2 \\
\hline \hline FREEZE- & & & & & & & & \\
\hline THAW & & & & & & & & 8 \\
\hline & 4 & & 446.7 & 61.5 & 57178 & 7876 & 57 & 8 \\
\hline & $8 T 1$ & & 412.2 & 51.9 & 52765 & 6639 & 53 & 7 \\
\hline & $8 T 2$ & & 369.6 & 69.1 & 47310 & 8840 & 47 & 9 \\
\hline & 12 & & 461.2 & 57.1 & 59029 & 7312 & 59 & 7 \\
\hline & $12-$ & & 362.3 & 32.9 & 46371 & 4214 & 46 & 4 \\
\hline & SEALED & & & & & & & \\
\hline
\end{tabular}


Table D-12. Modulus Data from Bending Tests of Pultruded Samples

\begin{tabular}{|c|c|c|c|c|c|c|c|}
\hline & & \multicolumn{2}{|l|}{ Ibf/in } & \multicolumn{2}{|l|}{ psi } & \multicolumn{2}{|l|}{$10^{3} \mathrm{psi}$} \\
\hline & & slope & error & $\mathbf{E}$ & error & $\mathbf{E}$ & error \\
\hline \multicolumn{8}{|l|}{ CONTROL } \\
\hline & resin & & & & & & \\
\hline & composite & & & & & & \\
\hline & 4 & 964.8 & 58.3 & 1975849 & 119310 & 1976 & 119 \\
\hline & $8 \mathrm{~T} 1$ & 863.1 & 131.8 & 1767677 & 269981 & 1768 & 270 \\
\hline & $8 \mathrm{~T} 2$ & 936.9 & 39.9 & 1918867 & 81729 & 1919 & 82 \\
\hline & 12 & 989.8 & 43.6 & 2027097 & 89357 & 2027 & 89 \\
\hline \multicolumn{8}{|l|}{ WATER 25} \\
\hline \multirow[t]{5}{*}{1000} & resin & & & & & & \\
\hline & 4 & 813.3 & 74.9 & 1665584 & 153332 & 1666 & 153 \\
\hline & $8 \mathrm{~T} 1$ & 943.9 & 52.9 & 1933018 & 108303 & 1933 & 108 \\
\hline & $8 \mathrm{~T} 2$ & 899.7 & 79.8 & 1842531 & 163429 & 1843 & 163 \\
\hline & 12 & 809.6 & 26.1 & 1658156 & 53515 & 1658 & 54 \\
\hline \multirow[t]{5}{*}{2000} & resin & & & & & & \\
\hline & 4 & 919.9 & 45.7 & 1883921 & 93647 & 1884 & 94 \\
\hline & $8 \mathrm{~T} 1$ & 1077.9 & 55.3 & 2207471 & 113181 & 2207 & 113 \\
\hline & $8 \mathrm{~T} 2$ & 894.9 & 109.8 & 1832755 & 224913 & 1833 & 225 \\
\hline & 12 & 942.2 & $\begin{array}{l}65.3 \\
\end{array}$ & 1929544 & 133683 & 1930 & 134 \\
\hline \multirow[t]{5}{*}{3000} & resin & & & & & & \\
\hline & 4 & 1022.8 & 65.4 & 2094701 & 134020 & 2095 & 134 \\
\hline & $8 \mathrm{~T} 1$ & 1026.9 & 76.7 & 2103112 & 157168 & 2103 & 157 \\
\hline & $8 \mathrm{~T} 2$ & 1088.3 & 47.9 & 2228770 & 98142 & 2229 & 98 \\
\hline & 12 & 1108.9 & 65.5 & 2271027 & 134111 & 2271 & 134 \\
\hline \multicolumn{8}{|l|}{ WATER 50} \\
\hline \multirow[t]{5}{*}{1000} & resin & & & & & & \\
\hline & 4 & 925.3 & 44.5 & 1895001 & 91166 & 1895 & 91 \\
\hline & $8 \mathrm{~T} 1$ & 1035.9 & 18.1 & 2121523 & 37076 & 2122 & 37 \\
\hline & $8 \mathrm{~T} 2$ & 960.5 & 78.8 & 1967200 & 161369 & 1967 & 161 \\
\hline & 12 & 995.6 & 123.9 & 2039037 & 253831 & 2039 & 254 \\
\hline \multirow[t]{5}{*}{2000} & resin & & & & & & \\
\hline & 4 & 912.2 & 55.4 & 1868124 & 113363 & 1868 & 113 \\
\hline & $8 \mathrm{~T} 1$ & 1124.5 & 44.1 & 2302908 & 90231 & 2303 & 90 \\
\hline & $8 \mathrm{~T} 2$ & 952.8 & 23.1 & 1951239 & 47293 & 1951 & 47 \\
\hline & 12 & 858.2 & 89.4 & 1757539 & 183079 & 1758 & 183 \\
\hline \multirow[t]{5}{*}{3000} & resin & & & & & & \\
\hline & 4 & 908.4 & 70.4 & 1860499 & 144146 & 1860 & 144 \\
\hline & $8 \mathrm{~T} 1$ & 1185.5 & 26.6 & 2427904 & 54469 & 2428 & 54 \\
\hline & $8 \mathrm{~T} 2$ & 1044.7 & 69.8 & 2139614 & 142973 & 2140 & 143 \\
\hline & 12 & 1102.1 & 7.1 & 2257169 & 14483 & 2257 & 14 \\
\hline \multicolumn{8}{|l|}{ WATER 75} \\
\hline 1000 & resin & & & & & & \\
\hline
\end{tabular}




\begin{tabular}{|c|c|c|c|c|c|c|c|}
\hline & 44 & 835.7 & 66.1 & 1711486 & 135475 & 1711 & 135 \\
\hline & $8 \mathrm{~T} 1$ & 952.0 & 106.1 & 1949665 & 217267 & 1950 & 217 \\
\hline & $8 \mathrm{~T} 2$ & 823.3 & 36.2 & 1686153 & 74062 & 1686 & 74 \\
\hline & 12 & 889.3 & 123.8 & 1821218 & 253521 & 1821 & 254 \\
\hline & $\begin{array}{c}12- \\
\text { SEALED }\end{array}$ & 660.5 & 131.1 & 1352786 & 268592 & 1353 & 269 \\
\hline \multirow[t]{6}{*}{2000} & resin & & & & & & \\
\hline & 4 & 966.9 & 28.4 & 1980170 & 58081 & 1980 & 58 \\
\hline & $8 \mathrm{~T} 1$ & 919.9 & 11.4 & 1883928 & 23339 & 1884 & 23 \\
\hline & $8 \mathrm{~T} 2$ & 864.1 & 50.3 & 1769704 & 103045 & 1770 & 103 \\
\hline & 12 & 968.6 & 75.0 & 1983597 & 153597 & 1984 & 154 \\
\hline & $\begin{array}{c}12- \\
\text { SEALED }\end{array}$ & 661.5 & 92.3 & 1354738 & 189060 & 1355 & 189 \\
\hline \multirow[t]{6}{*}{3000} & resin & & & & & & \\
\hline & 4 & 1006.1 & 53.1 & 2060547 & 108809 & 2061 & 109 \\
\hline & $8 \mathrm{~T} 1$ & 936.0 & 31.3 & 1916908 & \begin{tabular}{|l|}
64153 \\
\end{tabular} & 1917 & 64 \\
\hline & $8 \mathrm{~T} 2$ & 889.3 & 123.8 & 1821218 & 253521 & 1821 & 254 \\
\hline & 12 & 912.0 & 33.8 & 1867756 & $\begin{array}{l}69254 \\
\end{array}$ & 1868 & 69 \\
\hline & $\begin{array}{c}12- \\
\text { SEALED }\end{array}$ & 860.0 & 94.3 & 1761205 & 193034 & 1761 & 193 \\
\hline \multicolumn{8}{|l|}{ STRESSED } \\
\hline & 4 & 858.4 & 49.7 & 1757928 & 101690 & 1758 & 102 \\
\hline & $8 \mathrm{~T} 1$ & 901.1 & 71.4 & 1845528 & 146216 & 1846 & 146 \\
\hline & $8 \mathrm{~T} 2$ & 730.4 & 58.2 & 1495825 & 119113 & 1496 & 119 \\
\hline & 12 & 964.7 & 24.2 & 1975719 & 49469 & 1976 & 49 \\
\hline \multirow[t]{4}{*}{1000} & 4 & 898.8 & \begin{tabular}{ll|}
6.9 \\
\end{tabular} & 1840647 & 14165 & 1841 & 14 \\
\hline & $8 \mathrm{~T} 1$ & 932.3 & 89.7 & 1909275 & 183645 & 1909 & 184 \\
\hline & $8 \mathrm{~T} 2$ & 779.5 & 14.2 & 1596443 & 29171 & 1596 & 29 \\
\hline & 12 & 989.7 & 39.7 & 2026831 & 81404 & 2027 & 81 \\
\hline \multirow[t]{4}{*}{1500} & 4 & 877.6 & 24.0 & 1797297 & 49104 & 1797 & 49 \\
\hline & $8 \mathrm{~T} 1$ & 1026.2 & 18.7 & 2101589 & 38196 & 2102 & 38 \\
\hline & $8 \mathrm{~T} 2$ & 922.1 & 57.8 & 1888358 & 118332 & 1888 & 118 \\
\hline & 12 & 1033.3 & 39.2 & 2116192 & 80243 & 2116 & 80 \\
\hline \multicolumn{8}{|l|}{$\begin{array}{c}\text { FREEZE- } \\
\text { THAW }\end{array}$} \\
\hline & resin & & & & & & \\
\hline & composite & & & & & & \\
\hline & 4 & 888.4 & 56.6 & 1819368 & 115821 & 1819 & 116 \\
\hline & $8 \mathrm{~T} 1$ & 890.2 & 101.9 & 1823082 & 208594 & 1823 & 209 \\
\hline & $8 \mathrm{~T} 2$ & 882.9 & 117.0 & 1808145 & 239642 & 1808 & 240 \\
\hline & 12 & 923.4 & 91.2 & 1891055 & 186801 & 1891 & 187 \\
\hline & $\begin{array}{c}12- \\
\text { SEALED }\end{array}$ & 745.5 & 49.7 & 1526866 & 101806 & 1527 & 102 \\
\hline
\end{tabular}


Table D-13. Strength Data from Bending Tests of Neat Resin

\begin{tabular}{|c|c|r|r|r|r|r|r|r|}
\hline & & & \multicolumn{1}{|c|}{ lb } & \multicolumn{1}{c|}{ psi } & \multicolumn{1}{|c|}{$\mathbf{1 0}^{3}$ psi } \\
\hline & & & Load, P & error & Strength & error & Strength & error \\
\hline \hline CONTROL & & & & & & & & \\
\hline \hline & resin & & 71.6 & 16.0 & 13746 & 3081 & 14 & 3 \\
\hline & resin repeat & & 47.2 & 4.1 & 9053 & 792 & 9 & 1 \\
\hline WATER 25 & & & & & & & & \\
\hline 1000 & resin & & 27.1 & 16.7 & 5206 & 3214 & 5 & 3 \\
\hline 2000 & resin & & 16.2 & 4.9 & 3105 & 938 & 3 & 1 \\
\hline 3000 & resin & & 17.2 & 2.7 & 3307 & 518 & 3 & 1 \\
\hline WATER 50 & & & & & & & & \\
\hline 1000 & resin & & 56.8 & 5.6 & 10904 & 1070 & 11 & 1 \\
\hline 2000 & resin & & 68.5 & 13.0 & 13146 & 2498 & 13 & 2 \\
\hline 3000 & resin & & 72.3 & 13.6 & 13881 & 2609 & 14 & 3 \\
\hline WATER 75 & & & & & & & & \\
\hline 1000 & resin & & 26.2 & 2.6 & 5021 & 500 & 5 & 1 \\
\hline 2000 & resin & & 29.0 & 3.8 & 5568 & 729 & 6 & 1 \\
\hline 3000 & resin & & 28.0 & 8.3 & 5381 & 1596 & 5 & 2 \\
\hline \hline FREEZE- & & & & & & & & \\
THAW & & & & & & & & \\
\hline & resin & & 45.5 & 4.6 & 8745 & 888 & 9 & 1 \\
\hline
\end{tabular}




\section{APPENDIX E PREDICTION OF COMPOSITE PROPERTIES [33]}

The pultruded composites for this research have the fiber architecture shown in Figure E-1.

\begin{tabular}{|c|}
\hline CSM \\
\hline Fabric $[90 / 45 /-45]$ \\
\hline 62 Yield of 6.0 rov/in \\
\hline 3 Layers of Fabric [90/45/-45] \\
\hline 62 Yield of 6.0 rov/in \\
\hline Fabric [90/45/-45] \\
\hline CSM \\
\hline
\end{tabular}

Figure E-1. Fiber Architecture of Pultruded Composites

The composite with fabrics is analyzed using micromechanics and macromechanics principles. Classical Lamination Theory (CLT) is used to evaluate axial and bending stiffness of the composite laminate. The fabric in the composite is considered to be an equivalent isotropic material. (Refer to step 6). The following equations are used for computing the axial and bending stiffness of the composite laminate.

\section{Step 1: Compute Material Properties}

The material properties include modulus of elasticity, shear modulus and density of the fiber and the matrix. The manufacturer usually gives these properties. From the above properties, one can compute Poisson's ratio for fiber and matrix. In the current problem, the material properties are considered as follows:

Modulus of elasticity of fiber $=\mathbf{E}_{\mathbf{f}} \quad(\mathrm{psi})=1.05 \mathrm{E}+07$ 
Modulus of elasticity of Matrix $=\mathbf{E}_{\mathbf{m}}(\mathrm{psi})=7.34 \mathrm{e}+05$

Shear modulus of fiber $=\mathbf{G}_{\mathbf{f}}(\mathrm{psi})=4.18 \mathrm{e}+06$

Poisson' s ratio of fiber $=\mathrm{v}_{f}=\frac{E_{f}}{2 G_{f}}-1=0.26 \quad$ Poisson's ratio of matrix $\quad=\mathrm{v}_{\mathrm{m}}=\frac{E_{m}}{2 G_{m}}-1=0.55$

\section{Step 2: Compute Fiber Volume Fraction}

Fiber volume fraction $\left(\mathbf{V}_{\mathbf{f}}\right)$ for each lamina present in the composite is calculated. The composite consists of NX-1010 fabric, which was considered as a CSM (Chopped Strand Mat), rovings and TH-4000 fabric. The fabric has three layers that result in 40 $\mathrm{oz} / \mathrm{yd}^{2}$. Each of $40 \mathrm{oz} / \mathrm{yd}^{2}$ mat contains $16 \mathrm{oz} / \mathrm{yd}^{2}$ at $90^{\circ}, 12 \mathrm{oz} / \mathrm{yd}^{2}$ at $45^{\circ}$, and $12 \mathrm{oz} / \mathrm{yd}^{2}$ at $-45^{0}$.

\section{For Rovings}

$$
\mathrm{v}_{\mathrm{f}}=\frac{n \pi D^{2}}{4 b t}
$$

Where,

$$
\begin{aligned}
& \mathrm{n}=\text { number of rovings } \\
& \mathrm{b}=\text { width of laminae (in) } \\
& \mathrm{t}=\text { thickness of roving layer (in) } \\
& \mathrm{D}=\text { Diameter of fiber }=\sqrt{\frac{1}{\rho_{f} \mathrm{Y} 9 \pi}} \\
& \tilde{n}_{f} \text { is density of fiber }\left(\mathrm{lb} / \mathrm{in}^{3}\right) \\
& \mathrm{Y}=\text { yield }
\end{aligned}
$$

\section{For CSM and Fabric}

$$
v_{f}=\frac{W_{f}}{\rho_{f} L_{v}}
$$

Where,

$$
\begin{aligned}
& \mathrm{W}_{\mathrm{f}}=\text { Weight of fiber }(\mathrm{lb}) \\
& \mathrm{L}_{\mathrm{v}}=\text { Volume of } 1 \mathrm{ft} \times 1 \mathrm{ft} \text { of lamina }
\end{aligned}
$$




\section{Step 3: Evaluate Lamina Properties}

Stiffness properties of laminae are computed by the rule of mixtures, which relates the properties of the fabric and the matrix to the unit composite ply.

\section{For Fabric and Rovings}

Longitudinal Modulus (psi): $E_{11}=E_{f} V_{f}+E_{m}\left(1-V_{f}\right)$

Poisson's Ratio:

$$
\mathrm{v}_{12}=\mathrm{v}_{f} V_{f}+\mathrm{v}_{m}\left(1-V_{m}\right) \quad \mathrm{v}_{21}=\frac{\mathbf{v}_{12} E_{22}}{E_{11}}
$$

Transverse Modulus (psi): $\quad E_{22}=\frac{E_{f} E_{m}}{E_{f} V_{m}+E_{m} V_{f}}$

Shear Modulus (psi):

$$
G_{12}=\frac{G_{f} G_{m}}{G_{f} V_{m}+G_{m} V_{f}}
$$

\section{For CSM (Chopped Strand Mat)}

Elastic Modulus of CSM (psi): $\quad E_{\text {ran }}=\frac{3}{8} E_{11}+\frac{5}{8} E_{22}$

Shear Modulus of CSM (psi): $\quad G_{r a n}=\frac{1}{8} E_{11}+\frac{1}{4} E_{22}$

Poisson's Ratio of CSM (psi): $\quad \mathrm{v}_{\text {ran }}=\left(\frac{E_{\text {ran }}}{2 G_{\text {ran }}}\right)-1$

\section{Step 4: Calculate In-Plane Reduced Stiffness Matrix (Q)}

\section{For Rovings and Fabric}

$$
\begin{gathered}
Q_{11}=\frac{E_{11}}{\delta} \\
Q_{12}=\frac{\mathrm{v}_{12} E_{22}}{\delta} \\
Q_{22}=\frac{E_{22}}{\delta}
\end{gathered}
$$




$$
\begin{gathered}
Q_{66}=G_{12} \\
\boldsymbol{\delta}=1-\boldsymbol{v}_{12} \boldsymbol{v}_{21}
\end{gathered}
$$

\section{For CSM (Chopped Strand Mat)}

$$
\begin{aligned}
& Q_{11}=Q_{22}=\frac{E_{r a n}}{\delta} \\
& Q_{12}=\frac{\boldsymbol{v}_{r a n} E_{r a n}}{\delta} \\
& Q_{66}=G_{r a n}
\end{aligned}
$$

\section{Step 5: Calculate Transformed Reduced Stiffness Matrix $[\bar{Q}]$}

$$
\begin{aligned}
& \bar{Q}_{11}=Q_{11} \cos ^{4} \boldsymbol{\theta}+2\left(Q_{12}+2 Q_{66}\right) \sin ^{2} \boldsymbol{\theta} \cos ^{2} \boldsymbol{\theta}+Q_{22} \sin ^{4} \boldsymbol{\theta} \\
& \bar{Q}_{12}=\left(Q_{11}+Q_{22}-4 Q_{66}\right) \sin ^{2} \boldsymbol{\theta} \cos ^{2} \boldsymbol{\theta}+Q_{12}\left(\sin ^{4} \boldsymbol{\theta}+\cos ^{4} \boldsymbol{\theta}\right) \\
& \bar{Q}_{22}=Q_{11} \sin ^{4} \boldsymbol{\theta}+2\left(Q_{12}+2 Q_{66}\right) \sin ^{2} \boldsymbol{\theta} \cos ^{2} \boldsymbol{\theta}+Q_{22} \cos ^{4} \boldsymbol{\theta} \\
& \bar{Q}_{16}=\left(Q_{11}-Q_{12}-2 Q_{66}\right) \sin \boldsymbol{\theta} \cos ^{3} \boldsymbol{\theta}+\left(Q_{12}-Q_{22}+2 Q_{66}\right) \sin ^{3} \boldsymbol{\theta} \cos \boldsymbol{\theta} \\
& \bar{Q}_{26}=\left(Q_{11}-Q_{12}-2 Q_{66}\right) \sin \boldsymbol{\theta}^{3} \cos \boldsymbol{\theta}+\left(Q_{12}-Q_{22}+2 Q_{66}\right) \sin \boldsymbol{\theta} \cos ^{3} \boldsymbol{\theta} \\
& \bar{Q}_{66}=\left(Q_{11}+Q_{22}-2 Q_{12}-2 Q_{66}\right) \sin ^{2} \boldsymbol{\theta} \cos ^{2} \boldsymbol{\theta}+Q_{66}\left(\sin { }^{4} \boldsymbol{\theta}+\cos ^{4} \boldsymbol{\theta}\right)
\end{aligned}
$$

For CSM and rovings the $[\bar{Q}]$ matrix is the same as the $[\mathrm{Q}]$ matrix. The fabric (40 oz) consists of fibers oriented in $45^{\circ}, 90^{\circ}$ and $-45^{\circ}$. Therefore transformed reduced stiffness matrices are to be found for the fibers oriented in $45^{\circ}, 90^{\circ}$ and $-45^{0}$. 


\section{Step 6: Compute the Final $[\bar{Q}]$ Matrix}

Here the final $[\bar{Q}]$ remains the same for CSM and rovings as computed in Step 5. The fabric (ie $40 \mathrm{oz} / \mathrm{yd}^{2}$ ) has $12 \mathrm{oz} / \mathrm{yd}^{2}$ at $45^{\circ}, 16 \mathrm{oz} / \mathrm{yd}^{2}$ at $90^{\circ}$, and $12 \mathrm{oz} / \mathrm{yd}^{2}$ at $-45^{\circ}$. As we already know the $[\bar{Q}]$ for the $45^{\circ}, 90^{\circ}$, and $-45^{0}$ separately as computed in Step 5 , for the fabric, the contribution of each fiber orientation to the final $[\bar{Q}]$ is proportional to its weight. Therefore final $[\bar{Q}]$ matrix for stitched fabric will be:

$[\bar{Q}]_{\text {stitched fabric }}=1 / 4\left\{[\bar{Q}]_{45}+[\bar{Q}]_{90}+[\bar{Q}]_{-45}\right\}$

Here the fabric is no longer treated as an orthotropic layer, but rather it is considered as an isotropic layer.

\section{Step 7: Compute the Stiffness Matrix}

Laminate properties can be computed using extensional stiffness matrix [A], coupling stiffness matrix [B], and bending stiffness matrix [D]. The $[A]$ matrix, $[B]$ matrix, and [D] matrix are developed by incorporating the lamina properties into the lamination theory. The stiffnesses are calculated as follows:

$$
\begin{gathered}
A_{i j}=\sum_{n=1}^{N}\left(Q_{i j}\right) \cdot t_{n} \\
D_{i j}=\sum_{n=1}^{N}\left(Q_{i j}\right) \cdot\left(t_{n} \cdot z_{n}^{2}+\frac{t_{n}^{3}}{12}\right) \\
B_{i j}=\sum_{n=1}^{N}\left(Q_{i j}\right){ }_{n} \cdot t_{n} \cdot z_{n}
\end{gathered}
$$

\section{Step 8: Compute Laminate Modulus}

Tension Modulus

$$
E_{x}^{t}=\frac{A_{11} A_{22}-A_{12}^{2}}{t A_{22}}
$$

Bending Modulus

$$
E_{x}^{b}=\frac{12\left(D_{11} D_{22}-D_{22}^{2}\right)}{t^{3} D_{22}}
$$




\section{Step 9: Compute Axial Stiffness and Bending Stiffness}

Axial Stiffness $=E_{x}^{t} A$

Bending Stiffness $=E_{x}^{b} I$

Where,

$\mathrm{A}=$ cross sectional area of the composite laminate

$\mathrm{I}=$ Moment of Inertia of the composite laminate

The computation of axial and bending modulus of the laminate as per the above procedure using a spreadsheet program is shown in the next section. 


\begin{tabular}{|c|c|c|c|c|c|}
\hline \multicolumn{6}{|c|}{ Computation of Laminate Moduli } \\
\hline \multicolumn{6}{|c|}{ Micromechanic and Macromechanic Approach } \\
\hline & & & & & \\
\hline Section & \multicolumn{2}{|l|}{ Rectangular strip } & & & \\
\hline Dimension & $0.5^{\prime \prime} \times 0.375^{\prime \prime}$ & & & & \\
\hline \multicolumn{6}{|l|}{ Fiber Architecture } \\
\hline $1 \mathrm{oz}$ of CSM & 0.015 & & & & \\
\hline fabric [90/45/-45] & 0.047 & & & & \\
\hline $62 Y$ of 6 rov/in. & 0.055 & & & & \\
\hline fabric [90/45/-45] & 0.047 & & & & \\
\hline fabric [90/45/-45] & 0.047 & & & & \\
\hline fabric $[90 / 45 /-45]$ & 0.047 & & & & \\
\hline $62 Y$ of 6 rov/in. & 0.055 & & & & \\
\hline fabric $[90 / 45 /-45]$ & 0.047 & & & & \\
\hline $1 \mathrm{oz}$ of CSM & 0.015 & & & & \\
\hline Total & 0.375 & & & & \\
\hline \multicolumn{6}{|l|}{ Step 1} \\
\hline \multicolumn{6}{|c|}{ Computation of Material Properties } \\
\hline$E_{\text {fiber }}$ & $\mathbf{E}_{\text {matrix }}$ & $\mathbf{G}_{\text {fiber }}$ & $\mathbf{G}_{\text {matrix }}$ & $\mathbf{v}_{\text {fiber }}$ & $\mathbf{v}_{\text {matrix }}$ \\
\hline (psi) & (psi) & (psi) & (psi) & & \\
\hline $1.05 \mathrm{E}+07$ & $7.34 \mathrm{E}+05$ & $4.18 \mathrm{E}+06$ & $2.37 \mathrm{E}+05$ & 0.26 & 0.55 \\
\hline \multicolumn{6}{|l|}{ Step 2} \\
\hline \multicolumn{6}{|c|}{ Computation of Fiber Volume Fraction $\left(V_{f}\right)$ of CSM } \\
\hline & & & & & \\
\hline Thk of lamina & Wt. Of Fabric & Wt. Of Fabric & Wt.of $1 \mathrm{ft}^{2}$ & Density of & \\
\hline (in.) & (oz/yd2) & $(\mathrm{oz} / \mathrm{ft} 2)$ & (Ib) & (Ib/in3) & \\
\hline 0.015 & 9 & 1.000 & 0.063 & 0.092 & \\
\hline Volume of & Volume of & Fiber Volume & Matrix Volume & & \\
\hline fiber & composite & fraction (Vf) & fraction $(\mathrm{Vm})$ & & \\
\hline 0.679 & 2.16 & 0.31 & 0.69 & & \\
\hline \multicolumn{6}{|c|}{ Computation of Fiber Volume Fraction $\left(\mathrm{V}_{\mathrm{f}}\right)$ of Fabric } \\
\hline & & & & & \\
\hline Thk of lamina & Wt. Of Fabric & Wt. Of Fabric & Wt.of $1 \mathrm{ft}^{2}$ & Density of & \\
\hline (in.) & (oz/yd2) & $(0 z / f t 2)$ & (Ib) & (Ib/in3) & \\
\hline 0.019 & 16 & 1.778 & 0.111 & 0.092 & \\
\hline 0.014 & 12 & 1.333 & 0.083 & 0.092 & \\
\hline 0.014 & 12 & 1.333 & 0.083 & 0.092 & \\
\hline Volume of & Volume of & Fiber Volume & Matrix Volume & & \\
\hline fiber & composite & fraction & fraction & & \\
\hline 1.208 & 2.736 & 0.44 & 0.56 & & \\
\hline 0.906 & 2.016 & 0.45 & 0.55 & & \\
\hline 0.906 & 2.016 & 0.45 & 0.55 & & \\
\hline
\end{tabular}




\begin{tabular}{|c|c|c|c|c|c|}
\hline \multicolumn{6}{|c|}{\begin{tabular}{|l|l|} 
Step 3 & \\
\end{tabular}} \\
\hline \multicolumn{6}{|c|}{ Evaluation of Laminae Properties } \\
\hline Fiber & $E_{11}$ & $E_{22}$ & $\mathbf{G}_{12}$ & $\mathbf{v}_{12}$ & $\mathbf{v}_{21}$ \\
\hline $1 \mathrm{oz}$ of $\mathrm{csm}$ & $3.81 \mathrm{E}+06$ & $1.04 \mathrm{E}+06$ & & & \\
\hline $40 \mathrm{oz}$ of fabric & - & - & - & - & - \\
\hline 16 oz of 90 & $5.04 \mathrm{E}+06$ & $1.25 \mathrm{E}+06$ & $4.06 \mathrm{E}+05$ & 0.419 & 0.104 \\
\hline 12 oz of 45 & $5.12 \mathrm{E}+06$ & $1.26 \mathrm{E}+06$ & $4.11 \mathrm{E}+05$ & 0.417 & 0.103 \\
\hline 12 oz of -45 & $5.12 E+06$ & $1.26 \mathrm{E}+06$ & $4.11 \mathrm{E}+05$ & 0.417 & 0.103 \\
\hline $62 Y$ of $6 \mathrm{rov} / \mathrm{in}$. & $5.92 \mathrm{E}+06$ & $1.51 \mathrm{E}+06$ & $4.75 \mathrm{E}+05$ & 0.393 & 0.100 \\
\hline fabric $[90 / 45 /-45]$ & - & - & - & - & - \\
\hline 16 oz of 90 & $5.04 \mathrm{E}+06$ & $1.25 \mathrm{E}+06$ & $4.06 \mathrm{E}+05$ & 0.419 & 0.104 \\
\hline 12 oz of 45 & $5.12 \mathrm{E}+06$ & $1.26 \mathrm{E}+06$ & $4.11 \mathrm{E}+05$ & 0.417 & 0.103 \\
\hline 12 oz of -45 & $5.12 \mathrm{E}+06$ & $1.26 \mathrm{E}+06$ & $4.11 \mathrm{E}+05$ & 0.417 & 0.103 \\
\hline fabric [90/45/-45] & - & - & - & - & - \\
\hline 16 oz of 90 & $5.04 \mathrm{E}+06$ & $1.25 \mathrm{E}+06$ & $4.06 \mathrm{E}+05$ & 0.419 & 0.104 \\
\hline $12 \mathrm{oz}$ of 45 & $5.12 E+06$ & $1.26 \mathrm{E}+06$ & $4.11 \mathrm{E}+05$ & 0.417 & 0.103 \\
\hline 12 oz of -45 & $5.12 E+06$ & $1.26 \mathrm{E}+06$ & $4.11 E+05$ & 0.417 & 0.103 \\
\hline fabric [90/45/-45] & - & - & - & - & - \\
\hline 16 oz of 90 & $5.04 \mathrm{E}+06$ & $1.25 \mathrm{E}+06$ & $4.06 \mathrm{E}+05$ & 0.419 & 0.104 \\
\hline 12 oz of 45 & $5.12 \mathrm{E}+06$ & $1.26 \mathrm{E}+06$ & $4.11 \mathrm{E}+05$ & 0.417 & 0.103 \\
\hline 12 oz of -45 & $5.12 \mathrm{E}+06$ & $1.26 \mathrm{E}+06$ & $4.11 \mathrm{E}+05$ & 0.417 & 0.103 \\
\hline $62 Y$ of $6 \mathrm{rov} / \mathrm{in}$. & $5.92 \mathrm{E}+06$ & $1.51 \mathrm{E}+06$ & $4.75 \mathrm{E}+05$ & 0.393 & 0.100 \\
\hline fabric $[90 / 45 /-45]$ & - & - & - & - & - \\
\hline 16 oz of 90 & $5.04 \mathrm{E}+06$ & $1.25 \mathrm{E}+06$ & $4.06 \mathrm{E}+05$ & 0.419 & 0.104 \\
\hline 12 oz of 45 & $5.12 \mathrm{E}+06$ & $1.26 \mathrm{E}+06$ & $4.11 \mathrm{E}+05$ & 0.417 & 0.103 \\
\hline 12 oz of -45 & $5.12 E+06$ & $1.26 \mathrm{E}+06$ & $4.11 \mathrm{E}+05$ & 0.417 & 0.103 \\
\hline $1 \mathrm{oz}$ of CSM & $2.08 \mathrm{E}+06$ & $2.08 \mathrm{E}+06$ & $7.35 \mathrm{E}+05$ & 0.412 & 0.412 \\
\hline & & & & & \\
\hline \multicolumn{6}{|l|}{ Step 4} \\
\hline \multicolumn{6}{|c|}{ Calculation of In-Plane Reduced Stiffness Matrix } \\
\hline Fiber Architecture & $\boldsymbol{\delta}$ & & & & \\
\hline 1 oz of CSM & 0.830 & & & & \\
\hline fabric [90/45/-45] & - & & & & \\
\hline 16 oz of 90 & 0.957 & & & & \\
\hline 12 oz of 45 & 0.957 & & & & \\
\hline 12 oz of -45 & 0.957 & & & & \\
\hline $62 Y$ of $6 \mathrm{rov} / \mathrm{in}$. & 0.961 & & & & \\
\hline fabric $[90 / 45 /-45]$ & - & & & & \\
\hline 16 oz of 90 & 0.957 & & & & \\
\hline 12 oz of 45 & 0.957 & & & & \\
\hline 12 oz of -45 & 0.957 & & & & \\
\hline fabric [90/45/-45] & - & & & & \\
\hline 16 oz of 90 & 0.957 & & & & \\
\hline 12 oz of 45 & 0.957 & & & & \\
\hline 12 oz of -45 & 0.957 & & & & \\
\hline fabric [90/45/-45] & - & & & & \\
\hline 16 oz of 90 & 0.957 & & & & \\
\hline 12 oz of 45 & 0.957 & & & & \\
\hline 12 oz of -45 & 0.957 & & & & \\
\hline $62 \mathrm{Y}$ of $6 \mathrm{rov} / \mathrm{in}$. & 0.961 & & & & \\
\hline fabric $[90 / 45 /-45]$ & - & & & & \\
\hline 16 oz of 90 & 0.957 & & & & \\
\hline 12 oz of 45 & 0.957 & & & & \\
\hline 12 oz of -45 & 0.957 & & & & \\
\hline $1 \mathrm{oz}$ of CSM & 0.830 & & & & \\
\hline
\end{tabular}




\begin{tabular}{|c|c|c|c|c|c|}
\hline Fiber Architecture & $\mathbf{Q}_{11}$ & $\mathbf{Q}_{12}$ & $\mathbf{Q}_{21}$ & $\mathbf{Q}_{22}$ & $\mathbf{Q}_{66}$ \\
\hline $1 \mathrm{oz}$ of CSM & $2.50 \mathrm{E}+06$ & $1.03 \mathrm{E}+06$ & $1.03 \mathrm{E}+06$ & $2.50 \mathrm{E}+06$ & $7.35 \mathrm{E}+05$ \\
\hline fabric [90/45/-45] & - & - & - & - & - \\
\hline $16 \mathrm{oz}$ of 90 & $5.27 \mathrm{E}+06$ & $5.46 \mathrm{E}+05$ & $5.46 \mathrm{E}+05$ & $1.30 \mathrm{E}+06$ & $4.06 \mathrm{E}+05$ \\
\hline $12 \mathrm{oz}$ of 45 & $5.35 \mathrm{E}+06$ & $5.49 \mathrm{E}+05$ & $5.49 \mathrm{E}+05$ & $1.32 \mathrm{E}+06$ & $4.11 \mathrm{E}+05$ \\
\hline 12 oz of -45 & $5.35 \mathrm{E}+06$ & $5.49 \mathrm{E}+05$ & $5.49 \mathrm{E}+05$ & $1.32 \mathrm{E}+06$ & $4.11 \mathrm{E}+05$ \\
\hline $62 \mathrm{Y}$ of $6 \mathrm{rov} / \mathrm{in}$. & $6.17 \mathrm{E}+06$ & $6.17 \mathrm{E}+05$ & $6.17 \mathrm{E}+05$ & $1.57 \mathrm{E}+06$ & $4.75 E+05$ \\
\hline fabric [90/45/-45] & - & - & - & - & - \\
\hline $16 \mathrm{oz}$ of 90 & $5.27 \mathrm{E}+06$ & $5.46 \mathrm{E}+05$ & $5.46 \mathrm{E}+05$ & $1.30 \mathrm{E}+06$ & $4.06 \mathrm{E}+05$ \\
\hline $12 \mathrm{oz}$ of 45 & $5.35 \mathrm{E}+06$ & $5.49 \mathrm{E}+05$ & $5.49 \mathrm{E}+05$ & $1.32 \mathrm{E}+06$ & $4.11 \mathrm{E}+05$ \\
\hline 12 oz of -45 & $5.35 \mathrm{E}+06$ & $5.49 \mathrm{E}+05$ & $5.49 E+05$ & $1.32 \mathrm{E}+06$ & $4.11 \mathrm{E}+05$ \\
\hline fabric [90/45/-45] & - & & & - & - \\
\hline 16 oz of 90 & $5.27 \mathrm{E}+06$ & $5.46 \mathrm{E}+05$ & $5.46 \mathrm{E}+05$ & $1.30 \mathrm{E}+06$ & $4.06 \mathrm{E}+05$ \\
\hline 12 oz of 45 & $5.35 \mathrm{E}+06$ & $5.49 \mathrm{E}+05$ & $5.49 \mathrm{E}+05$ & $1.32 \mathrm{E}+06$ & $4.11 \mathrm{E}+05$ \\
\hline 12 oz of -45 & $5.35 \mathrm{E}+06$ & $5.49 \mathrm{E}+05$ & $5.49 \mathrm{E}+05$ & $1.32 \mathrm{E}+06$ & $4.11 \mathrm{E}+05$ \\
\hline fabric [90/45/-45] & - & & - & - & - \\
\hline $16 \mathrm{oz}$ of 90 & $5.27 \mathrm{E}+06$ & $5.46 \mathrm{E}+05$ & $5.46 \mathrm{E}+05$ & $1.30 \mathrm{E}+06$ & $4.06 \mathrm{E}+05$ \\
\hline $12 \mathrm{oz}$ of 45 & $5.35 \mathrm{E}+06$ & $5.49 \mathrm{E}+05$ & $5.49 \mathrm{E}+05$ & $1.32 \mathrm{E}+06$ & $4.11 \mathrm{E}+05$ \\
\hline 12 oz of -45 & $5.35 \mathrm{E}+06$ & $5.49 \mathrm{E}+05$ & $5.49 \mathrm{E}+05$ & $1.32 \mathrm{E}+06$ & $4.11 \mathrm{E}+05$ \\
\hline $62 \mathrm{Y}$ of $6 \mathrm{rov} / \mathrm{in}$. & $6.17 \mathrm{E}+06$ & $6.17 \mathrm{E}+05$ & $6.17 \mathrm{E}+05$ & $1.57 \mathrm{E}+06$ & $4.75 \mathrm{E}+05$ \\
\hline fabric [90/45/-45] & - & - & - & - & - \\
\hline 16 oz of 90 & $5.27 \mathrm{E}+06$ & $5.46 \mathrm{E}+05$ & $5.46 \mathrm{E}+05$ & $1.30 \mathrm{E}+06$ & $4.06 \mathrm{E}+05$ \\
\hline $12 \mathrm{oz}$ of 45 & $5.35 \mathrm{E}+06$ & $5.49 \mathrm{E}+05$ & $5.49 E+05$ & $1.32 \mathrm{E}+06$ & $4.11 \mathrm{E}+05$ \\
\hline 12 oz of -45 & $5.35 \mathrm{E}+06$ & $5.49 \mathrm{E}+05$ & $5.49 \mathrm{E}+05$ & $1.32 \mathrm{E}+06$ & $4.11 \mathrm{E}+05$ \\
\hline $1 \mathrm{oz}$ of CSM & $2.50 \mathrm{E}+06$ & $1.03 \mathrm{E}+06$ & $1.03 \mathrm{E}+06$ & $2.50 \mathrm{E}+06$ & $7.35 \mathrm{E}+05$ \\
\hline & & & & & \\
\hline \multicolumn{6}{|l|}{ Step 5} \\
\hline \multicolumn{6}{|c|}{ Calculation of Transformed Reduced Stiffness Matrix } \\
\hline \multirow[t]{2}{*}{\begin{tabular}{|c|} 
Fiber Architecture \\
\end{tabular}} & Orient. of fabric & Orient. of fabric & & & \\
\hline & (degrees) & (Radians) & & & \\
\hline $1 \mathrm{oz}$ of $\mathrm{CSM}$ & 0 & 0.00 & & & \\
\hline $62 Y$ of $6 \mathrm{rov} / \mathrm{in}$. & 0 & 0.00 & & & \\
\hline \multicolumn{6}{|c|}{40 oz of fabric has fibers oriented in $45^{\circ}, 90^{\circ}$, and $-45^{\circ}$} \\
\hline & & & & & \\
\hline & 90 & 1.57 & & & \\
\hline & 45 & 0.79 & & & \\
\hline & -45 & -0.79 & & & \\
\hline Fiber Architecture & $\mathbf{Q}_{\mathrm{b} 11}$ & $\mathbf{Q}_{\mathrm{b} 12}$ & $\mathbf{Q}_{\mathrm{b} 21}$ & & \\
\hline $1 \mathrm{oz}$ of $\mathrm{CSM}$ & $2.50 \mathrm{E}+06$ & $1.03 \mathrm{E}+06$ & $1.03 \mathrm{E}+06$ & & \\
\hline \multicolumn{6}{|c|}{$40 \mathrm{oz}$ of fabric has fibers oriented in $45^{\circ}, 90^{\circ}$, and $-45^{\circ}$} \\
\hline & & & & & \\
\hline 90 & $1.30 \mathrm{E}+06$ & $5.46 \mathrm{E}+05$ & $5.46 \mathrm{E}+05$ & & \\
\hline 45 & $2.35 \mathrm{E}+06$ & $1.53 \mathrm{E}+06$ & $1.53 \mathrm{E}+06$ & & \\
\hline-45 & $2.35 \mathrm{E}+06$ & $1.53 \mathrm{E}+06$ & $1.53 \mathrm{E}+06$ & & \\
\hline $62 Y$ of $6.5 \mathrm{rov} / \mathrm{in}$. & $6.17 \mathrm{E}+06$ & $6.17 \mathrm{E}+05$ & $6.17 \mathrm{E}+05$ & & \\
\hline
\end{tabular}




\begin{tabular}{|c|c|c|c|c|}
\hline Fiber Architecture & $\mathbf{Q}_{\mathrm{b} 22}$ & $\mathbf{Q}_{\mathrm{b} 16}$ & $\mathbf{Q}_{\mathrm{b} 26}$ & $\mathbf{Q}_{\mathrm{b} 66}$ \\
\hline $1 \mathrm{oz}$ of $\mathrm{CSM}$ & $2.50 \mathrm{E}+06$ & $0.00 \mathrm{E}+00$ & $0.00 \mathrm{E}+00$ & $7.35 \mathrm{E}+05$ \\
\hline & & & & \\
\hline \multicolumn{5}{|c|}{40 oz of fabric has fibers oriented in $45^{\circ}, 90^{\circ}$, and $-45^{\circ}$} \\
\hline & & & & \\
\hline 90 & $5.27 \mathrm{E}+06$ & $3.45 \mathrm{E}-12$ & $2.40 \mathrm{E}-10$ & $4.06 \mathrm{E}+05$ \\
\hline 45 & $2.35 \mathrm{E}+06$ & $1.01 \mathrm{E}+06$ & $1.01 \mathrm{E}+06$ & $1.39 \mathrm{E}+06$ \\
\hline-45 & $2.35 \mathrm{E}+06$ & $-1.01 E+06$ & $-1.01 E+06$ & $1.39 \mathrm{E}+06$ \\
\hline $62 Y$ of $6.5 \mathrm{rov} / \mathrm{in}$. & $1.57 \mathrm{E}+06$ & $0.00 \mathrm{E}+00$ & $0.00 \mathrm{E}+00$ & $4.75 \mathrm{E}+05$ \\
\hline \multicolumn{5}{|c|}{\begin{tabular}{l|l|l} 
Step 6 & & \\
\end{tabular}} \\
\hline \multicolumn{5}{|c|}{ Computation of Final Transformed Stiffness Matrix } \\
\hline Fiber Architecture & $Q_{b 11}$ & $Q_{b 12}$ & $Q_{b 21}$ & \\
\hline $1 \mathrm{oz}$ of $\mathrm{CSM}$ & $2.50 \mathrm{E}+06$ & $1.03 \mathrm{E}+06$ & $1.03 \mathrm{E}+06$ & \\
\hline fabric $[90 / 45 /-45]$ & $1.93 \mathrm{E}+06$ & $1.14 \mathrm{E}+06$ & $1.14 \mathrm{E}+06$ & \\
\hline $62 Y$ of 6 rov/in. & $6.17 E+06$ & $6.17 \mathrm{E}+05$ & $6.17 \mathrm{E}+05$ & \\
\hline fabric [90/45/-45] & $1.93 \mathrm{E}+06$ & $1.14 \mathrm{E}+06$ & $1.14 \mathrm{E}+06$ & \\
\hline fabric [90/45/-45] & $1.93 \mathrm{E}+06$ & $1.14 \mathrm{E}+06$ & $1.14 \mathrm{E}+06$ & \\
\hline fabric [90/45/-45] & $1.93 \mathrm{E}+06$ & $1.14 \mathrm{E}+06$ & $1.14 \mathrm{E}+06$ & \\
\hline $62 Y$ of 6 rov/in. & $6.17 E+06$ & $6.17 \mathrm{E}+05$ & $6.17 \mathrm{E}+05$ & \\
\hline fabric [90/45/-45] & $1.93 E+06$ & $1.14 \mathrm{E}+06$ & $1.14 \mathrm{E}+06$ & \\
\hline $1 \mathrm{oz}$ of CSM & $2.50 \mathrm{E}+06$ & $1.03 \mathrm{E}+06$ & $1.03 \mathrm{E}+06$ & \\
\hline Fiber Architecture & $\overline{Q_{b 22}}$ & $\mathbf{Q}_{\mathrm{b} 16}$ & $\mathbf{Q}_{\mathrm{b} 26}$ & $\mathbf{Q}_{\mathrm{b} 66}$ \\
\hline $1 \mathrm{oz}$ of CSM & $2.50 \mathrm{E}+06$ & $0.00 \mathrm{E}+00$ & $0.00 \mathrm{E}+00$ & $7.35 \mathrm{E}+05$ \\
\hline fabric [90/45/-45] & $3.52 E+06$ & $0.00 \mathrm{E}+00$ & $0.00 \mathrm{E}+00$ & $9.98 \mathrm{E}+05$ \\
\hline $62 Y$ of $6 \mathrm{rov} / \mathrm{in}$. & $1.57 \mathrm{E}+06$ & $0.00 \mathrm{E}+00$ & $0.00 \mathrm{E}+00$ & $4.75 \mathrm{E}+05$ \\
\hline fabric [90/45/-45] & $3.52 E+06$ & $0.00 \mathrm{E}+00$ & $0.00 \mathrm{E}+00$ & $9.98 \mathrm{E}+05$ \\
\hline fabric [90/45/-45] & $3.52 \mathrm{E}+06$ & $0.00 \mathrm{E}+00$ & $0.00 \mathrm{E}+00$ & $9.98 \mathrm{E}+05$ \\
\hline fabric [90/45/-45] & $3.52 E+06$ & $0.00 \mathrm{E}+00$ & $0.00 \mathrm{E}+00$ & $9.98 \mathrm{E}+05$ \\
\hline $62 Y$ of 6 rov/in. & $1.57 E+06$ & $0.00 \mathrm{E}+00$ & $0.00 \mathrm{E}+00$ & $4.75 \mathrm{E}+05$ \\
\hline fabric [90/45/-45] & $3.52 E+06$ & $0.00 \mathrm{E}+00$ & $0.00 \mathrm{E}+00$ & $9.98 \mathrm{E}+05$ \\
\hline $1 \mathrm{oz}$ of $\mathrm{CSM}$ & $2.50 \mathrm{E}+06$ & $0.00 \mathrm{E}+00$ & $0.00 \mathrm{E}+00$ & $7.35 \mathrm{E}+05$ \\
\hline
\end{tabular}




\begin{tabular}{|c|c|c|c|c|}
\hline \multirow{2}{*}{\multicolumn{5}{|c|}{\begin{tabular}{|l|l} 
Step 7 & \\
Computation of Stiffness Matrix \\
\end{tabular}}} \\
\hline & & & & \\
\hline \multicolumn{5}{|c|}{ Distance from mid-surface of laminate to each laminae (z) } \\
\hline Fiber Architecture & z (in) & & & \\
\hline $1 \mathrm{oz}$ of CSM & -0.1800 & & & \\
\hline fabric [90/45/-45] & -0.149 & & & \\
\hline $62 Y$ of 6 rov/in. & -0.0980 & & & \\
\hline fabric [90/45/-45] & -0.0470 & & & \\
\hline fabric $[90 / 45 /-45]$ & 0.0000 & & & \\
\hline fabric $[90 / 45 /-45]$ & 0.0470 & & & \\
\hline $62 Y$ of 6 rov/in. & 0.0980 & & & \\
\hline fabric $[90 / 45 /-45]$ & 0.1490 & & & \\
\hline $1 \mathrm{oz}$ of CSM & 0.1800 & & & \\
\hline \multicolumn{5}{|c|}{ Computation of extensional stiffness } \\
\hline \multirow[t]{2}{*}{ Fiber architecture } & Thk.of laminae & $\mathbf{A}_{11}$ & $A_{12}$ & $A_{21}$ \\
\hline & (in) & (Ibs/in) & (Ibs/in) & (Ibs/in) \\
\hline $1 \mathrm{oz}$ of CSM & 0.015 & $3.75 \mathrm{E}+04$ & $1.54 \mathrm{E}+04$ & $1.54 \mathrm{E}+04$ \\
\hline fabric $[90 / 45 /-45]$ & 0.047 & $9.08 \mathrm{E}+04$ & $5.34 \mathrm{E}+04$ & $5.34 \mathrm{E}+04$ \\
\hline $62 Y$ of 6 rov/in. & 0.055 & $3.39 \mathrm{E}+05$ & $3.40 \mathrm{E}+04$ & $3.40 \mathrm{E}+04$ \\
\hline fabric $[90 / 45 /-45]$ & 0.047 & $9.08 \mathrm{E}+04$ & $5.34 \mathrm{E}+04$ & $5.34 \mathrm{E}+04$ \\
\hline fabric $[90 / 45 /-45]$ & 0.047 & $9.08 \mathrm{E}+04$ & $5.34 \mathrm{E}+04$ & $5.34 \mathrm{E}+04$ \\
\hline fabric [90/45/-45] & 0.047 & $9.08 \mathrm{E}+04$ & $5.34 \mathrm{E}+04$ & $5.34 \mathrm{E}+04$ \\
\hline $62 Y$ of 6 rov/in. & 0.055 & $3.39 \mathrm{E}+05$ & $3.40 \mathrm{E}+04$ & $3.40 \mathrm{E}+04$ \\
\hline fabric [90/45/-45] & 0.047 & $9.08 \mathrm{E}+04$ & $5.34 \mathrm{E}+04$ & $5.34 \mathrm{E}+04$ \\
\hline \multirow[t]{2}{*}{$1 \mathrm{oz}$ of CSM } & 0.015 & $3.75 \mathrm{E}+04$ & $1.54 \mathrm{E}+04$ & $1.54 \mathrm{E}+04$ \\
\hline & & $1.21 \mathrm{E}+06$ & $3.66 \mathrm{E}+05$ & $3.66 \mathrm{E}+05$ \\
\hline \multirow[t]{2}{*}{ Fiber architecture } & $A_{22}$ & $A_{16}$ & $A_{26}$ & $A_{66}$ \\
\hline & (Ibs/in) & (Ibs/in) & (Ibs/in) & (Ibs/in) \\
\hline $1 \mathrm{oz}$ of CSM & $3.75 \mathrm{E}+04$ & $0.00 \mathrm{E}+00$ & $0.00 \mathrm{E}+00$ & $1.10 \mathrm{E}+04$ \\
\hline fabric [90/45/-45] & $1.66 \mathrm{E}+05$ & $0.00 \mathrm{E}+00$ & $0.00 \mathrm{E}+00$ & $4.69 \mathrm{E}+04$ \\
\hline $62 Y$ of 6 rov/in. & $8.64 \mathrm{E}+04$ & $0.00 \mathrm{E}+00$ & $0.00 \mathrm{E}+00$ & $2.61 \mathrm{E}+04$ \\
\hline fabric [90/45/-45] & $1.66 \mathrm{E}+05$ & $0.00 \mathrm{E}+00$ & $0.00 \mathrm{E}+00$ & $4.69 \mathrm{E}+04$ \\
\hline fabric [90/45/-45] & $1.66 \mathrm{E}+05$ & $0.00 \mathrm{E}+00$ & $0.00 \mathrm{E}+00$ & $4.69 \mathrm{E}+04$ \\
\hline fabric [90/45/-45] & $1.66 \mathrm{E}+05$ & $0.00 \mathrm{E}+00$ & $0.00 \mathrm{E}+00$ & $4.69 \mathrm{E}+04$ \\
\hline $62 Y$ of 6 rov/in. & $8.64 \mathrm{E}+04$ & $0.00 \mathrm{E}+00$ & $0.00 \mathrm{E}+00$ & $2.61 \mathrm{E}+04$ \\
\hline fabric [90/45/-45] & $1.66 \mathrm{E}+05$ & $0.00 \mathrm{E}+00$ & $0.00 \mathrm{E}+00$ & $4.69 \mathrm{E}+04$ \\
\hline \multirow[t]{2}{*}{$1 \mathrm{oz}$ of CSM } & $3.75 \mathrm{E}+04$ & $0.00 \mathrm{E}+00$ & $0.00 \mathrm{E}+00$ & $1.10 \mathrm{E}+04$ \\
\hline & $1.08 \mathrm{E}+06$ & $0.00 \mathrm{E}+00$ & $0.00 \mathrm{E}+00$ & $3.09 \mathrm{E}+05$ \\
\hline
\end{tabular}




\begin{tabular}{|c|c|c|c|c|c|}
\hline \multicolumn{6}{|c|}{ Computation of bending-extension coupling stiffness } \\
\hline Fiber architecture & Thk.of laminae & Z & $B_{11}$ & $\mathrm{~B}_{12}$ & $B_{21}$ \\
\hline & (in) & (in) & (lbs) & (lbs) & (Ibs) \\
\hline $1 \mathrm{oz}$ of $\mathrm{CSM}$ & 0.015 & -0.1800 & $-6.75 \mathrm{E}+03$ & $-2.78 \mathrm{E}+03$ & $-2.78 \mathrm{E}+03$ \\
\hline fabric $[90 / 45 /-45]$ & 0.047 & -0.149 & $-1.35 \mathrm{E}+04$ & $-7.96 \mathrm{E}+03$ & $-7.96 \mathrm{E}+03$ \\
\hline $62 Y$ of $6 \mathrm{rov} / \mathrm{in}$. & 0.055 & -0.0980 & $-3.32 \mathrm{E}+04$ & $-3.33 \mathrm{E}+03$ & $-3.33 E+03$ \\
\hline fabric [90/45/-45] & 0.047 & -0.0470 & $-1.35 \mathrm{E}+04$ & $-7.96 \mathrm{E}+03$ & $-7.96 \mathrm{E}+03$ \\
\hline fabric [90/45/-45] & 0.047 & 0.0000 & $-1.35 \mathrm{E}+04$ & $-7.96 \mathrm{E}+03$ & $-7.96 \mathrm{E}+03$ \\
\hline fabric [90/45/-45] & 0.047 & 0.0470 & $-1.35 \mathrm{E}+04$ & $-7.96 \mathrm{E}+03$ & $-7.96 \mathrm{E}+03$ \\
\hline $62 \mathrm{Y}$ of $6 \mathrm{rov} / \mathrm{in}$. & 0.055 & 0.0980 & $-3.32 E+04$ & $-3.33 E+03$ & $-3.33 \mathrm{E}+03$ \\
\hline fabric [90/45/-45] & 0.047 & 0.1490 & $-1.35 \mathrm{E}+04$ & $-7.96 \mathrm{E}+03$ & $-7.96 \mathrm{E}+03$ \\
\hline \multirow{2}{*}{1 oz of CSM } & 0.015 & 0.1800 & $-6.75 E+03$ & $-2.78 \mathrm{E}+03$ & $-2.78 E+03$ \\
\hline & & & $-1.48 E+05$ & $-5.20 \mathrm{E}+04$ & $-5.20 \mathrm{E}+04$ \\
\hline \multirow[t]{2}{*}{ Fiber architecture } & $B_{22}$ & $B_{16}$ & $B_{26}$ & $B_{66}$ & \\
\hline & (Ibs) & (lbs) & (Ibs) & (lbs) & \\
\hline $1 \mathrm{oz}$ of $\mathrm{CSM}$ & $-6.75 \mathrm{E}+03$ & $0.00 \mathrm{E}+00$ & $0.00 \mathrm{E}+00$ & $-1.98 \mathrm{E}+03$ & \\
\hline fabric [90/45/-45] & $-2.47 E+04$ & $0.00 \mathrm{E}+00$ & $0.00 \mathrm{E}+00$ & $-6.99 \mathrm{E}+03$ & \\
\hline $62 \mathrm{Y}$ of $6 \mathrm{rov} / \mathrm{in}$. & $-8.47 E+03$ & $0.00 \mathrm{E}+00$ & $0.00 \mathrm{E}+00$ & $-2.56 \mathrm{E}+03$ & \\
\hline fabric [90/45/-45] & $-2.47 E+04$ & $0.00 \mathrm{E}+00$ & $0.00 \mathrm{E}+00$ & $-6.99 \mathrm{E}+03$ & \\
\hline fabric [90/45/-45] & $-2.47 E+04$ & $0.00 \mathrm{E}+00$ & $0.00 \mathrm{E}+00$ & $-6.99 \mathrm{E}+03$ & \\
\hline fabric [90/45/-45] & $-2.47 \mathrm{E}+04$ & $0.00 \mathrm{E}+00$ & $0.00 \mathrm{E}+00$ & $-6.99 \mathrm{E}+03$ & \\
\hline $62 \mathrm{Y}$ of $6 \mathrm{rov} / \mathrm{in}$. & $-8.47 \mathrm{E}+03$ & $0.00 \mathrm{E}+00$ & $0.00 \mathrm{E}+00$ & $-2.56 \mathrm{E}+03$ & \\
\hline fabric [90/45/-45] & $-2.47 E+04$ & $0.00 \mathrm{E}+00$ & $0.00 \mathrm{E}+00$ & $-6.99 \mathrm{E}+03$ & \\
\hline \multirow[t]{2}{*}{$1 \mathrm{oz}$ of CSM } & $-6.75 E+03$ & $0.00 \mathrm{E}+00$ & $0.00 \mathrm{E}+00$ & $-1.98 \mathrm{E}+03$ & \\
\hline & $-1.54 \mathrm{E}+05$ & $0.00 \mathrm{E}+00$ & $0.00 \mathrm{E}+00$ & $-4.40 E+04$ & \\
\hline \multicolumn{6}{|c|}{ Computation of bending-extension coupling stiffness } \\
\hline \multirow[t]{2}{*}{ Fiber architecture } & Thk.of laminae & Z & $D_{11}$ & $D_{12}$ & $D_{21}$ \\
\hline & (in) & (in) & (lbs-in) & (lbs-in) & (lbs-in) \\
\hline $1 \mathrm{oz}$ of $\mathrm{CSM}$ & 0.015 & -0.1800 & $1.22 \mathrm{E}+03$ & $5.00 \mathrm{E}+02$ & $5.00 \mathrm{E}+02$ \\
\hline fabric $[90 / 45 /-45]$ & 0.047 & -0.149 & $2.03 \mathrm{E}+03$ & $1.20 \mathrm{E}+03$ & $1.20 \mathrm{E}+03$ \\
\hline $62 Y$ of 6 rov/in. & 0.055 & -0.0980 & $3.34 \mathrm{E}+03$ & $3.35 \mathrm{E}+02$ & $3.35 \mathrm{E}+02$ \\
\hline fabric $[90 / 45 /-45]$ & 0.047 & -0.0470 & $2.03 \mathrm{E}+03$ & $1.20 \mathrm{E}+03$ & $1.20 \mathrm{E}+03$ \\
\hline fabric $[90 / 45 /-45]$ & 0.047 & 0.0000 & $2.03 \mathrm{E}+03$ & $1.20 \mathrm{E}+03$ & $1.20 \mathrm{E}+03$ \\
\hline fabric [90/45/-45] & 0.047 & 0.0470 & $2.03 \mathrm{E}+03$ & $1.20 \mathrm{E}+03$ & $1.20 \mathrm{E}+03$ \\
\hline $62 \mathrm{Y}$ of $6 \mathrm{rov} / \mathrm{in}$. & 0.055 & 0.0980 & $3.34 \mathrm{E}+03$ & $3.35 \mathrm{E}+02$ & $3.35 \mathrm{E}+02$ \\
\hline fabric [90/45/-45] & 0.047 & 0.1490 & $2.03 E+03$ & $1.20 \mathrm{E}+03$ & $1.20 \mathrm{E}+03$ \\
\hline \multirow[t]{2}{*}{$1 \mathrm{oz}$ of CSM } & 0.015 & 0.1800 & $1.22 \mathrm{E}+03$ & $5.00 \mathrm{E}+02$ & $5.00 \mathrm{E}+02$ \\
\hline & & & $1.93 E+04$ & $7.65 \mathrm{E}+03$ & $7.65 \mathrm{E}+03$ \\
\hline \multirow[t]{2}{*}{ Fiber architecture } & $D_{22}$ & $D_{16}$ & $D_{26}$ & $D_{66}$ & \\
\hline & (Ibs-in) & (Ibs-in) & (Ibs-in) & (Ibs-in) & \\
\hline $1 \mathrm{oz}$ of $\mathrm{CSM}$ & $1.22 \mathrm{E}+03$ & $0.00 \mathrm{E}+00$ & $0.00 \mathrm{E}+00$ & $3.57 \mathrm{E}+02$ & \\
\hline fabric [90/45/-45] & $3.70 \mathrm{E}+03$ & $0.00 \mathrm{E}+00$ & $0.00 \mathrm{E}+00$ & $1.05 \mathrm{E}+03$ & \\
\hline $62 \mathrm{Y}$ of $6 \mathrm{rov} / \mathrm{in}$. & $8.51 \mathrm{E}+02$ & $0.00 \mathrm{E}+00$ & $0.00 \mathrm{E}+00$ & $2.58 \mathrm{E}+02$ & \\
\hline fabric $[90 / 45 /-45]$ & $3.70 \mathrm{E}+03$ & $0.00 \mathrm{E}+00$ & $0.00 \mathrm{E}+00$ & $1.05 \mathrm{E}+03$ & \\
\hline fabric $[90 / 45 /-45]$ & $3.70 \mathrm{E}+03$ & $0.00 \mathrm{E}+00$ & $0.00 \mathrm{E}+00$ & $1.05 \mathrm{E}+03$ & \\
\hline fabric $[90 / 45 /-45]$ & $3.70 \mathrm{E}+03$ & $0.00 \mathrm{E}+00$ & $0.00 \mathrm{E}+00$ & $1.05 E+03$ & \\
\hline $62 \mathrm{Y}$ of $6 \mathrm{rov} / \mathrm{in}$. & $8.51 \mathrm{E}+02$ & $0.00 \mathrm{E}+00$ & $0.00 \mathrm{E}+00$ & $2.58 \mathrm{E}+02$ & \\
\hline fabric $[90 / 45 /-45]$ & $3.70 \mathrm{E}+03$ & $0.00 \mathrm{E}+00$ & $0.00 \mathrm{E}+00$ & $1.05 \mathrm{E}+03$ & \\
\hline \multirow[t]{2}{*}{$1 \mathrm{oz}$ of CSM } & $1.22 \mathrm{E}+03$ & $0.00 \mathrm{E}+00$ & $0.00 \mathrm{E}+00$ & $3.57 E+02$ & \\
\hline & $2.27 \mathrm{E}+04$ & $0.00 \mathrm{E}+00$ & $0.00 \mathrm{E}+00$ & $6.48 \mathrm{E}+03$ & \\
\hline
\end{tabular}




\begin{tabular}{|c|c|c|}
\hline Step 8 & & \\
\hline Computation of in-plane moc & of laminate & \\
\hline$E_{x}^{t}=\left[\left(A_{11} A_{22}\right)-A^{2}{ }_{12}\right] /\left(t A_{22}\right)$ & $2.89 E+06$ & \\
\hline Computation of bending mo & of laminate & \\
\hline & & \\
\hline$E x^{b}=\left[12\left(D_{11} D_{22}-D_{12}{ }^{2}\right)\right] /\left(t^{3} D_{22}\right)$ & $3.80 \mathrm{E}+06$ & \\
\hline Computation of shear modul & laminate (G & \\
\hline$G x y=12 D_{66} / t 3$ & $1.47 \mathrm{E}+06$ & \\
\hline Shear Strength & $1.47 \mathrm{E}+04$ & \\
\hline (assuming shear strain of 0.01 & & \\
\hline
\end{tabular}

